Review

\title{
Synthesis, Properties and Applications of Biodegradable Polymers Derived from Diols and Dicarboxylic Acids: From Polyesters to Poly(ester amide)s
}

\author{
Angélica Díaz ${ }^{1}$, Ramaz Katsarava ${ }^{2, *}$ and Jordi Puiggalí ${ }^{1, *}$
}

1 Chemical Engineering Department, Polytechnic University of Catalonia, Av. Diagonal 647, E-08028 Barcelona, Spain; E-Mail: angelicadiaz07@hotmail.com

2 Institute of Chemistry and Molecular Engineering, Agricultural University of Georgia, 13 km. David Aghmashenebeli Alley, Tbilisi 0159, Georgia

* Authors to whom correspondence should be addressed;

E-Mails: r.katsarava@agruni.edu.ge (R.K.); Jordi.Puiggali@upc.edu (J.P.);

Tel.: +995-59-915-9209 (R.K.); +34-93-401-6684 (J.P.);

Fax: +995-32-233-7594 (R.K.); +34-93-401-7150 (J.P.).

Received: 27 February 2014; in revised form: 31 March 2014 / Accepted: 31 March 2014 /

Published: 25 April 2014

\begin{abstract}
Poly(alkylene dicarboxylate)s constitute a family of biodegradable polymers with increasing interest for both commodity and speciality applications. Most of these polymers can be prepared from biobased diols and dicarboxylic acids such as 1,4-butanediol, succinic acid and carbohydrates. This review provides a current status report concerning synthesis, biodegradation and applications of a series of polymers that cover a wide range of properties, namely, materials from elastomeric to rigid characteristics that are suitable for applications such as hydrogels, soft tissue engineering, drug delivery systems and liquid crystals. Finally, the incorporation of aromatic units and $\alpha$-amino acids is considered since stiffness of molecular chains and intermolecular interactions can be drastically changed. In fact, poly(ester amide)s derived from naturally occurring amino acids offer great possibilities as biodegradable materials for biomedical applications which are also extensively discussed.
\end{abstract}

Keywords: poly(alkylene dicarboxylate)s; poly(ester amide)s; $\alpha$-amino acid derivatives; bio-based polymers; carbohydrate derivatives; biodegradability; scaffolds; biomedical applications 


\section{Introduction}

Aliphatic polyesters are attracting increasing attention to solve "white pollution" concerns caused by traditional non-biodegradable polymers and also for their use as speciality polymers in applications that mainly involve the biomedical field [1-6]. In fact, polyesters are considered the most competitive biodegradable polymers commercialized up to now. Poly(alkylene dicarboxylate)s constitute a specific family of polyesters that offer great possibilities especially considering that most of them can be obtained from renewable resources. The extensive application of such polymers could not only mitigate the negative effect of non-degradable plastics on the environment but also reduce the dependence on fossil resources [7-10]. Poly(butylene succinate) (PBS) is probably nowadays the most significant poly(alkylene dicarboxylate) due to the unusual combination of good properties and the successful efforts carried out to solve typical problems of this family such as the limited molecular weight attained by polycondesation reactions between different monomers. Biodegradability of poly(alkylene dicarboxylate)s can be clearly improved by preparing random copolymers with low crystallinity and melting point, whereas incorporation of rigid units like biobased carbohydrates and even aromatic dicarboxylates may lead to better mechanical properties. Similar advantages can also be achieved through the incorporation of $\alpha$-amino acids units since strong hydrogen bonding interactions are characteristic of the derived poly(ester amide)s, while degradation characteristics could be kept due to the susceptibility of formed ester and amide groups to enzymes with either estearase or protease activities.

The present work is focused to review the more recent developments performed with polymers derived from diol and dicarboxylic acids and highlights current activities on the biomedical field. The review is constituted by seven sections: the first five deal with generic issues concerning poly(alkylene dicarboxylate)s such as synthesis procedures, crystalline structure of homopolymers, characteristics of aliphatic copolymers. Incorporation of rigid units and degradability while the last two sections summarize more specific subjects such as selected applications and poly(ester amide)s based on $\alpha$-amino acids.

\section{Synthesis of Poly(alkylene dicarboxylate)s}

\subsection{Thermal Polycondensation}

Aliphatic polyesters derived from diols and dicarboxylic acids are crystalline and biodegradable materials that can be used as an alternative of more conventional biodegradable polyesters prepared by ring opening polymerization of lactones (e.g., polyglycolide, polylactide and poly(e-caprolactone)). Poly(alkylene dicarboxylate)s can be easily prepared by thermal polycondensation of diols and dicarboxylic acids or either their diesters or dichlorides. Nevertheless, this synthesis have problems associated to the use of solvents, and high vacuum and temperature conditions required to favour condensation reactions and the removal of water or alcohol byproducts. In general, the average molecular weight of poly(alkylene dicarboxylate)s is limited $\left(M_{\mathrm{n}}\right.$ lower than $\left.30,000 \mathrm{~g} / \mathrm{mol}\right)$ if conventional polycondensation chemistry is used and toxic catalysts are avoided [11-13].

The use of dicarboxylic acid dichlorides is limited due to their high cost and occurrence of side reactions [14]. Nevertheless, high molecular weights were for example reported for poly(butylene adipate) (PBA) but under high vacuum and temperatures that render a high ratio of volatile byproducts $[15,16]$. 


\subsection{Polycondensation Catalysts}

Polycondensation of diols with dicarboxylic acids can also be performed by employing nonspecific lipases [17,18], but in this case final cost is also increased due to the expensive enzyme and even for the subsequent separation process that is required to eliminate the enzyme. Nevertheless, some advantages should be indicated since it is an eco-friendly method, that could proceed without any environmental pollution and effectively avoid both phase separation of the reactants and the use of toxic solvents. For example, the synthesis of poly(butylene sebacate) has been reported by a lipase-catalyzed synthesis in absence of organic solvents [19].

Polymerization of 1,4-butanediol with adipic or sebacic acid has successfully been carried out in diisopropyl ether using a lipase from Mucor miehei [20,21]. Nevertheless, the best results were achieved under solvent-free conditions with Candida artarctica (CALB) [22,23]. Pseudomonas aeruginosa, Candida cylindracea and Klebsiella oxytota lipases have also been revealed effective for the polycondesantion of sebacic acid with 1,8-octanediol in an aqueous medium [24].

The study of efficient catalysts in polyester polycondensation is another basic point to improve molecular weights. Titanium compounds (e.g., titanium (IV) isopropoxide, titanium (IV) isobutoxide or titanium (IV) $n$-butoxide) are usually employed to synthesize PBS since they display a high catalytic activity [25-27]. However, cautions should be taken into account since Ti-based catalysts may also enhance significant degradation reactions. Recently, new catalysts (e.g., those based on scandium triflates) have been developed to achieve the bulk polycondensation of methyl ester of sebacic acid with 1,4-butanediol under mild conditions (e.g., reaction temperature close to $35^{\circ} \mathrm{C}$ ) [28]. Moreover, these catalysts can be recovered and reused by solubilization in chloroform and extraction with water. Stannic components have also been studied for the synthesis of PBS in solution despite long reaction times being required [29]. The use of bismuth-based compounds for the synthesis of aliphatic polyesters has also been reported [30,31]. The efficiency of different catalyst has been just compared for PBS synthesis. Either organometal or metal-oxide compounds were considered, being elucidated the following metal ranking: $\mathrm{Ti}>\mathrm{Ge}>\mathrm{Zr} \sim \mathrm{Sn}>\mathrm{Hf}>\mathrm{Sb}>\mathrm{Bi}$ [32]. Thus, zirconium- and germanium-based catalysts appeared to be interesting substitutes for the commonly-used titanium compounds.

Mild condensation reactions can also be achieved by employing triflates (e.g., scandium triflate or lanthanide triflate) as catalysts as reported for the condensation of methylsuccinate with different diols [33,34] and sebacic acid with 1,4-butanediol [35]. Polycondensation of adipic acid or sebacic acid with aliphatic diols using an inorganic acid $\left(\mathrm{H}_{3} \mathrm{PO}_{4}\right.$ or $\left.\mathrm{H}_{2} \mathrm{SO}_{4}\right)$ as catalyst combined with mild temperatures and low vacuum has also been evaluated [36]. This method was revealed effective to get aliphatic polyesters with appropriate molecular size (e.g., $M_{\mathrm{W}}$ close to $85,000 \mathrm{~g} / \mathrm{mol}$ for sebacic acid derivatives) for possible use in the preparation of degradable disposable medical supplies.

\subsection{Ring Opening Polymerization Methods}

Ring opening polymerization (ROP) has several advantages over polycondensation, but the low availability and high manufacturing costs of cyclic ester oligomers (CEOs) at industrial scale has prevented its general application for the synthesis of poly(alkylene dicarboxylate)s. Nevertheless, several efforts have been focused to develop CEOs by enzymatic synthesis since mild reaction 
conditions are usually required and high selectivity is obtained. The enzymatic cyclization of $\alpha, \omega$-diacids $\left(\mathrm{C}_{4}-\mathrm{C}_{14}\right)$ and diols $\left(\mathrm{C}_{7}-\mathrm{C}_{18}\right)$ with lipases of different origin (e.g., $\left.\mathrm{CALB}\right)$ has been studied under different conditions, being found that macrocycles were favoured when high dilution, high temperature and polar solvents were employed [37].

The synthesis of PBS starting from cyclic butylene succinate oligomers via ROP using CALB as biocatalyst has also recently been reported [38]. The enzyme-synthesized PBS product had an average molecular weight of $M_{\mathrm{W}} 130,000 \mathrm{~g} / \mathrm{mol}$ that was significantly higher than that obtained by the direct polycondensation of 1,4-butanediol (BDO) and dimethyl succinate by lipase catalysis ( $M_{\mathrm{W}}$ of 45,000 $\mathrm{g} / \mathrm{mol}$ ). It has also been indicated that CEOs as an unique family of products can be obtained by CALB-catalyzed esterification of a non-activated succinic acid (SA)/BDO mixture under water removal conditions and in a fed-batch system [39].

\subsection{Poly(alkylene dicarboxylate)s from Biobased Monomers}

Biodegradable poly(alkylene dicarboxylate)s derived from biobased monomers have an additional interest as above indicated and specifically those obtained from diols like 1,3-propanediol, BDO and 1,10-decanediol, and dicarboxylic acids such as those based on carbohydrates and SA, adipic acid, sebacic acid and fatty acids. Thus, SA and BDO can be fully synthesized using sugar-based feedstock by bacterial fermentation [40,41]. Specifically, SA can be obtained with high yield by A. succiniciproducens using glycerol as substrate $^{3}$ whereas BDO can be easily prepared by the reduction of SA. The indicated monomers are employed to get a fully bio-based PBS, which is one of the most investigated degradable polyesters because of its relatively high melting point $\left(T_{\mathrm{m}}=103{ }^{\circ} \mathrm{C}\right)$ and favorable mechanical properties. In fact PBS could be a very interesting substitution for polyolefins in some applications.

A number of promising approaches toward bio-based production of adipic acid, or more often, precursors of adipic acid like cis-muconic acid and glucaric acid, have nowadays been described, offering alternatives to the established petroleum-based processes [42]. In general, procedures combine a biotechnological process for fermentative production of a bio-based precursor using selected or engineered microbial strains and an environmentally conscious chemo-catalytic process for the conversion of the precursor to adipic acid. Large efforts are focused to get non-food-based fermentable raw materials, in particular lignocellulosics, by the degradation of structural carbohydrates of plant cells [43]. Bio-based production of adipic acid could also be achieved with engineered yeast strains by $\alpha$ - and/or $\omega$-oxidation of long-chain $n$-alkanes, alcohols or fatty acid substrates [44].

1,3-Propanediol (1,3-PD) is a chemical compound that can be obtained from several bioprocess cultivation techniques facilitated by natural and/or genetically engineered microbes [45]. 1,3-PD is produced in nature by bioconversion of glycerol but also the development of recombinant strains makes feasible its production from sugars like glucose. 1,3-PD has gained interest as a raw material for biodegradable polyesters due also to the presence of odd number of methylene units. Homopolyesters and copolyesters constituted by 1,3-PD and carboxylic acids can be easily synthesized by two-step polycondensation in the bulk at high temperature and under reduced pressure [46].

Polyesters having long linear polymethylenic segments are gaining interest since crystallinity may be enhanced as well as their crystallization and melting temperatures. Fatty acids coming from plant 
oils have extensively been considered and specifically $\mathrm{C}_{19}$ and $\mathrm{C}_{23} \alpha, \omega$-dicarboxylic acid esters have been prepared from methyl oleate and ethyl erucate, respectively $[47,48]$.

Long chain and even number $\alpha, \omega$-dicarboxylic acid esters can also be obtained from metathesis reactions by coupling of two $\mathrm{CH}_{2}=\mathrm{CH}\left(\mathrm{CH}_{2}\right)_{n} \mathrm{COOR}$ fragments, followed by hydrogenation to the saturated product. These $\omega$-functionalized 1-olefins can be prepared by pyrolysis of fatty acids. Thus, ricinoleic acid gives rise to undecenoic acid [49], which after the metathesis reaction renders the 1,20-eicosanedioic acid. This monomer was successfully polymerized with eisosane-1,20-diol, obtained from the diacid via reduction (Figure 1), to yield the semicrystalline polyester 20,20 $\left(\chi_{\mathrm{c}}=68 \%, T_{\mathrm{m}}=106^{\circ} \mathrm{C}\right.$ and $\left.\Delta H_{\mathrm{m}}=151 \mathrm{~J} / \mathrm{g}\right)[50]$.

Figure 1. Synthesis of monomers of polyester 20,20, based on [50].

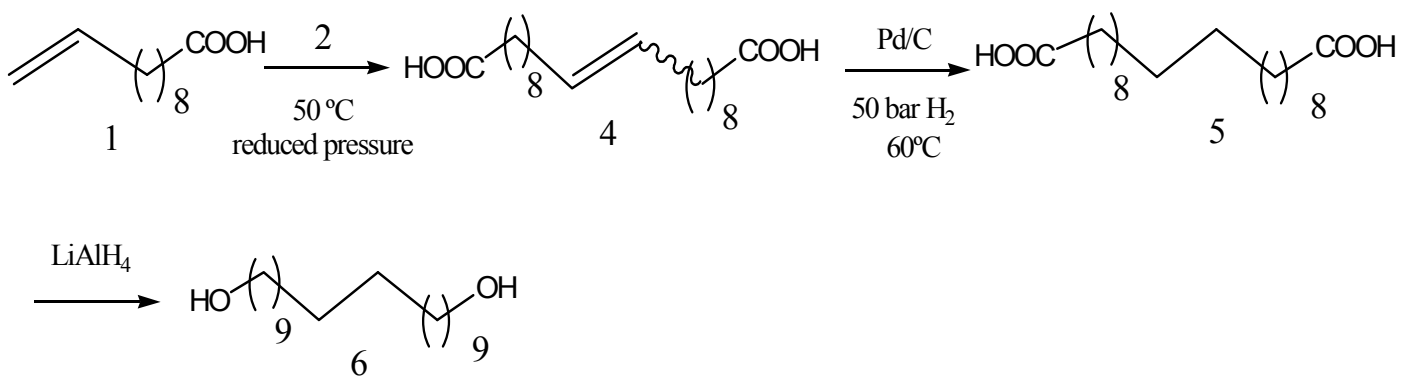

Saturated aliphatic dicarboxylic acids with chain lengths from $\mathrm{C} 11$ to $\mathrm{C} 18$ can be produced via fermentation of a vegetable oil with genetically optimized yeast strains (e.g., C. tropicalis with a blocked $\beta$-oxidation) [51]. This biotechnological synthesis provides a cost-efficient and green alternative process to get new biodegradable polyesters. For example, biobased $\omega$-carboxy fatty acid monomers like 1,18-cis-9-octadecenedioic, 1,22-cis-9-docosenedioic and 1,18-cis-9,10-epoxy-octadecanedioic acids were obtained by mutated $C$. tropicalis, as building blocks for lipase-catalysed conversion to linear unsaturated and epoxidized polyesters. These functionalyzed polymers are interesting since allows further cross-linking reactions and also the incorporation of bioactive moieties [44].

Polyalkylene dicarboxylates containing rigid units merit attention since an improvement of mechanical and thermal properties could be expected after their incorporation in the main chain. Specifically, aliphatic-aromatic copolymers have been deeply studied as will then be described, but polymers incorporating 1,4-cyclohexylene units are also worthy to be mentioned. Specifically, derivatives of 1,4-cyclohexanedimethanol, 1,4-cyclohexanedicarboxylic acid and dimethyl-1,4-cyclohexanedicarboxylate have been considered [52]. These monomers have the advantage that can be prepared from biomass (e.g., from terpenes) [52,53], although costs are presently too much high for a commercial application. The indicated cycloaliphatic ring monomers were stable and able to react in two-step polycondensation without particular problems. The combination of specific cyclic building blocks with the correct cis/trans ratio makes feasible to get polymers with tunable properties. Thus, the effect on thermal properties reached its maximum level when the cycle-containing monomers were the diacid or the diester and when the trans isomers predominated [53].

Isosorbide and isomannide are 1,4:3,6-dianhydrohexitols (DAHs) derived from D-glucitol and D-mannitol, respectively. These carbohydrates are obtained from polysaccharides such as starch, cellulose, and mannans extracted from cereals [54]. DAHs have been employed as biobased building 
blocks for the synthesis of polyesters with liquid crystal and biodegradable properties [55-58]. The chirality in the DAHs is a fundamental parameter for modulation of polyesters properties based on them [54].

Syntheses of DAHs derived polyesters are mainly performed in the melt or in solution using activated diacid components like acid chlorides. Polymerization at high temperatures may lead to an undesirable triol moiety due to the generation of $\mathrm{HCl}$ that can attack the cyclic ethers present in the monomer unit. The use of biobased dicarboxylic acids such as SA to prepare isosorbide derivatives has also been tested. Bulk polycondensation rendered samples with relatively low molecular weight and high glass transition temperature (i.e., higher than $48{ }^{\circ} \mathrm{C}$ ) due to the chain rigidity imposed by the cyclic structure of isosorbide [59]. A series of polyester based on isosorbide was also synthesized from succinic, adipic, and sebacic acids via simple nonsolvent polycondensation [60]. Polymers supported cell growth and showed versatile properties, including $T_{\mathrm{g}}, T_{\mathrm{m}}$, biodegradability and mechanical strength.

Hyperbranched (HB) polymers are materials that appear suitable for a wide range of applications (e.g., surface modification, reactive component in coating and resin formulations, nanotechnology, polymeric plasticizers and polymeric additives for improving rheology and flow) due to the excellent properties (e.g., high solubility, low solution viscosity, melt rheology characteristics and high functionality) given by the high branching and terminal groups densities [61-63]. HB polymers can be prepared in a one-pot synthesis since in general a strict control on branching and the final structure is not necessary. Nevertheless, HB polymers have some limitations that concern the high branching density achieved when branching sites exist in each repeating unit. In this case, formation of molecular entanglements in the bulk material is prevented and high brittleness and poor mechanical properties are expected. The use of linear oligomeric starting materials should increase the distance between branching points and potentially render hyperbranched hybrid materials with better characteristics.

Specifically, biodegradable polyester hybrids have been synthesized by melt polycondensation of PBA prepolymers terminated with carboxylic acid groups with glycerol or pentaerythritol as branching agent [11]. An accurate study on the synthesis and characterization has also been performed for the one-pot reaction between tailored PBA samples terminated with methyl ester groups and 1,1,1-tris(hydroxy methyl)propane (TMP) [64]. This synthesis involved two steps as depicted in Figure 2. It was found that both inter- and intramolecular transetherification occurred as the mol \% of TMP and the reaction times increased, whereas at low mol \% of TMP (i.e., $1.5 \mathrm{~mol} \%$ ) and low reaction time the transesterification reaction involving the hydroxyl groups of TMP and the methyl ester end groups of the PBA prevailed. Both intermolecular side reactions (transetherification and transesterification) could lead to a molecular weight increase.

PBS has a linear structure that may lead to low melt strength and melt viscosity. In this case applications in thermoplastic processing, foaming, and filming may be hindered, being highly interesting to enhance molecular weight by employing chain extenders and also by introducing branches into the chain structure. These derivatives have been commercialized as Bionolle ${ }^{\circledR}$, a material with an excellent processability that can be employed in the fields of textile and plastics $[65,66]$.

Octamethylcyclotetrasilazane, hexaphenylcyclotrisilazane and 2,2'-(1,4-phenylene)-bis(2-oxazoline) have been proved highly effective as chain extenders [67,68], especially when catalysts like $p$-toluenesulfonic acid were employed. However, transesterification reactions may also take place during the chain extension reaction causing disturbing effects on the chain microstructure. 
Figure 2. Synthesis of linear-hyperbranched hybrid poly(butylene adipate) copolymers, based on [65].

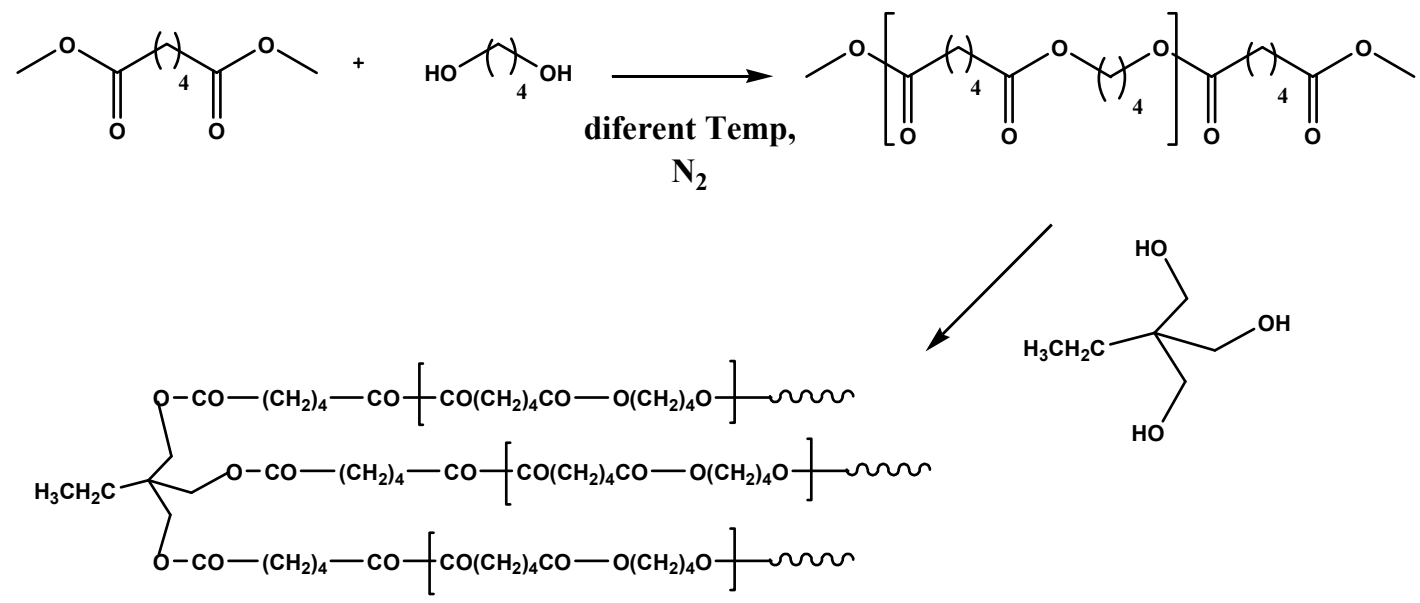

Incorporation of long-chain branches can be easily performed by adding multifunctional comonomer branching agents during the polycondensation reaction. Entanglement among polymer chains in melt and concentrated solutions should logically be increased with the presence of long-chain branches and an improvement of rheological properties should be expected [69,70]. TMP and 1,2,4-butanetriol (1,2,4-BT) have been employed as chain branching agents in the synthesis of PBS, being reported to render a significant increase of complex viscosities, while a decrease of loss tangent or elongation at break was also indicated [71,72]. Addition of only $1 \mathrm{~mol} \%$ of 1,2,4-BT segments (Figure 3) has a great impact on mechanical properties and appears for example sufficient to enhance the tensile strength of linear PBS by $31 \%$ [71].

Figure 3. Synthesis of long-chain branched poly(butylene succinate) (PBS), based on [72].

The R group means the result of esterification with fragments having carboxylic end groups.

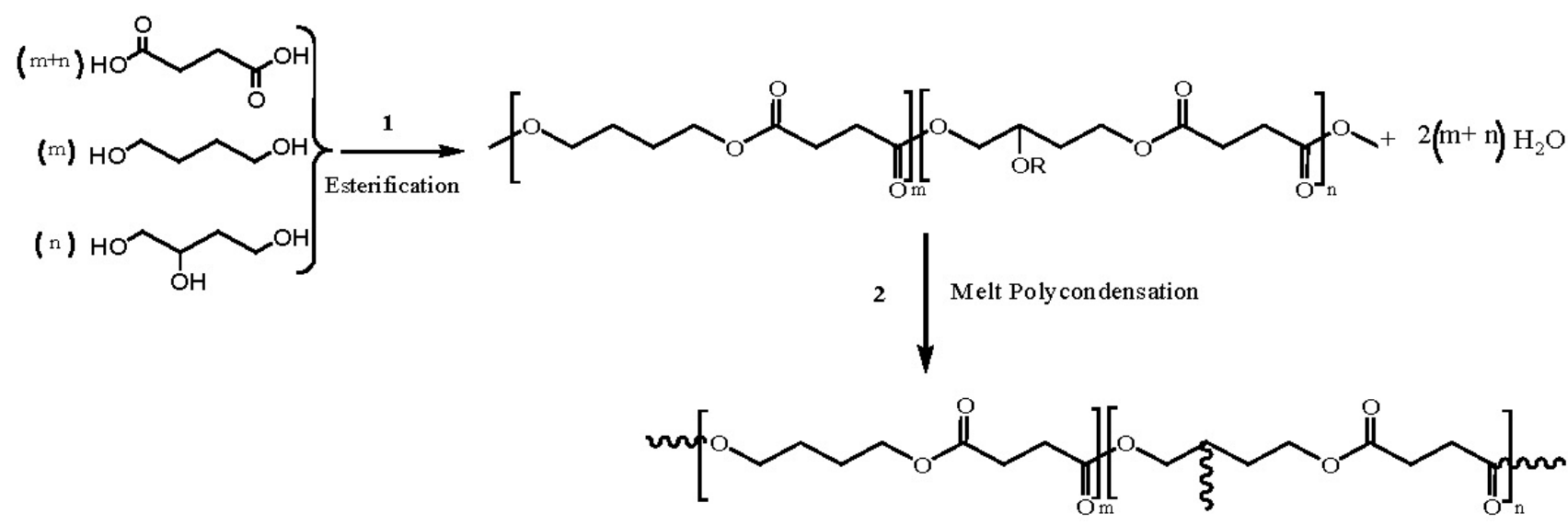

The effect of ethyl and $n$-octyl branches on the properties of PBS have also been studied $[73,74]$ being reported in this case that these relatively short branches may cause an improvement of biodegradability, the elongation at break, and the tear strength without notable decrease of tensile strength and tensile modulus. However, the melt viscosity of these branched PBS copolymers was even lower than that of linear PBS. 
A widespread application of PBS is also prevented due to its poorer mechanical properties and higher price compared to conventional polyesters based on aromatic dicarboxylate units such as poly(ethylene terephthalate) and poly(butylene terephthalate) [75]. These units should reduce the final cost of the polymer and on the other hand may provide a good combination of physical properties. Different approaches have been undertaken to incorporate aromatic units to PBS, although biodegradability should be in general negatively affected $[75,76]$.

\section{Crystalline Structure of Poly(alkylene dicarboxylate)s}

Structural studies on polyalkylene dicarboxylates indicate variability on the molecular conformation. Kink conformations can be found in polymers with a low number of methylene groups, such as polyesters $2,4,2,6,2,8,4,4,4,6$ and 6,6 [77-82]. In fact, quantum mechanical calculations on small diesters [83] showed the tendency of methylene units to adopt gauche conformations when a short aliphatic segment was placed between two carbonyl groups. On the other hand, an extended conformation was postulated for polyesters with long polymethylene sequences [84]. In general, all the above referred polyesters crystallize according to monoclinic or orthorhombic unit cells [85], the dimensions of the chain axis projected unit cell being similar to that reported for polyethylene when the polyester has an extended conformation. In this case, energy calculations suggested a packing structure where molecular chains had an orientation of methylene segments similar to that of polyethylene (i.e., a setting orientation angle close to $\pm 45^{\circ}$ ) [86].

A glide plane $a$ has usually been postulated for relating the two molecules with an extended conformation that belongs to the unit cell. Consequently, molecular chain segments were not shifted along the chain axis direction when they pack according to orthorhombic unit cells, and models were built by placing the ester groups of the different chains at the same level. Nevertheless, structural studies carried out with PBS [87], poly(hexamethylene sebacate) [88] and poly(dodecamethylene sebacate) [13] demonstrated that the two molecular chains of the unit cell were related by a diagonal glide plane $n$. This packing symmetry may have important repercussions on the lamellar folding surface. Specifically for polyester 12,10 , folds constituted by methylene groups were postulated to occur along the (100) crystallographic direction where chain segments were not shifted, whereas ester groups were supposed to be involved along the (110) direction where neighbouring chains had a $c / 2$ shift [89].

Polymorphism has been determined for some polyesters having short polymethylene sequences (i.e., poly(ethylene succinate), PBS and poly(butylene adipate)) [90] since an extended conformation ( $\beta$-form) was found in addition to the indicated kink conformation ( $\alpha$-form) (Figure 4). In general, the transition from the $\alpha$-form to the $\beta$-form occurred reversibly under the application and release of tension.

Electron diffraction patterns of polyesters with the extended zig-zag conformation indicated that the unit cells projected along the chain axis were rectangular, the parameters being close to $a=0.500-0.504 \mathrm{~nm}$, and $b=0.73-0.75 \mathrm{~nm}$. These cells contained as indicated two molecular segments, but recent works on some BDO (i.e., polyesters 4,8, 4,10 and 4,12) [91] and 1,6-hexanediol (i.e., polyesters 6,8 and 6,12) [92] derivatives have revealed the existence of unit cells where the $b$-axis parameter was doubled. These more complex structures were characterized by the fact that 
neighbouring molecules along the $b$-axis were only equivalent in chain axis projection. Complex structures were also determined for polyesters 6,6 [93] and 6,4 [94] (Figure 5) since the corresponding unit cells contained eight molecular segments.

Figure 4. Crystal structures for the $\alpha$-form (A) and the $\beta$-form (B) of PBS on the $a-b$ (bottom) and $b-c$ (top) base planes. All hydrogen atoms are omitted. Reproduced from Ichikawa et al. [87], copyright (2000), by permission of Elsevier Science Ltd.

(A)
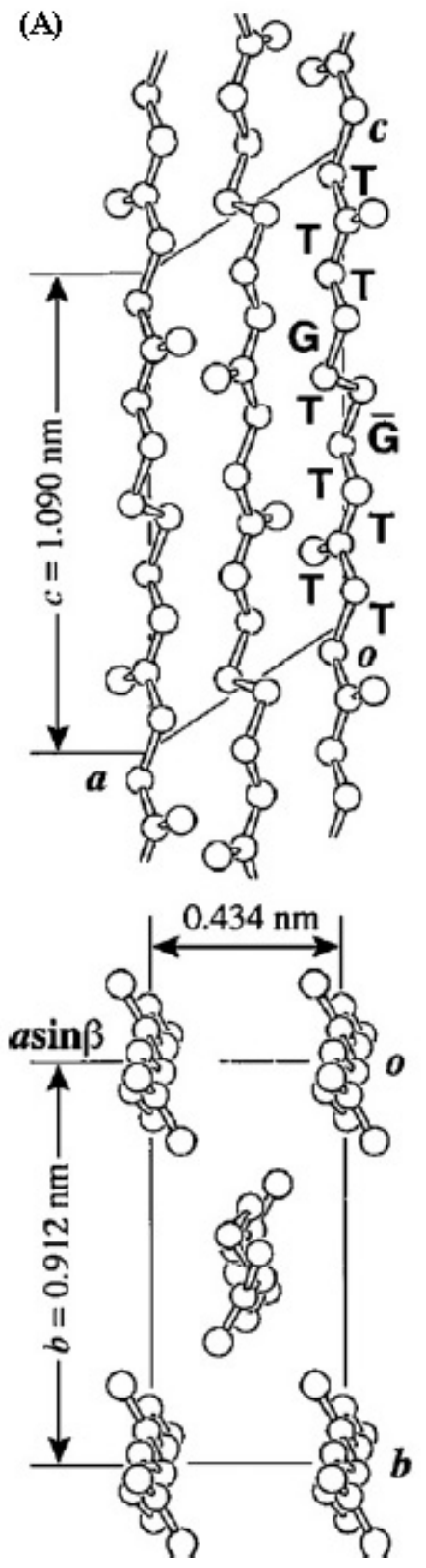

(B)
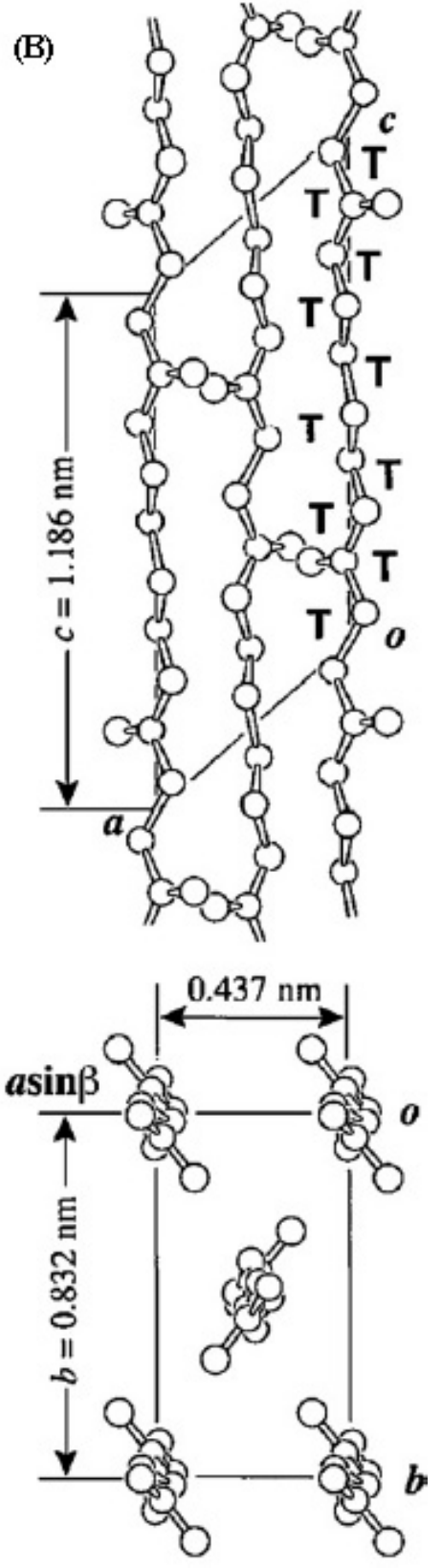
Figure 5. View parallel to the $c$-axis direction showing the packing of polyester 6,4 assuming a large unit cell with $a$ and $b$ parameters of 1.612 and $1.464 \mathrm{~nm}$, respectively. In projection this packing can be defined by a conventional rectangular cell containing only two chain segments (dotted lines). Reproduced from Gestí et al. [94], copyright (2007), by permission of Elsevier Science Ltd.

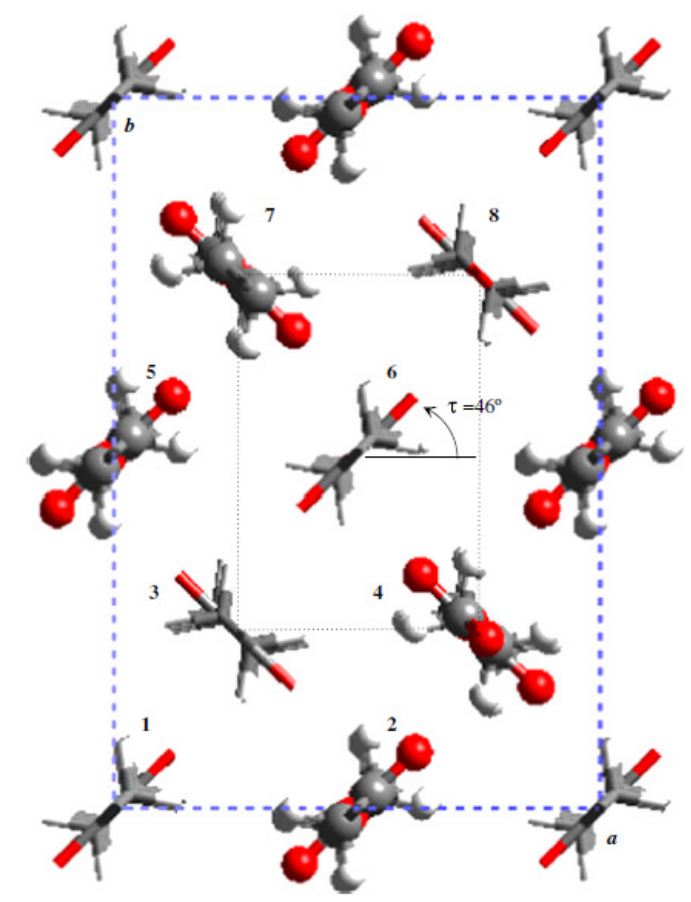

\section{Copolymers Constituted by Different Diol or/and Dicarboxylic Acid Units}

Preparation of new copolyalkylene dicarboxylates offers a key opportunity to increase the range of degradable materials and even to generate a set of products with easily tunable properties. Thus, different types of PBS copolymers and blends have recently been developed as above explained to increase biodegradability, decrease costs, increase commercial offer and even modify final properties.

Incorporation of comonomers has also a great influence on melting behavior, sample crystallinity, lamellar surface morphology, and consequently enzymatic degradability [95-97]. Several works have recently been addressed to study the crystallization process of random copoly(alkylene dicarboxylate)s. This kind of studies is significant not only because of the processability and applicability of the materials, but also for its strong correlation with the biodegradation process [98]. The studied copolymers were mainly constituted by even units, and specifically poly(butylene succinate-co-ethylene succinate) [99], poly(hexylene succinate-co-hexylene adipate) [100], poly(hexylene sebacate-co-hexylene adipate) $[101,102]$, poly(hexylene sebacate-co-hexylene suberate) [9] and poly(hexylene suberate-co-hexylene adipate) [103] are representative examples.

Random copolymers constituted by two crystallizable units may show a different crystallization behavior depending on the compatibility of the two components in crystal lattices. Isomorphic co-crystallization is characterized by the formation of only one crystalline phase containing both crystalline units. In this case, these units must meet strict molecular requirements such as having a similar chemical structure and even molecular conformation to allow their incorporation into 
the resulting crystalline structure with minimum distortion. In contrast, two crystalline phases and pseudo-eutectic behavior are observed when isodimorphism occurs. Increase of minor comonomer concentration in each crystalline phase lowers the melting temperature and crystallinity of copolymers. Obviously, requirements are in this case less strict, and consequently isodimorphism is most commonly observed in random copolymer crystallization.

Isodimorphism implies that at least one of the two crystalline phases incorporates the corresponding minor component in its crystalline lattice. In this sense, distribution of comonomer units in crystalline and non-crystalline regions is another differentiating factor in semicrystalline copolymers consisting of a random distribution of two chemical units. Comonomer units can generally be excluded in the organized lamellae and remain only in the amorphous phase or are compatible in such a way that they are able to share a crystalline lattice (Figure 6).

Figure 6. Scheme of the comonomer (a) and inclusion (b) arrangements in lamellae for full exclusion and inclusion models. In the latter case, isomorphic and isodimorphic structuresare considered. In the last case, the two crystalline phases are represented with blue and red colors and the comonomer inclusion has been drawn for both phases. Reproduced from Díaz et al. [104], copyright (2014), by permission of Elsevier Science Ltd.

a) Comonomer exclusion

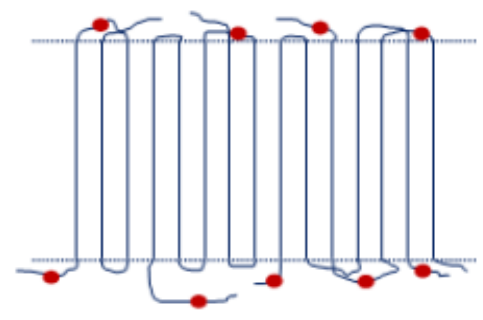

b) Comonomer inclusion

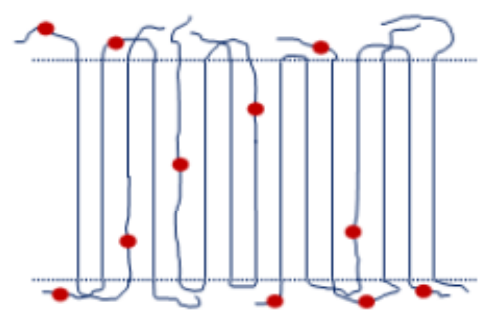

Isomorphism: Single crystalline phase over all compositions

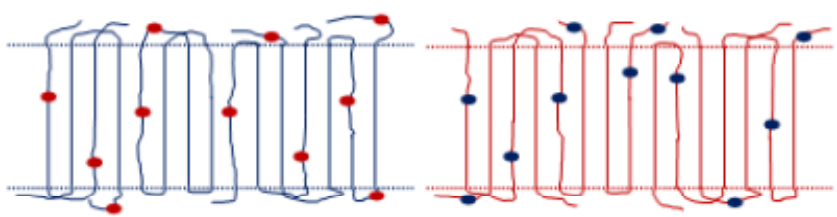

Isodimorphism: Two crystallime phases depending on composition. Comonomer inclusion is on one or both crystalline phases.

For example, poly(butylene azelate-co-butylene succinate) copolymers clearly showed a melting point depression with comonomer content, which fitted exclusion models [104]. Combined DSC and FTIR data demonstrated a peculiar behavior for these copolymers when had a similar azelate/succinate content since crystallization of butylene azelate rich fragments was enhanced by rapid cooling [105]. 
It was postulated that the development of the poly(butylene azelate) crystalline phase was more favored when the temperature associated with the formation of its primary nuclei was reached fast enough to avoid termination of previous PBS crystallization. Probably, crystallization of poly(butylene azelate) was hindered in a confined system derived for a complete PBS crystallization.

\section{Biodegradable Poly(alkylene dicarboxylate)s Having Rigid Aromatic or Carbohydrate Units}

Incorporation of aromatic moieties allows increasing the strength and performance properties of biodegradable aliphatic polyesters. Thus, these aliphatic-aromatic polymers appear an ideal solution to get fully biodegradable materials with properties similar to commodity polymers such as polyethylene. Nevertheless, the use of these aromatic derivatives as biodegradable materials may be restricted in some cases by legislation when a minimum content from renewable resources should be required.

Ecoflex $^{\mathrm{TM}}$ and Eastar Bio ${ }^{\mathrm{TM}}$ produced by BASF and Eastman, respectively, are probably the most important commercially available aliphatic-aromatic polyesters. These copolyesters are derived from 1,4-butanediol and adipic and terephthalic acids that render soft and hard segments, respectively (Figure 7). Metabolization of this kind of copolyesters was proven in a compost environment [106] and even thermophilic actinomycetes microorganisms (e.g., Thermomonospora fusca strain) were found capable to rapidly depolymerize these copolyesters [107,108], being the degrading enzyme characterized as a lipase-like hydrolase [109].

Figure 7. Chemical structure of poly(butylene adipate-co-terephthalate) showing the rigid and flexible moieties derived from terephthalic and adipic units, respectively.

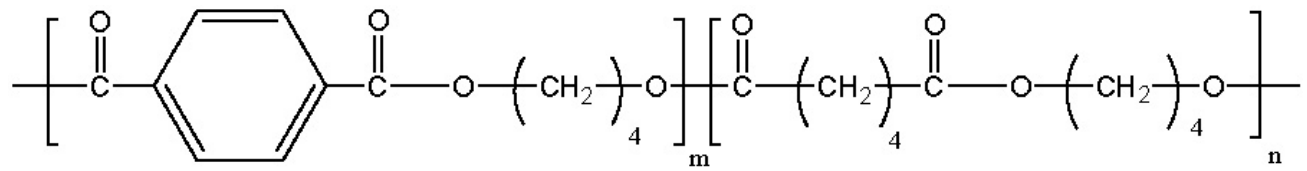

BT

BA

Random copolyesters based on BDO and different ratios between adipic and terephthalic units (PBAT) were synthesized from thermal polycondensation of the appropriate mixture of monomers or by melt transesterification of the mixture of homopolymers [110]. Hydrolytic degradation was demonstrated to took mainly place through cleavage of the adipate ester groups. Therefore significant differences in the degradation rate were found depending on the adipate content. Copolymers appeared to be enzymatically degradable with lipases (e.g., from Pseudomona cepacia), although the degradation rate was slow and again dependent on the adipate content.

PBAT copolymers exhibit a highly complex micro-structure since well differentiated domains exists side by side in one polymer chain as a consequence of the highly different aliphatic and aromatic monomers. Further investigations on the degradation process were carried out from well characterized aliphatic-aromatic polyesters (i.e., blend, block, random and alternating samples having a 50:50 ratio between adipic and terephthalic units) that were exposed to degradation tests using a lipase as biological active agent [111]. Results clearly demonstrated that the mobility of the polymer chains (the ability of chain segments to temporarily escape for a certain distance from the embedding crystal) was the major and general controlling factor for the biodegradability of polyesters. The mobility of the 
polymer chains in the crystalline regions at the temperature at which degradation is evaluated depends on how higher is the melting temperature: the susceptibility to an enzymatic attack is significantly high when the melting point of the crystalline domains is not more than $30-40{ }^{\circ} \mathrm{C}$ above the temperature of degradation, and decreases for higher melting points.

Biodegradation of a series of aliphatic-aromatic copolyesters derived from terephthalic acid, BDO, and suberic acid/sebacic acid have also been investigated. Results pointed out a determinant influence of crystallinity on degradation rate [112].

Cocrystallization could occur in the aliphatic-aromatic copolyesters derived from adipic and terephthalic acids since the soft BA segments could adjust their chain conformation to that of the rigid BT segments [113]. During biodegradation the crystallinity of copolymers clearly increased as expected for a faster degradation of amorphous regions.

Blending of polymers is a practical way to obtain a material with tailored properties. Hence, Ecoflex has been blended with polylactide to provide a fully degradable material (Ecovio ${ }^{\mathrm{TM}}$ ) with significant renewable raw content and good mechanical properties (Figure 8). Blends of polyhydroxy(butyrate-co-valerate) (PHBV) and PBAT have recently attracted interests in research environment, since can also provide an excellent combination of mechanical properties of each component [114]. Incorporation of low-cost biomass into PHBV/PBAT blend to produce less expensive biocomposites has been considered and specifically promising results were attained with biofuel coproducts [115].

Figure 8. Comparison between mechanical properties of Ecoflex ${ }^{\mathrm{TM}}$, Ecovio ${ }^{\mathrm{TM}}$ and representative commodity polymers.

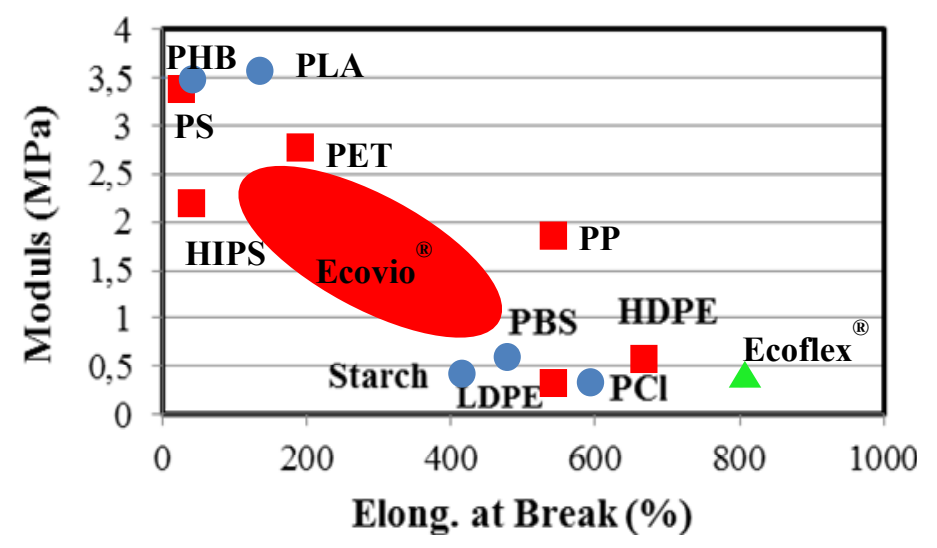

Interestingly, the addition of saturated fatty acids (e.g., caproic, lauric and stearic) was found to increase the crystallinity of biodegradable films made from blends of starch, glycerol and PBAT. Hydrophilicity of films did not decrease by addition of the fatty acid, which played a higher influence on crystallinity as longer the carbon chain was [116].

Agar is a well-known biopolymer constituted by 1,3-linked $\beta$-D-galactopyranose and 1,4-linked 3,6-anhydro- $\alpha$-L-galactopyranose residues that has been widely used in different reinforcing agents for PABT [117]. These biocomposites were developed using extrusion and injection molding technique and physicomechanical, thermal, and morphological analyses performed.

Analysis of nano-biocomposites based on PBAT and organomodified layered silicates has also been undertaken $[118,119]$. It has been concluded that the appropriate incorporation of montmorillonite as a 
nanofiller can improve PBAT properties (e.g., enhanced thermal stability and increased stiffness) and thus increase the attractiveness of the polymer as sustainable material.

Poly(butylene 1,12-dodecanedioate) (PBD) together with other polyesters derived from the 1,12-dodecanedioic acid are highly promising materials due to their high thermal stability, high level of crystallinity, and high crystallization rate [120,121]. Therefore, novel aliphatic-aromatic random copolyesters based on the incorporation of terephthalic acid units to PBD have received attention [122]. A fine modulation of the content of the co-units for this class of copolymers was required in order to achieve materials with the most desired properties in terms of physical performances and biodegradability since as above indicated these properties are negatively correlated.

Copolymers having PBS and poly(1,2-propylene terephthalate) (PPT) blocks were synthesized via chain extension from a mixture of diol terminated prepolymers using hexamethylene diisocyanate as a chain extender. The amorphous and aromatic PPT segment was chosen to modify the mechanical properties of PBS and reduce its cost. It was found that the incorporation of appropriate amounts of PPT segments improved the impact strength of the multiblock copolymers without seriously decreasing tensile strength, flexural strength, thermal stability and melting point. These good properties were a direct consequence of the presence of amorphous and rigid PPT blocks, the establishment of allophanate crosslinks and a regular sequential structure. Crystallization rate and biodegradation rate were reduced by the copolymerization but remained at acceptable values when the PPT content was 5 wt. \% [123].

Aliphatic units derived from naturally occurring carbohydrates (e.g., tetroses, pentoses and aldoses) have been employed to impart degradability and hydrophilicity to aromatic polyesters (e.g., poly(butylene terephthalate) and poly(ethylene terephthalate)) [124-128]. Thermal properties of these copolymers were found very dependent on the sugar constitution and copolyester composition. In general, samples were thermally stable above $300{ }^{\circ} \mathrm{C}$ and semicrystalline for contents in carbohydrates up to $30 \%$.

Incorporation of bifunctional, sugar-based monomers with a bicyclic structure is of great interest, due to their ability to add stiffness to a polymer backbone. High molecular weight polycondensates containing such monomers can be prepared by solid-state modification (SSM) of an existing semicrystalline polyester. SSM is performed below the melting temperature of the crystalline phase of the polymer and far above its glass transition temperature. In this way, chain segments present in the mobile amorphous fraction are modified with the added (macro)monomer by transesterification reactions while mobility restrictions prevent the crystalline phase as well as the rigid amorphous fraction from taking part in transesterification reactions [129].

Macrodiols derived from isosorbide [130], 2,3:4,5-di-O-methylene-galactitol [131], 2,4:3,5-di- $O$ methylene-D-mannitol [131] and the bicyclic acetalized diol 2,4:3,5-di-O-methylene-D-glucitol (Glux) [132] have been incorporated into poly(butylene terephthalate) by SSM. Glux-based materials showed higher melting points and glass transition temperatures than the other sugar-based copolyesters prepared by SSM. These remarkable thermal properties were a direct result of the inherently rigid structure of Glux and the relatively slow randomization of the block-like chemical microstructure of the Glux-based copolyesters in the melt.

The relatively poor reactivity of the secondary hydroxyl groups at the 2- and 5-positions of isohexides is as a major drawback that limits their use as a polyester monomer [133]. Isoidide 
dicarboxylic acid (IIDCA) is a 1-carbon extended isohexide derivative that should have a higher reactivity with retention of rigidity [134]. In this way, a series of polyesters based on IIDCA and linear $\alpha, \omega$-diols $\mathrm{HO}-\left(\mathrm{CH}_{2}\right)_{n}-\mathrm{OH}(n=2,4,6,8,10,12)$ has been synthesized under rather mild reaction conditions. Weight-average molecular weights in the range of 13,000-34,000 g/mol were indicated and demonstrated a higher reactivity of IIDCA compared to the parent isohexides [135]. It should be stated that those polyesters based on ethylene glycol, 1,4-butanediol and 1,10-decanediol can be considered fully bio-based.

The bicyclic carbohydrate-based diol 2,4:3,5-di- $O$-methylene- $d$-mannitol (Manx) is highly reactive in polycondensation and capable of producing stereoregular polymers with fairly high molecular weights. This monomer has been employed to get aliphatic polyesters by reaction with dimethyl succinate. The homopolymer showed good properties and appears interesting for applications where biodegradability and molecular stiffness are priority requirements. In addition, random copolymers have been obtained using mixtures of the carbohydrate diol and 1,4-butanediol in the reaction with dimethyl succinate. All copolymers were semicrystalline, degraded enzymatically faster than PBS and displayed tunable thermal and mechanical properties according to the content in Manx units [136].

\section{Degradation of Poly(alkylene dicarboxylate)s}

Besides biodegradability, thermal stability and thermal degradation behavior of biodegradable polymers are important for their processing, application, and thermal recycling and in general are crucial for the development of safe materials. Therefore, thermal degradation of aliphatic polyesters based on dicarboxylic acids and diols has extensively been studied [137-144]. In general, these polyesters can be well-processed since start to decompose at temperatures significantly higher than their melting point. Decomposition has been described to take place, mainly, through $\beta$-hydrogen bond scission and secondarily by $\alpha$-hydrogen bond scission (Figure 9). Thermal degradation under an oxidate environment may proceed according to a different mechanism and for example $\alpha-\mathrm{H}$ abstraction mechanism that led to the formation of a hydroperoxide intermediate was characteristic of PBS thermal oxidation [138].

Figure 9. Schemes showing the $\beta$ - and $\alpha$-hydrogen bond scissions for aliphatic polyesters derived in this case from 1,3-propanediol and azelaic acid, based on [144].
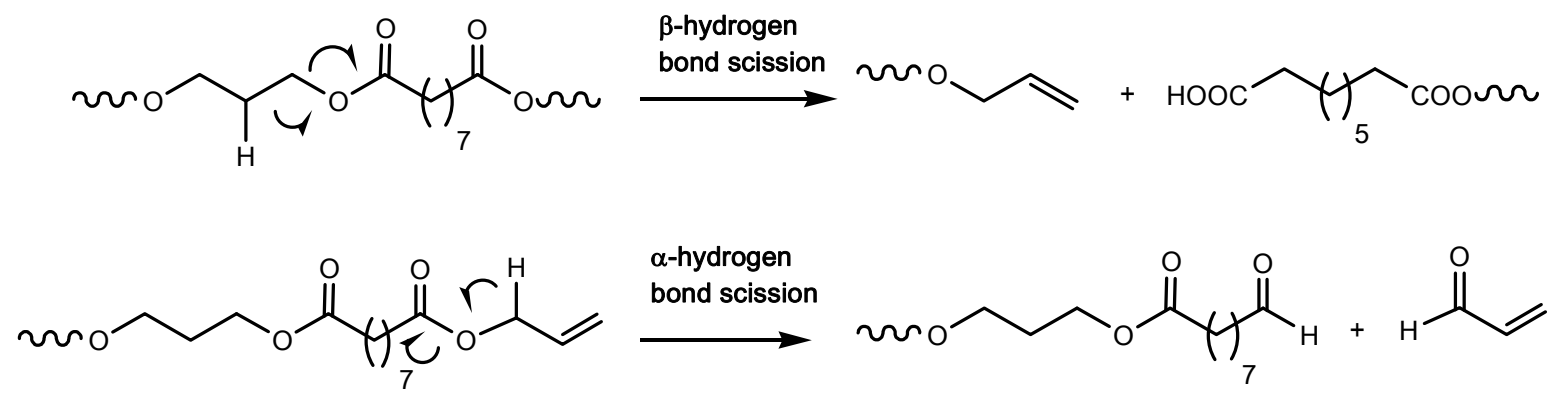

Aliphatic polyesters can easily be degraded enzymatically and constitute nowadays an important group of polymers to solve white pollution. Enzymatic degradation studies suggested that biodegradation rate was faster for polyesters made from moieties containing around six carbon atoms, whereas increasing or decreasing the spacing between ester groups made the polymers less susceptible 
to enzymatic degradation [145]. Thus, enzymatic hydrolysis of a series of poly (propylene alkane dicarboxylate)s with four to ten methylene units between the ester groups showed a maximum degradation rate for the suberate derivative and pointed out the significant role of the ester group density along the main chain [145].

Nevertheless, biodegradation rate is highly influenced by the degree of crystallinity, spherulite size and lamellar structure. Furthermore, melting temperature plays an important role since a polymer having a lower melting temperature is more susceptible to biodegradation due to the higher flexibility of their polymeric chains that allows fitting more easily into the active sites of enzymes [146].

Enzymatic degradation studies performed with high molecular weight poly(butylene succinate-co-ethylene succinate)s indicated that the degree of crystallinity was the dominant factor upon the degradation rate, whereas the sequence distribution of butylene and ethylene succinate subunits had little effect upon lipase activity [99].

Enzymatic degradation of network polyesters derived from polyhydric alcohols (i.e., 1,1,1-trimethylolpropane, 1,2,3,4-butanetetrol, D-glucitol, glycerol and pentaerithritol) and aliphatic dicarboxylic acids containing different numbers of methylene groups (i.e., 4, 6-14 and 20) has been studied [147-149]. Network structures are interesting since can provide better physical and chemical properties such as resistance to heat distortion and resistance to chemicals than linear polymers. Results obtained from series derived from the same dicarboxilic units indicated that degradation rate decreased with the increase in the number of hydroxyl groups in the alcohol units (i.e., with the increase on the cross-linking density) [149]. Furthermore, a remarkable dependence of enzymatic degradation on methylene chain length was observed and specifically samples with shorter methylene chains were more resistant to degradation as a consequence of the difficulty for the enzyme to penetrate into samples with smaller network size.

Degradation of semicrystalline polymers must also occur in the crystalline phases, mainly during the later stages of decomposition despite the closely-packed crystalline regions hinder the enzymatic attack. Single lamellar crystals obtained by crystallization from dilute solutions are ideal systems to detect how enzymatic degradation proceeds. Extensive studies have been performed with single crystals of polyesters such as poly([R]-3-hydroxybutyrate) [150,151] poly( $\varepsilon$-caprolactone) [152] (PCL), poly(L-lactide) [153], poly(ethylene succinate) [154] and poly(tetramethylene adipate) [155]. Recognition of the position of ester bonds in the molecular chain is required by the active site of the enzyme for cleavage of the molecular chain and consequently it seems very important that these groups were accessible either on the folding surface or on the lateral faces of lamellar crystals.

Usually, enzymatic degradation progressed mainly from the edges of lamellar crystals without a decrease in molecular weight and lamellar thickness. However, the central portion of poly(butylene adipate) crystals was also degraded by enzymatic attacks, suggesting the existence of loosely-packed chain regions inside lamellae [155]. Enzymatic degradation studies performed with poly(octylene suberate) showed that in this case the main attack was on the lamellar surfaces [156]. Interestingly, crystal sectors had different susceptibility to enzymatic attack and furthermore degradation was observed to progress preferentially along a crystalline direction (Figure 10). It was concluded that both molecular packing and the nature of molecular folds play a crucial role in the enzymatic degradation process. 
Enzymatic degradability of polyalkylene dicarboxylates derived from BDO and succinate or azelate units (i.e., polyesters 4,4 and 4,9) differed considerably as presumable from their high different melting points. Samples having distinctive, controlled biodegradability could be easily generated by copolymerization. Hence, poly(butylene azelate-co-butylene succinate) copolymers had significant amorphous domains that facilitated enzymatic attack and led to post-exposure surface textures that were clearly different from those developed in the more crystalline homopolyester samples [105]. Constituent spherulites were highlighted during degradation when they had the appropriate size and were surrounded by significant amorphous zones. In a second step, degradation was observed to take place inside the spherulites and revealed a ringed structure. Edge-on and flat-on lamellae should have different susceptibility to the enzymatic attack and consequently it was possible to detect these ringed morphologies (Figure 11). Results pointed out the capability of enzymes to degrade crystalline regions in a way that depended on morphology (i.e., flat-on or edge-on crystals) and the supramolecular arrangement.

Figure 10. Lamellar crystals of poly(octamethylene suberate) after exposure to the enzymatic medium containing lipase for 2 (a); 2.5 (b); 3 (c) and $3.5 \mathrm{~h}$ (d). Reproduced from Casas and Puiggalí [156], copyright (2009), by permission of Elsevier Science Ltd.
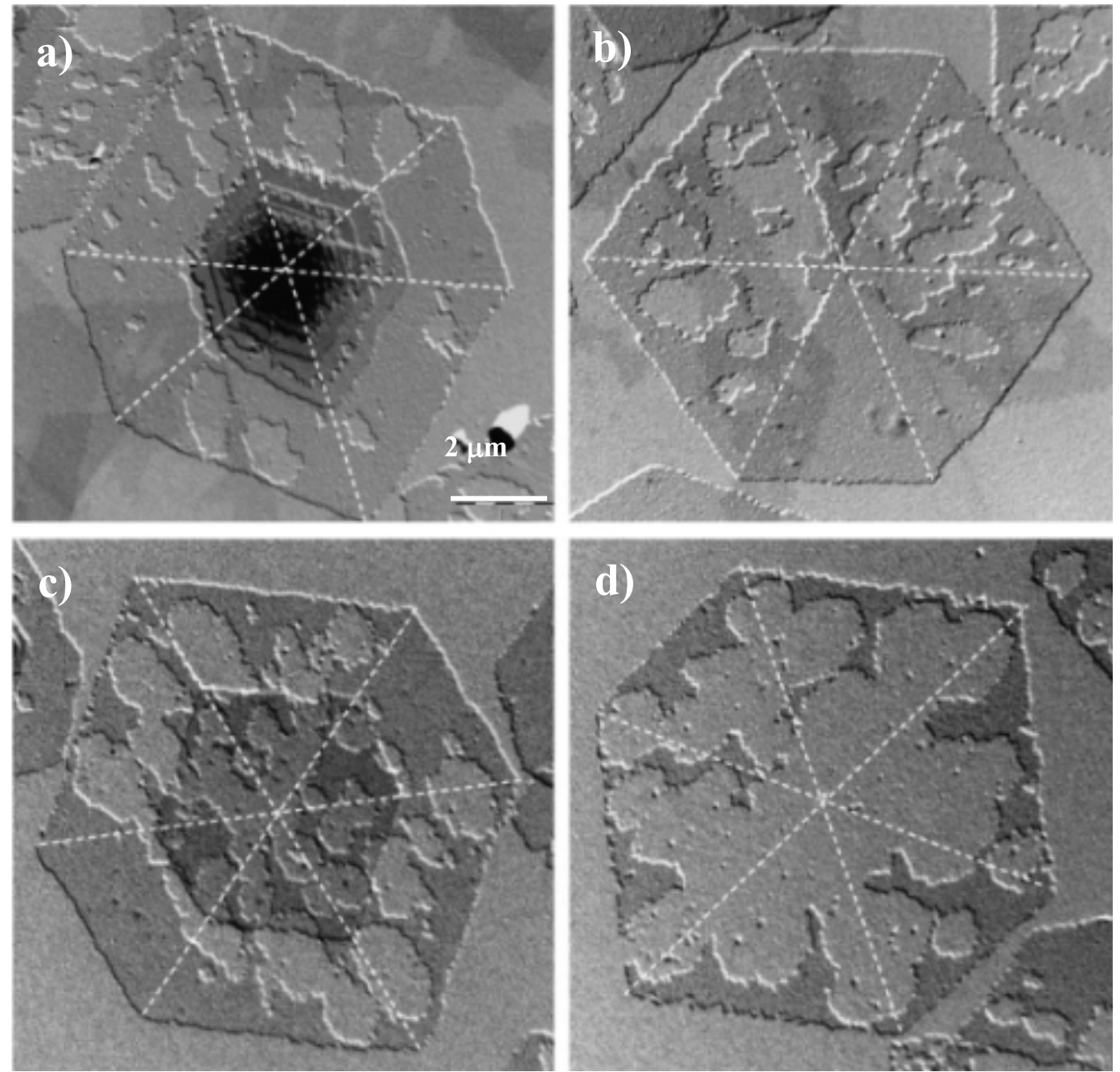
Figure 11. Scanning electron micrographs of a poly(butylene azelate-co-butylene succinate) sample after exposure to the lipase medium at $25^{\circ} \mathrm{C}$ for $3(\mathbf{a}) ; 7$ (b); 14 (c) and 21 days (d). White arrows point out spherulitic morphologies that are progressively highlighted. Reproduced from Díaz et al. [105], copyright (2014), by permission of Elsevier Science Ltd.
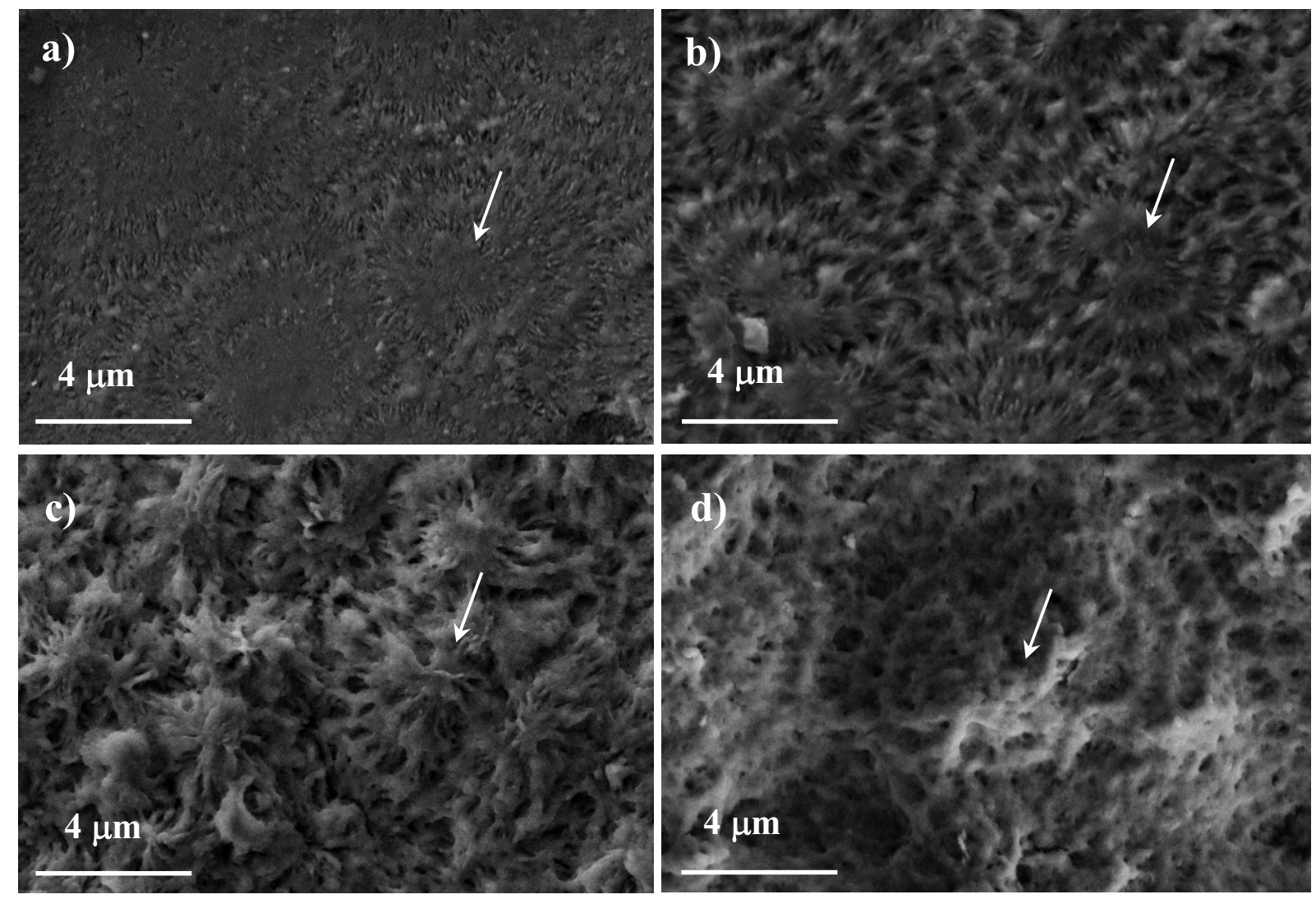

Enzymatic degradation by immobilized lipase of PBS, its binary copolymers with $\varepsilon$-caprolactone or 1,4-cyclohexane dimethanol, and the corresponding ternary copolymers was evaluated in tetrahydrofurane/toluene $(2: 1 \mathrm{v} / \mathrm{v})$ mixed organic solvent containing a small amount of water. The minimum and maximum degradation yields corresponded to PBS (40\%) and the ternary copolymer (54\%), respectively [157].

Biodegradation rate of PBS is relatively slow because of its high crystallinity, which furthermore can be increased during storage and service. In this sense incorporation of a third monomer (i.e., a diol or a dicarboxylic acid) is an interesting alternative since may improve degradation properties and even extend its applications. Copolymers incorporating ethylene glycol [158,159] and propylene glycol [160-162] units have been studied, being found that the crystallization rate was dependent on the final composition. Similar features were found when BDO was polymerized with different ratios of dimethyl succinate and dimethyl adipate [163]. Nevertheless, it is expected a random microstructure for the derived copolymers that should lead to a sharply decrease on the melting temperature and consequently a limitation on the applied interest of the resulting samples [46]. Negative effects on both processability and mechanical properties must also be taken into account [164]. These problems can be avoided by preparing multiblock copolymers as those derived from the incorporation of poly(ethylene succinate) (PES) into PBS by using 1,6-hexamethylene diisocyanate (HDI) as a chain extender [165]. The melting point temperature $\left(T_{\mathrm{m}}\right)$ and relative degree of crystallinity $\left(X_{\mathrm{c}}\right)$ of the copolyesters were 
found to decrease first and then increase with PES content. The copolyesters showed excellent mechanical properties (e.g., fracture stress and strain of $61.8 \mathrm{MPa}$ and $1173 \%$, respectively, were determined for the copolymer having similar weight percentages of both blocks). Furthermore, degradation rate of these copolyesters was regulated in a wide range by their compositions, being the lowest rate found for the PBS homopolymer.

Studies on the biodegradation of aliphatic polyester nanocomposites show contradictory results about the influence of nanoparticles. On the one hand, an enhanced degradation is postulated mainly due the presence of hydroxyl groups in the added nanoparticles (e.g., the terminal hydroxylated edge groups of silicate layers) [166]. Basically, the hydrolysis of polyester/clay nanocomposites seems to depend upon both the nature of the pristine layered silicate and the surfactant used for the modification of the layered silicate [167]. Furthermore, the hydrophilicity of the silica surface enhanced the susceptibility of the nanocomposite to microbial attack as demonstrated for PBS/silica nanocomposites [168]. In the same way, hydrophilic fillers may enhance the degree of swelling of the otherwise hydrophobic matrix [169].

On the other hand, a decrease on the biodegradation rate has also been reported. In this case, arguments are based on the barrier properties of nanoparticles that should increase the difficulty for the micro-organism to reach the bulk matrix due to the more tortuous diffusion path [170]. Decrease on the biodegradation rate has also been related to interactions of the matrix with the nanofiller, water permeability, degree of crystallinity and anti-microbial property of the nano-filler [171].

The comparative effect on the enzymatic hydrolysis of three nanocomposites prepared by in situ polymerization and based on a poly(propylene sebacate) matrix and a $2 \mathrm{wt}$. \% content of either fumed silica nanoparticles $\left(\mathrm{SiO}_{2}\right)$, multiwalled carbon nanotubes (MWCNTs), or montmorillonite (MMT) has recently been reported [172]. A similar hydrolysis mechanism was determined, but in all cases nanoparticles hampered the action of the enzymes. It was postulated that the available surface area for hydrolysis was hindered and also that significant interactions took place between nanoparticles and the polymer matrix.

The addition of MWCNTs and MMT was found to enhance the thermal stability of the polymer, while $\mathrm{SiO}_{2}$ nanoparticles do not affect it [173]. The decomposition of nanocomposites proceeded with a complex reaction mechanism with the participation of at least two different steps: mainly through $\beta$-hydrogen bond scission and, secondarily, through $\alpha$-hydrogen bond scission.

Properties of $\mathrm{PBS} / \mathrm{SiO}_{2}$ nanocomposites prepared by the in situ polymerization were carefully investigated to determine the potential interactions taking place between the hydroxyl end groups of PBS and the surface silanol groups of $\mathrm{SiO}_{2}$ [174]. It was found that at low concentrations the $\mathrm{SiO}_{2}$ nanoparticles acted as chain extenders, increasing the molecular weight of PBS, while at higher loadings they resulted in extended branching and crosslinking reactions (Figure 12), leading to smaller hydrodynamic dimensions and an apparent decrease on the molecular weight. Silica nanoparticles acted as nucleating agents, increasing the crystallization rate of $\mathrm{PBSu}$, although the degree of crystallinity was slightly reduced. 
Figure 12. Cross-linked structures obtained by reaction between the hydroxyl end groups of PBS and the surface silanol groups of fumed silica nanoparticle.

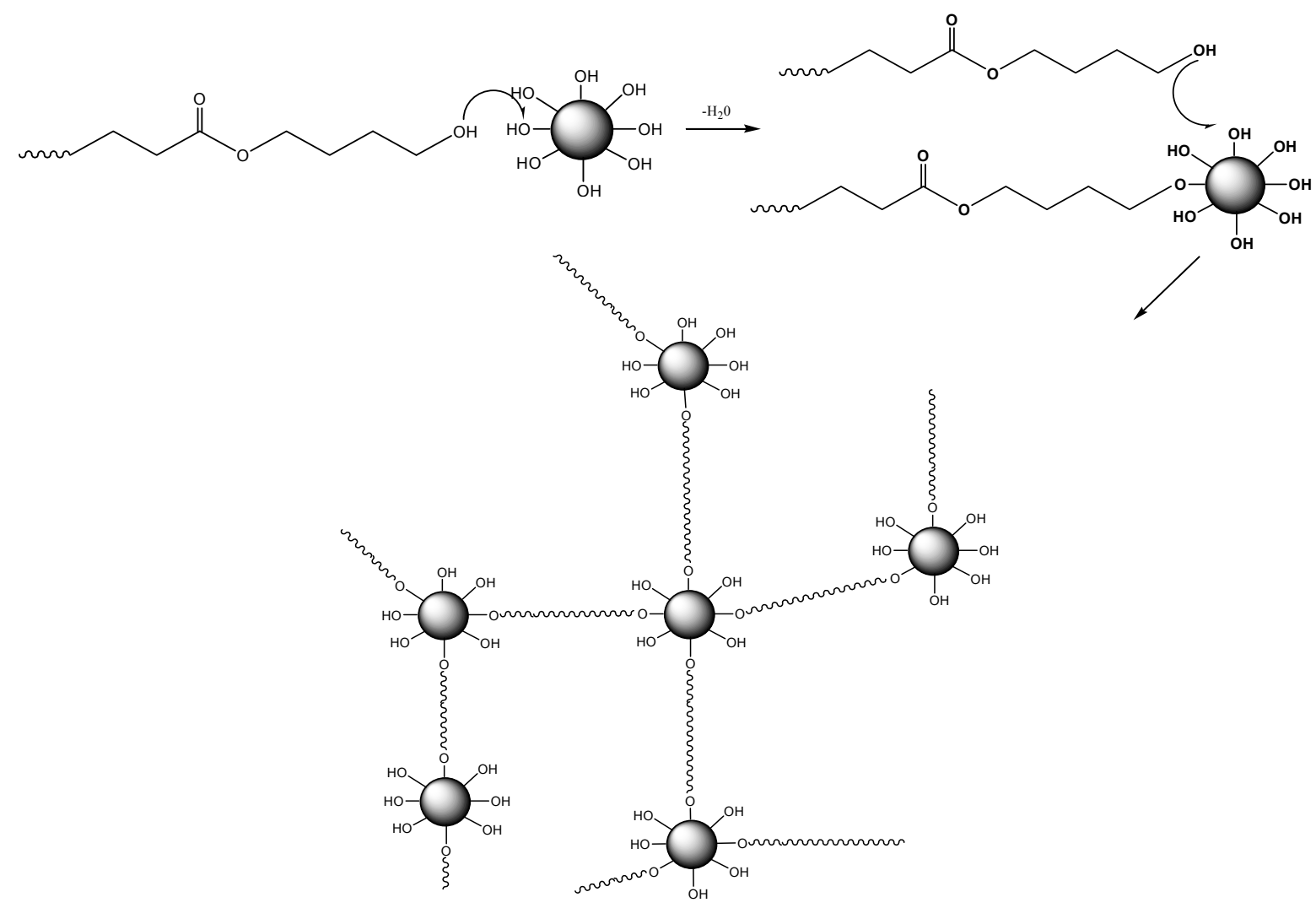

\section{Applications of Poly(alkylene dicarboxylate)s}

Development of antimicrobial packaging films has logically interest in hospital environments where sterile conditions are required for the medical equipment, but also in the food industry in order to increase the safety of food products. Antimicrobial agents can be added to films and also chemically bounded to its surface. In the first case, activity is linked to the migration of the agent which can alter properties of the food product (e.g., taste and quality). This problem does not exist in the second case, but the lack of functional groups in the polymer chains and also the demanding reaction conditions become restrictive points that may limit its application. Functionalization of polyesters can be easily performed by copper catalyzed azide-alkyne "click" chemistry [175], a reaction that can be carried out under mild conditions that do not alter the chain length of the polyester backbone. In this way, alkyne-containing poly(butylene adipate) was effectively functionalized with a quaternary phosphonium group, known for their antimicrobial properties (Figure 13) [176]. The resulting polyester showed great antimicrobial activity through direct contact without freely available active groups and consequently with potential application for food or medical purposes.

The arrangement in specific architectures of micro- and nanoscale biological elements present in the extracellular matrix (ECM) becomes essential for normal tissue function. For example, we should mention the parallel array organization of fibroblasts and cardiomyocytes in native myocardial tissue that ensures adequate electrical properties or the alignment of collagen fibers in the bone that provides high tensile strength [177,178]. Therefore, tissue engineering strategies include the control of cellular alignment, which can be achieved by means of micropatterning techniques [179]. A simple method to 
control the alignment of human adipose stem cells (hASCs) over biodegradable PBS has recently been reported [180]. Specifically, a variety of micropatterned surfaces of PBS were microengineered by micromolding (Figure 14) and their in vitro biological behaviour evaluated. Results clearly demonstrated that the engineered surfaces were able to maintain a high viability and direct the orientation of seeded hASCs in contrast with the random orientation found on non-patterned surfaces.

Figure 13. Synthetic of poly(butylene adipate) functionalized with quaternary phosphonium groups, based on [176]. The alkyne-containing polyester was prepared from 1,4-butanediol, the alkyne-containing diol 2-methyl-2-propargyl-1,3-propanediol and adipic acid.

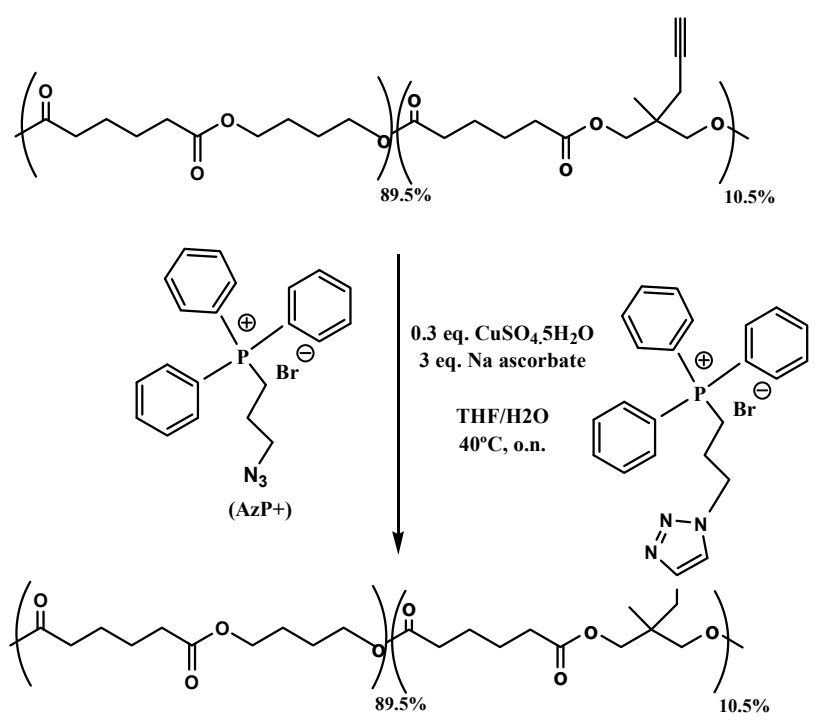

Figure 14. (a) Schematic representation of the preparation of micropatterned PBS surface. (b) SEM (left) and immunostaining (right) of human adipose stem cells (hASCs) cultured onto micropatterned PBS surfaces. Reprinted with permission from [180]. Copyright (2010), by permission of Elsevier Science Ltd.

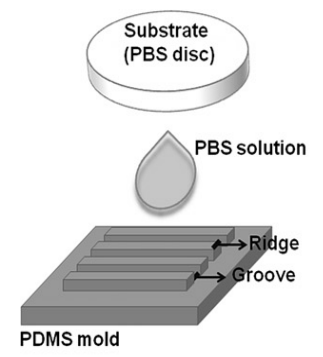

(a)

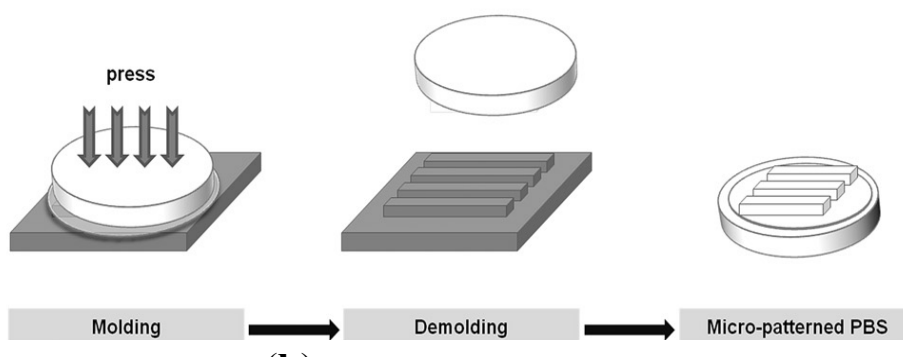

(b)
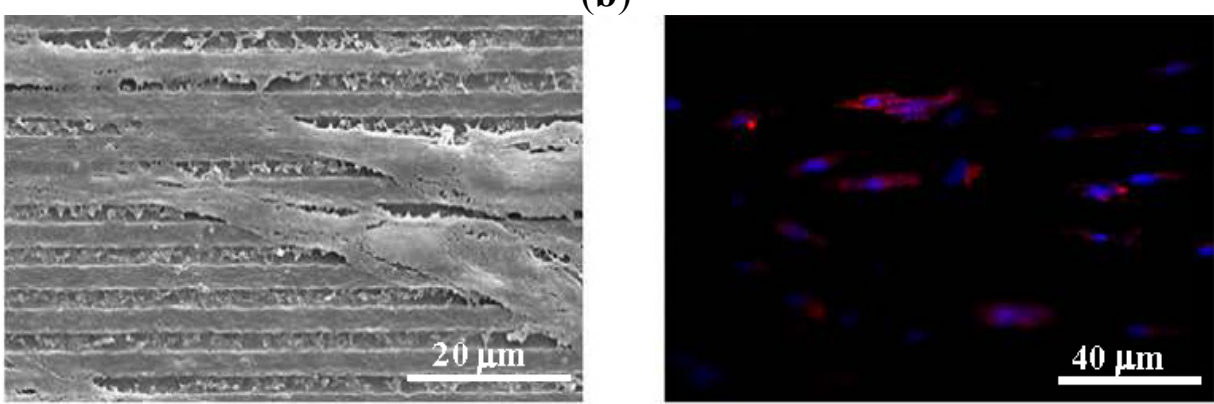
Materials with low elastic modulus (i.e., in the 0.1-100 MPa range) are preferred for soft tissue engineering applications, which is a limitation due to scarcity of biodegradable polymeric material possessing such elastomeric mechanical properties. In fact, scaffolds are designed to mimic the extracellular matrix of the target tissue, which usually is an elastic, resilient and highly hydrated polymer network. Efforts have mainly been focused to develop biodegradable polyurethanes, trimethylene carbonate-based copolymers and polyesters ( $\varepsilon$-caprolactone- and sebacate-based polymers) [181-184].

Reactive blending appears as an efficient and easy method to get copolymers displaying modulated final properties. To this end, bioresorbable poly(butylene/diethylene glycol succinate) multiblock copolymers were specifically synthesized $[185,186]$ starting from the parent homopolymers (i.e., PBS and poly(diethylene glycol succinate) (PDGS)) and used to fabricate biomimetic electrospun scaffolds. Interestingly, new materials supported cell growth and had a more pronounced elastomeric behaviour and a faster degradation rate than PBS [187].

Scaffolding materials have also been developed from elastomeric polyesters constituted by citric acid (CA) and sebacic acid (SA) [188-192]. These monomers are considered biocompatible since participate in different metabolic cycles in the human body [184,192-194] and can react with multifunctional alcohols (e.g., glycerol and octanediol) to yield hydrophilic and elastic hydrogels. Poly(octanediol citrate) (POC) and poly(glycerol sebacate) (PGS) (Figure 15) are polyesters with pendant $-\mathrm{COOH}$ and $-\mathrm{OH}$ functional groups that brings hydrophilicity and allows also the formation of physical crosslinks between polymer chains that are characteristic of elastomeric materials. Interestingly, PGS and POC have been employed to get biphasic systems ideal for blood vessel tissue engineering where PGS is used as an inner non-porous phase and POC constitutes the porous outer layer [195].

Figure 15. Chemical structures of linear poly(octanediol citrate) and poly(glycerol sebacate) with pendant hydroxyl and carboxyl groups.

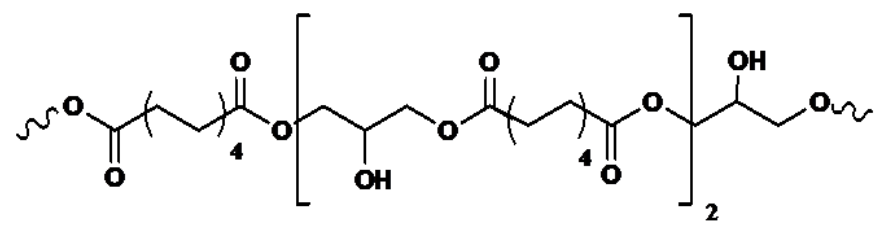

Polyglycerol sebacate (PGS)

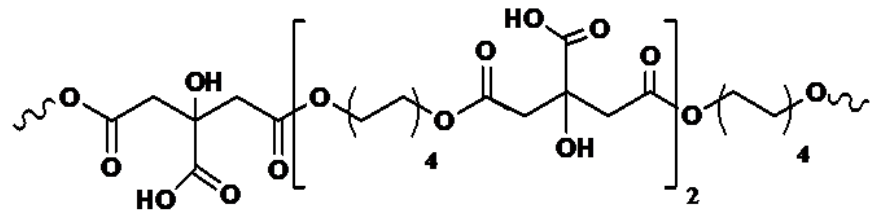

Polyoctanediol citrate (POC)

Random poly[octanediol-co-(citric acid)-co-(sebacic acid)] copolymers have also been considered [196]. These elastomeric materials exhibit versatility in mechanical properties, hydration and hydrolytic degradation by varying the citric acid/sebacic acid concentration in the reaction medium. Furthermore, cell culture results clearly showed that simple alteration of the copolymer composition influenced cellular growth on the polymer surface, a feature advantageous to expand the repertoire of available biodegradable polyesters suitable for bone tissue engineering. 
Rai et al. have recently been reported an excellent review concerning design and fabrication (e.g., rapid prototyping, solid-free form fabrication, micromolding, microablation and electrospinning) and biomedical applications (e.g., hard to soft tissue engineering, controlled drug delivery and tissue adhesives) of PGS based devices [197].

Sebacic acid has also been reacted with multifunctional alcohols giving rise to materials with good properties for cell growth and control over physicochemical and degradation properties through the use of different polyols [195].

Tissue engineering scaffolds can be easily prepared by the electrospinning technique, which is able to produce nanofibers from a wide range of polymers [198,199]. Furthermore, many kinds of drugs can be incorporated into such nanofibrous mats and then successfully released from them without a significant loss of their activity. Different examples can be mentioned about the specific use of electrospinning to render scaffolds from poly(alkylene dicarboxylate)s.

First attempts to get biodegradable PBS nanofibers were reported by Jeong et al. when different solvent mixtures were assayed [200]. PBS fibers had average diameters in the range of 125-315 nm and were highly crystalline.

Electrospun 1,6-diisocyanatohexane-extended PBS fiber mats appeared suitable as bone scaffolds since supported the grown and proliferation of bone cells [201]. A novel PBS/wollastonite/apatite composite scaffold useful for bone tissue applications was fabricated via electrospinning and biomimetic processes. The microstructure of these scaffolds could be adjusted by controlling the wollastonite content and the incubation time in simulated body fluid [202].

Reactive blending of PBS and poly(diethylene glycol succinate) rendered multiblock bioresorbable copolyesters with an elastomeric behaviour and able to be processed as electrospun scaffolds. These were found to support the growth and preserve the cardiac phenotype markers of cardiomyocyte H9c2 cells, demonstrating its potential utility in soft tissue engineering applications [187].

Biodegradable PBS fiber mats containing silver nanoparticles were prepared by the electrospinning process. Bacterial growth was found to be inhibited for a long period of time due to the long-term release performance of $\mathrm{Ag}$ from these fiber mats [203].

Drug-loaded PBS microspheres useful for wound treating were prepared by electrospinning. Diameters of these microspheres could be controlled within the 5 to $25 \mu \mathrm{m}$ range [204].

Non-linearly elastic biomaterials were successfully fabricated from poly(glycerol sebacate) (PGS) and PLLA using the core/shell electrospinning technique. PLLA was used as the shell material to constrain PGS during the curing process and was also added into the PGS-prepolymer core solution in order to increase the viscosity to suitable values for the electrospinning process [205]. These fibrous materials possessed excellent biocompatibility, supported human stem-cell-derived cardiomyocytes over several weeks in culture and had comparable properties than muscle tissue. Hence materials appear interesting for the therapy of soft tissues exposed to cyclic deformation [206]. PGS/gelatin core/shell nanofibers have also been produced by electrospinning for cardiac tissue engineering applications [207].

Core-shell fibrous scaffolds are usually designed with a core material that dictates the mechanical properties, and a shell polymer that solely affects the cell functions. Although the coaxial process seems ideal to combine properties of different materials, the control of the desired ratio between the two polymers may be difficult. Hence, electrospining of a solution containing the elastomeric polymer (i.e., PGS) and a fairly rigid biomaterial appears a simple and interesting alternative. Specifically, 
aligned nanofibrous PGS:gelatin scaffolds were fabricated, being demonstrated that they supported cardiac cell organization, phenotype and contraction and could potentially be used to develop clinically relevant constructs for cardiac tissue engineering [208].

Knitted structures of synthetic or biological materials have been proposed to construct functional 3-D scaffolds applicable in the repair/replacement and regeneration of tissues. Knitted textile substrates may show better mechanical properties (e.g., extensibility and compliance) compared with other woven substrates due to highly ordered arrangement of interlocking loops. Knitting technology may offer superior control over the scaffold design (e.g., size, shape, porosity and fibre alignment), manufacturing and reproducibility. In this way, fiber-based finely tuned porous architectures have been produced from PBS (Figure 16), which has the advantage of having a high level of processing control, from the filament to the final textile structure [209].

Figure 16. Morphology of PBS knitted constructs showing different levels of detail: Macroscopic image (a); top view (b) and fibre cross-sections (c,d). Reproduced from Almeida et al. [209], copyright (2013), by permission of Elsevier Science Ltd.
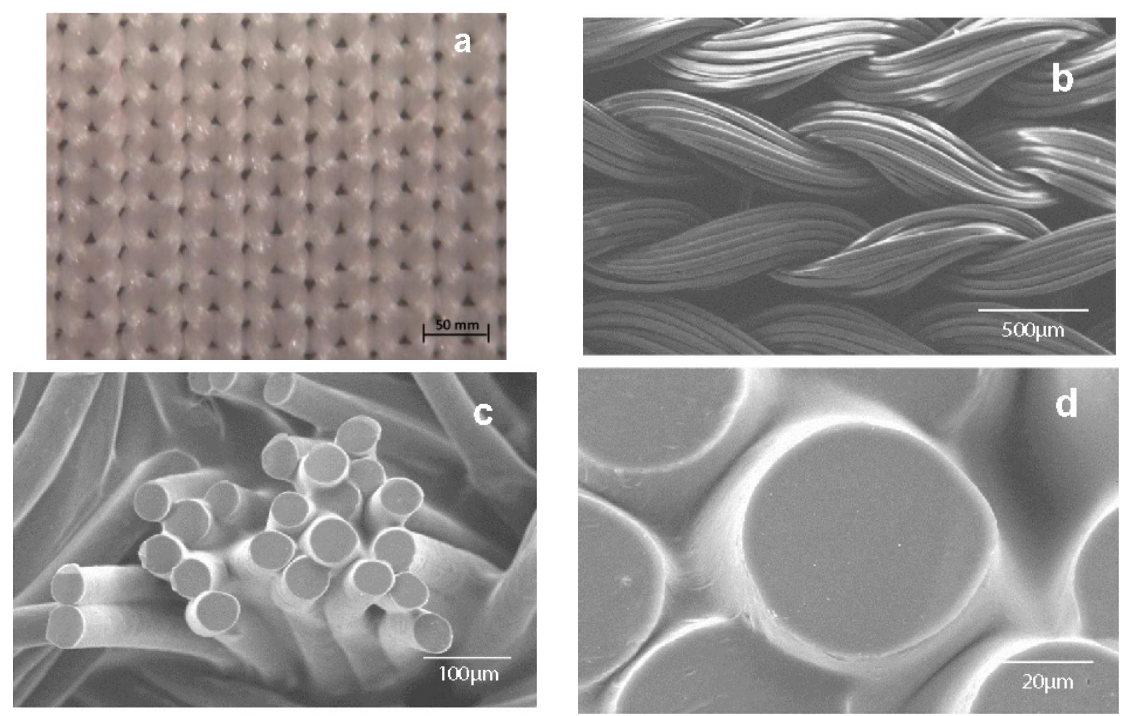

Hydrolytically degradable copolyester biomaterials based on glycolic acid in combination with sebacic acid and ethylene glycol have also been studied taking into account that several sebacic acid-based polymers have been approved by the Food and Drug Administration (FDA) in biomedical applications [210]. Furthermore, sebacic acid is a highly suitable monomer for the preparation of polyesters since short-chain aliphatic acids tend to give intramolecular condensation reactions. The new hydrolytically degradable copolyesters were soluble in common organic solvents, opposite to poly(glycolic acid), being postulated good perspectives for biomedical applications such as tissue engineering scaffolds and drug release [211].

\section{Poly(ester amide)s Derived from the Incorporation of Natural $\alpha$-Amino Acids to Polyalkylene Dicarboxylates}

An important limitation in the use of biodegradable (bioresorbable) polymers as biomedical materials is the potential toxicity of the degradation products, and so, research towards synthetic 
biodegradable polymers has mainly focused on materials entirely composed of naturally occurring and nontoxic ("physiological") building blocks. Among the physiological building blocks to be used for constructing biodegradable biomaterials naturally occurring $\alpha$-amino acids (AA) are one of the most attractive ones due to an ample availability and versatile nature - many amino acids are produced in many thousand tones [212] and the global market is forecast to reach US\$ 11.6 billion by the year 2015 [213], and almost all of 20 naturally occurring AA can be used for constructing biodegradable biomaterials that allows to tune their properties in the widest range. The AA that represent hetero-bifunctional compounds, allow to incorporate two the most desirable hetero-links into the polymeric backbones - ester bond via $C$-terminus (carboxyl group) and $H$-bond forming links such as amide bond via $N$-terminus (amino group). The former, well discussed in the paragraphs above, provides reasonable biodegradation (hydrolysis) rates of the polymers, improves processability and decreases immunogenicity of AA-based polymers; the latter provides desired mechanical properties at lower molecular weights, increases hydrophilicity of the polymers and promotes their active interaction with the surrounding tissues in a desirable manner after implantation. All these impart to poly(ester amide)s (PEA) an obvious advantage over biodegradable polyesters [214]. It is reasonable to note here that pure polyamides made of AA-poly $(\alpha$-amino acid)s have been proved to be less suitable as biodegradable materials for biomedical engineering use for many reasons, such as low rate of biodegradations and poor processability [215].

There are three the most important types of biodegradable PEA composed of AA—polydepsipeptides that are the co-polymers of $\alpha$-hydroxy (mostly glycolic and lactic acids) and $\alpha$-amino acids [216-218], tyrosine dipeptide based polymers [219], and polymers composed of AA and other nontoxic building blocks such as fatty diols and dicarboxylic acids [217,218,220]. Only the latter type of PEA, called as Amino acid based biodegradable poly(ester amide)s (AABBP) [220], relates to the family of alkylene dicarboxylates and will be discussed below in more details. The AABBP (Figure 17) can be considered as derivatives of alkylene dicarboxylates (AA-BB type polyesters) that are obtained by the insertion of AA residues amongst carbonyl group and ether oxygen in polyesters.

Figure 17. Schematic representation of AABBP as products of the insertion (empty arrows) of AA between ester bonds.

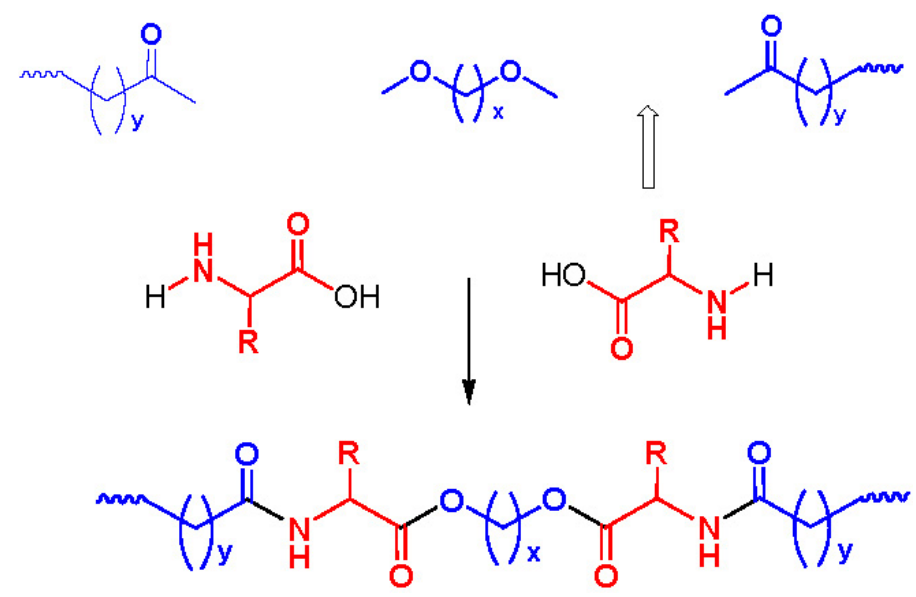

This kind of AABBP can be prepared using two types of dimerized forms of AA as key monomers (Figure 18), either bis-(amino acid)-alkylene diesters (AAAD) or $N, N$-diacyl-bis-amino acids (DABA). 
Figure 18. Two types of AA based monomers - bis-nucleophilic AAAD and bis-electrophilic DABA. R, side chain of AA; D, diol residue; A, Diacid residue.<smiles>[R]C(N)C(=O)OOOC(=O)C([R])N</smiles>

Bis-(amino acid)-alkylene diesters, AAAD<smiles>[R]C(NC(=O)I=C(NC([R])C(=O)O)C(=O)O)C(=O)O</smiles>

$N, N^{\prime}$-diacyl-bis-amino acid, DABA

The former contain two desirable ester bonds and the latter two desirable amide bonds per molecules. The synthesis and some specific features of these monomers are discussed in brief below.

\subsection{Monomers for Synthesizing AABBP}

\subsubsection{AA Based Monomers}

One of the key monomers for synthesizing AABBP are bis-nucleophilic AAAD, which are in fact diamino-diesters. These compounds are stable in the salt form, commonly as di-p-toluenesulfonic acid $(\mathrm{Tos} \mathrm{OH})$ salts (labeled as AAAD-S). One of the most rational ways of preparing AAAD-S is direct condensation of AA $(2 \mathrm{~mol})$ with fatty diols $(1 \mathrm{~mol})$ in refluxed benzene or toluene in the presence of TosOH monohydrate $(2 \mathrm{~mol})$. The TosOH$\cdot \mathrm{H}_{2} \mathrm{O}$ serves as both the reaction catalyst and amino group protector, preventing undesirable side reactions of amino groups with inherent ester groups of AAAD that lead to the formation of diketopiperazines, other cyclic and low-molecular-weight products of unknown structure (See Ref. [221] and references cited therein).

Two moles (plus a slight excess that serves as a catalyst) of TosOH$\cdot \mathrm{H}_{2} \mathrm{O}$ are needed for the synthesis of AAAD-S on the basis of hydrophobic AA that proceeds according to Figure 19.

Figure 19. Synthesis of AAAD-S on the basis of hydrophobic AA.
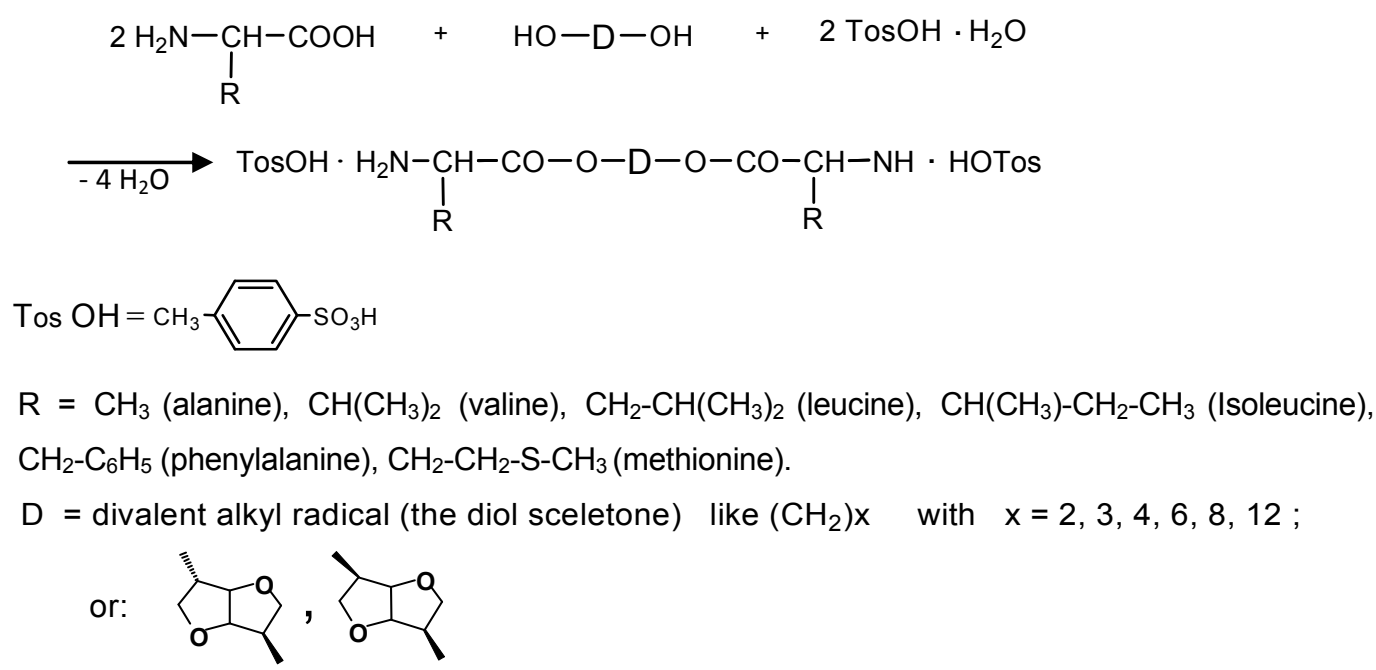

For the synthesis of diamino-diester monomers on the basis of amino acid L-arginine four moles (plus a slight excess that serves as a catalyst) of TosOH$\cdot \mathrm{H}_{2} \mathrm{O}$ should be used since two moles are consumed by the strong basic guanidine groups on the L-arginine side chain. As a result tetra- $p$-tolue-nesulfonic acid salts are obtained, as it is demonstrated in Figure 20. 
This synthetic strategy allows to generate diamino-diester monomer with two inherent biodegradable (hydrolyzable) ester bonds (blue arrows), two enzyme specific groups (green arrows), and the nonconventional "head-to-head" orientation (red arrows) (Figure 21) of AA put at a monomer stage, that provides low immunogenicity of the goal AABBP [220]. The desirable H-bond forming amide bonds are formed at a propagation stage after the interaction of $\alpha$-amino groups of AAAD-S with active derivatives of dicarboxylic acids (To be discussed below).

Figure 20. Synthesis of AAAD-S on the basis of L-arginine. $\mathrm{D}=\left(\mathrm{CH}_{2}\right)_{\mathrm{x}}$ with $x=2,3,6,12$ or $\left(\mathrm{CH}_{2}\right)_{2}-\left[\mathrm{O}-\left(\mathrm{CH}_{2}\right)_{2}\right]_{\mathrm{k}}$ with $k=1,2,3,5,11$.

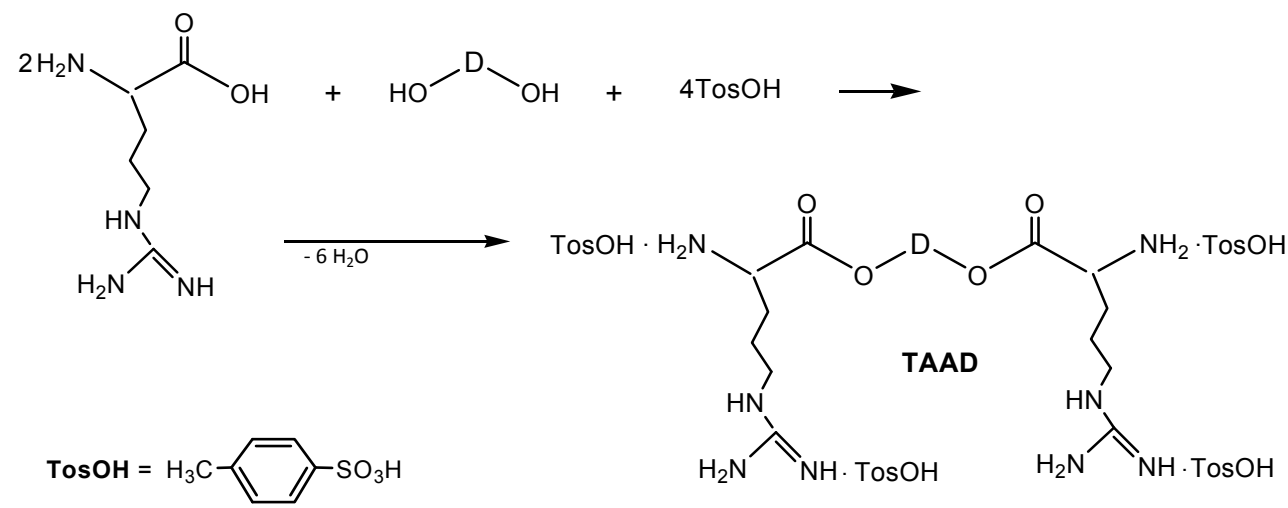

Figure 21. Structural peculiarities of AAAD-S monomers. Blue arrows, ester bonds; green arrows, enzyme specific groups; red arrows, the nonconventional "head-to-head" orientation.

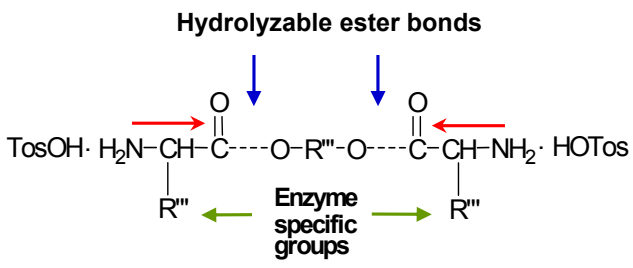

The merits of the synthetic schemes above consist in direct condensation of free amino acids with diols in refluxed benzene or toluene that results in the monomers with $80 \%-95 \%$ yield most of which are purified by recrystallization from water that makes the technology highly cost-effective. A wide variety of alkylenediols including $\alpha, \omega$-polymethylenediols and biobased diols such as dianhydrohexitols [217,218,220,222,223], as well as oligo-ethylene glycols [224-227] were used for synthesizing bis-amino-acid based diester salt monomers AAAD-S depicted in Figures 19 and 20. A huge variety of AA and diols used for synthesizing diamino-diester salt monomers allows varying material properties of the AABBP made of them.

Interesting AAAD (free bases) promising as starting monomers for synthesizing functional AABBP were obtained by the group of Mequanint and Gillies [228,229] following to multistage synthetic strategy widespread in peptide chemistry: they used heterodiprotected polyfunctional amino acids (purchasable products)- $N$-CBZ-L-aspartic acid- $\beta$ - $t$-butyl ester and $N^{\alpha}$-CBZ- $N^{\varepsilon}-t$-BOC-L-lysine, condensed (esterified) these compounds with 1,4-butanediol using coupling agent (DCC), and selectively removed one of the functional groups (another one was deprotected in polymers, see Figures 28 and 30 below). The structures of these functional monomers are represented in Figure 22. 
The AAAD above were successfully used as comonomers of AAAD-S (made of hydrophobic AA) in both solution active and interfacial polycondensations for obtaining functional polymers with satisfactory molecular weights. No data, however, were reported on the synthesis of high-molecular-weight homo-AABBP on their basis presumably due to insufficient purity of these complex and nontrivial monomers (they were not subjected to purification after synthesis-deprotection of corresponding precursors) that might be farther decreased due to side reactions typical for alkyl esters of $\alpha$-amino acids as free basis (discussed in a brief above). The decreasing molecular weight of AABBP with increasing the mole fraction of functionalized monomers in comonomer pairs AAAD/AAAD-S [228] could speak for this assumption.

Figure 22. AAAD monomers derivatives of $\beta-C$ protected and $\varepsilon-N$ protected lysine.

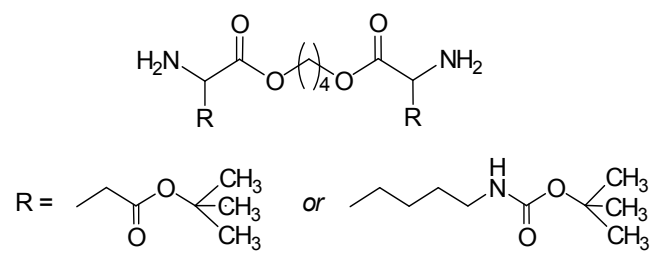

Another type of AA-based monomers is DABA in which the desirable amide bonds are incorporated at a monomer stage, and the biodegradable (hydrolysable) ester bonds are formed at a propagation stage. In these monomers the orientation of AA is also nonconventional, "tail-to-tail" type that can diminish the immunogenicity of the goal AABBP.

The DABA are obtained by the interaction of two moles of AA with diacid chlorides under Shotten-Baumann reaction conditions or in dioxane using $\mathrm{NaOH}, \mathrm{KOH}$ or $\mathrm{MgO}$ as an $\mathrm{HCl}$ acceptor [230,231], according to Figure 23.

Figure 23. Synthesis of DABA $(\mathrm{Z}=\mathrm{H})$ and DABA-M $\left(\mathrm{Z}=\mathrm{CH}_{3}\right) . \mathrm{A}=\left(\mathrm{CH}_{2}\right)_{4}$ or $p-\mathrm{C}_{6} \mathrm{H}_{4}$; $\mathrm{Z}=\mathrm{H}$ or $\mathrm{CH}_{3}$; For R, see Figure 19 above.

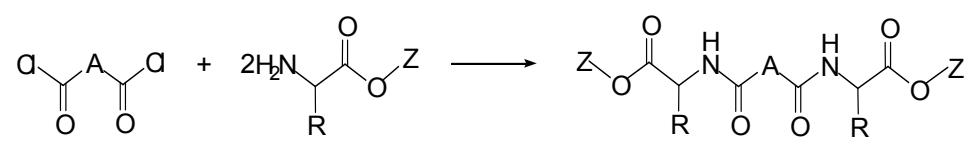

For synthesizing AABBP, DABA are used mostly as active bis-electrophilic monomers such as bis-azlactones [231,232] or activated diesters [233] that were obtained via appropriate transformations of DABA, or dimethyl diesters (DABA-M in Figure 23) that were synthesized by Puiggalí et al. [234] via interaction of diacid chlorides with AA (glycine) methyl ester with diacid chlorides in chloroform in the presence of triethylamine as $\mathrm{HCl}$ acceptor.

DABA as polycondensation type monomers can reveal a dual nature, either bis-electrophilic (when carboxyl groups are transformed into active derivatives) or bis-nucleophilic (when carboxyl groups are transformed into salts). In both cases the biodegradable (hydrolysable) ester bonds are formed at a chain propagation stage that will be discussed below. 


\subsubsection{Monomers - Counter-Partners for Synthesizing AABBP}

Active derivatives of dicarboxylic acids - either activated diesters or diacid chlorides were used as bis-electrophilic monomers in polycondensation reactions with AAAD/AAAD-S. Fatty diols were used as bis-nucleophilic monomers in polycondensation reactions with bis-azlactones or DABA-M, and bis-electrophilic dihalo-alkanes are used as bis-electrophilic monomers in polycondensation reaction with the salts of DABA.

Most of diacid chlorides and fatty diols are purchasable products. Activated diesters of general formula $\mathrm{R}_{1}-\mathrm{O}-\mathrm{CO}-\mathrm{A}-\mathrm{CO}-\mathrm{O}-\mathrm{R}_{1}$ are obtained using three synthetic methods: (i) by interaction of diacid chlorides $\mathrm{Cl}-\mathrm{CO}-\mathrm{A}-\mathrm{CO}-\mathrm{Cl}$ with various hydroxyl compounds $\mathrm{HOR}_{1}$ (activating agents), or by direct interaction of dicarboxylic acids (ii) with $\mathrm{HOR}_{1}$ in the presence of various condensing (coupling) agents or (iii) with various trans-esterifying agents that are derivatives of $\mathrm{HOR}_{1}$. All three methods give activated diesters in a good yield ranged from $60 \%$ to $90 \%$ (See [220] and references cited therein). The application of activated diesters allows to obtain AABBP on the basis of short-chain dicarboxylic acids such as succinic and adipic acids, dichlorides of which are less stable hydrolytically and, hence, less suitable for synthesizing high-molecular-weight polymers via interfacial polyconden-ation, or on the basis of such diacids, dichlorides of which are not available at all due to instability towards chlorinating agents. It is worth mentioning here that in case of succinyl chloride the hydrolysis is not the only factor resulting in low-molecular-weight polymers - the fast cyclization of intermediate amide into five-membered succinimide cycle leads to undesirable chain termination as well. When using more steady activated di-succinates as bis-electrophilic monomers, high-molecular-weight film-forming polysuccinamides were synthesized [235].

\subsection{AABBP Made of AAAD Monomers}

\subsubsection{AABBP via Solution Active Polycondensation}

This method is based on the application of various activated diesters as bis-electrophilic monomers in polycondensation reaction with bis-nucleophiles, mostly diamines [236,237]. The activated diesters showed much more "calm temper" as compared with diacid chlorides which are traditionally used in solution or interfacial polycondensations [238]. A large variety of activating agents $\mathrm{HOR}_{1}$ allows the tuning of the diesters activity in a wide range [236,237]. Besides, the activated diesters are stable against both amide type solvents and tertiary amines under the conditions of solution polycondensation [239] that minimizes undesirable site reactions and results in the formation of high-molecular-weight polymers. This stability of activated diesters allows the use of salts of diamines such as AAAD-S in solution polyamidation reactions, which needs tertiary amines for deprotonation of primary amino groups that are necessary for their interaction with electrophile-activated ester groups resulting in amide bond formation and representing the chain propagation reaction. Mostly di-p-nitrophenyl esters of diacids $\left(\mathrm{HOR}_{1}=p\right.$-nitrophenol) are used for synthesizing amide-type polymers due to the facile synthesis via all three methods above, a high reactivity and vast availability and low price of $\mathrm{p}$-nitrophenol. It is, however, rather problematic to remove $p$-nitrophenol from the polymers after polycondensation by simple washing with water due to its poor solubility in water. From this point of view more promising look bis- $N$-oxysuccinimidyl esters of diacids that 
also result in high-molecular-weight polyamides [240], and a by-product of polycondensation; $N$-hydroxysuccinimide is easily soluble in water.

Regular AABBP and Related Polymers

To this category we refer the polymers that have no functional groups except two terminal functional groups, normally one nucleohpilic and one electrophilic. According to the polycondensation theory of Kricheldorf [241,242] a substantial portion of molecules obtained via polycondensation have no terminal functional groups at all since they form macrocycles.

The first regular AABBP were synthesized by interaction of AAAD-S with activated diesters $\mathrm{R}_{1}-\mathrm{O}-\mathrm{CO}-\mathrm{A}-\mathrm{CO}-\mathrm{O}-\mathrm{R}_{1}$ of $\alpha, \omega$-alkylenedicarboxylic acids $\left[\mathrm{A}=\left(\mathrm{CH}_{2}\right)_{\mathrm{y}}\right.$ ] in organic solvents [243-246], according to Figure 24.

The polycondensation is normally carried out in high-polar aprotic solvents like $N, N$-dimethyl formamide (DMF), N,N-dimethyl acetamide (DMA), $N$-methyl-2-pyrrolidone ( $N$-MP), dimethyl sulfoxide (DMSO) and chloroform [246]. Since the alcoholysis of activated diesters is much slower compared to the aminolysis [247], protic solvents (alcohols) can also be used as reaction media for synthesizing AABBP. For example, a high-molecular-weight film-forming polymer was synthesized by polycondensation of di-p-nitrophenyladipate with AAAD-S composed of L-leucine and 1,6-hexanediol in isopropyl alcohol [248]. Tertiary amines (mostly triethylamine) are typically used as $p$-toluenesulfonic acid acceptor though inorganic acceptors such as sodium or potassium carbonates are also effective [246].

Figure 24. Synthesis of AABBP via active polycondensation.

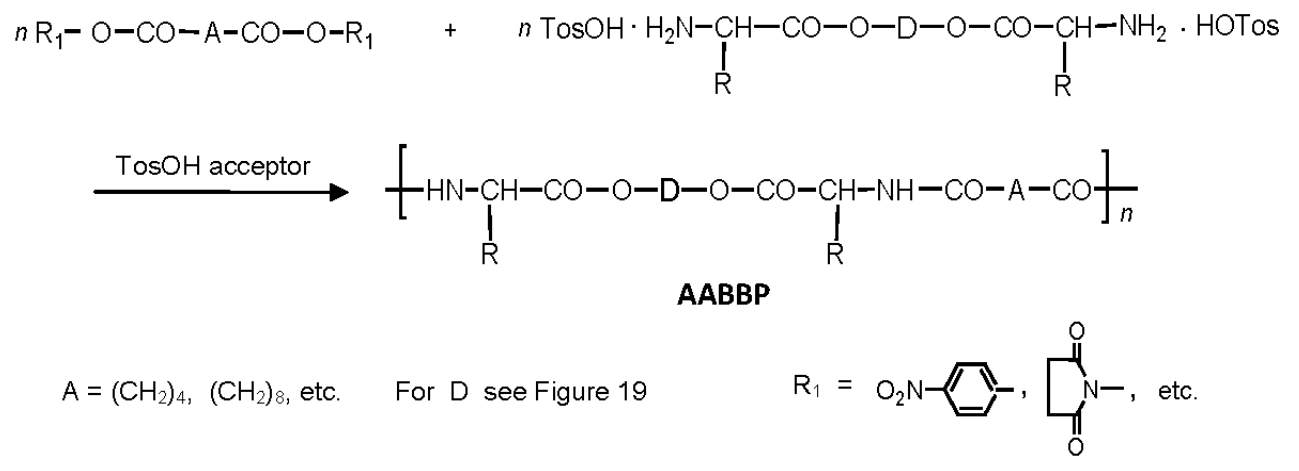

Solution active polycondensation allowed synthesizing high-molecular-weight polymers on the basis of monomeric alkylene dicarboxylates, namely alkylene disuccinates (diester-diacids) that were synthesized by interaction of diols ( $1 \mathrm{~mol})$ with succinic anhydride $(2 \mathrm{~mol})$. The diester-diacids were transformed into activated di-p-nitrophenyl esters that were used in Figure 24 as bis-electrophilic monomers resulting in high-molecular-weight polysuccinates [249], represented in Figure 25.

Figure 25. AABBP composed of alkylene disuccinates.

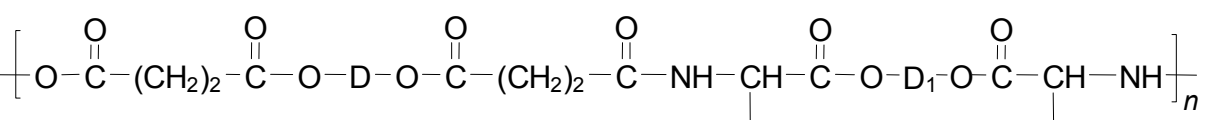

$$
\begin{aligned}
& \mathrm{R} \quad \mathrm{R} \\
& \mathrm{R}=\mathrm{CH}_{2} \mathrm{CH}\left(\mathrm{CH}_{3}\right)_{2}, \quad \mathrm{CH}_{2} \mathrm{C}_{6} \mathrm{H}_{5} ; \quad \mathrm{D}, \mathrm{D}_{1}=\left(\mathrm{CH}_{2}\right)_{4}, \quad\left(\mathrm{CH}_{2}\right)_{6}, \quad\left(\mathrm{CH}_{2}\right)_{8}
\end{aligned}
$$


The polymers contain two additional ester bonds (in total four ester bonds) per elemental link and showed increased biodegradation rates. Additionally, the enhanced hydrolysis of polysuccinates is linked with intramolecular catalysis (see [235] and references cited therein).

Another representatives of AABBP containing four hydrolyzable ester bonds per elemental link are polymers composed of $O, O^{\prime}$-diacyl-bis-glycolic acids (another kind of diester-diacids) obtained by interaction of glycolic acid $(2 \mathrm{~mol})$ with diacid chlorides $(1 \mathrm{~mol})$ [250,251]. The diester-diacids were transformed into activated di-p-nitrophenyl esters (like alkylene disuccinates above) that were used in Figure 24 as bis-electrophilic monomers resulted in a high-molecular-weight AA-BB-type polydepsipeptides, represented in Figure 26.

The regular AABBP synthesized via solution active polycondensation have high molecular weights $\left(M_{\mathrm{W}} \leq 180,000 \mathrm{Da}, \mathrm{GPC}\right)$ and rather narrow polydispersity $(1.20-1.81)$. The polymers have a wide range of glass transition temperature $\left(T_{\mathrm{g}}=5-102{ }^{\circ} \mathrm{C}\right)$, some of them are semicrystalline with $T_{\mathrm{m}}=103-153^{\circ} \mathrm{C}$. The highest $T_{\mathrm{g}}$ showed the polymers composed of bicyclic diols, dianhydrohexitols. The chemical structure influences the mechanical properties of AABBP which varies in a wide range: tensile strength from $15-20$ to $80-100 \mathrm{MPa}$, elongation at break from up to $200 \%$, and Young's modulus up to $2 \mathrm{GPa}$. The AABBP are soluble in common organic solvents such as DMF, THF, methylene chloride, chloroform, some of them in dioxane, acetone, and alcohols (methanol, ethanol, isopropanol) (See [220] and references cited therein). The low melting temperatures and solubility in common solvents make AABBP easily processable into different shapes.

Figure 26. AA-BB type polydepsipeptides.

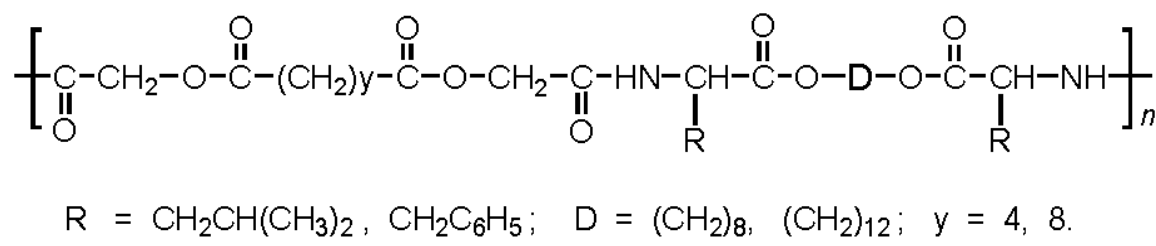

\section{Functional AABBP}

The solution active polycondensation turned out especially useful for synthesizing AABBP containing various functional groups in lateral chains. The first representatives of AABBP with lateral carboxyl groups (in fact polyanions) were obtained by Jokhadze et al. [252] using L-lysine derivative as a diamine comonomer, according to Figure 27 below.

Figure 27. Synthesis of AABBP with lateral carboxyl groups.

$$
\begin{aligned}
& \underset{\mathrm{COOBn}}{\mathrm{C}} \mathrm{CO}-\left(\mathrm{CH}_{2}\right)_{y}-\mathrm{CO}-\mathrm{NH}-\underset{\mathrm{C}}{\mathrm{C}}-\left(\mathrm{CH}_{2}\right)_{4}-\mathrm{NH} \mathrm{f}_{K} \operatorname{mmn}+\mathrm{CO}-\left(\mathrm{CH}_{2}\right)_{y}-\mathrm{CO}-\mathrm{NH}-\underset{\mathrm{R}}{\mathrm{C}} \mathrm{H}-\mathrm{COO}-\mathrm{D}-\mathrm{OCO}-\underset{\mathrm{R}}{\mathrm{C}} \mathrm{H}-\mathrm{NH} f_{i} \\
& \downarrow^{\mathrm{Pd} / \mathrm{H}_{2}}
\end{aligned}
$$

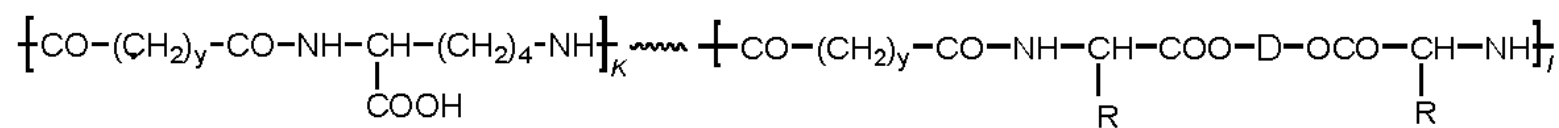

$$
\begin{aligned}
& k=0.10,0.25,0.50 ; \quad I=1-k ; \quad \mathrm{R}=\mathrm{CH}_{2} \mathrm{CH}\left(\mathrm{CH}_{3}\right)_{2}, \quad \mathrm{CH}_{2} \mathrm{C}_{6} \mathrm{H}_{5} ; \quad \mathrm{D}=\left(\mathrm{CH}_{2}\right)_{4}, \quad\left(\mathrm{CH}_{2}\right)_{6}, \quad\left(\mathrm{CH}_{2}\right)_{8}
\end{aligned}
$$


These polymers showed excellent biocompatibility [253,254] and were successfully used as vascular stent coatings [255].

The polyacids depicted in Figure 27 represent copolymers of poly(ester amide)s and polyamides. Pure AABBP-polyacids (copolymers) were prepared by the group of Mequanint and Gillies [229] via solution active polycondensation of comonomer pairs bis-(L-aspartic acid- $\beta$ - $t$-butyl ester)-1,4-butylene diester (Figure 22) and AAAD-S (composed of L-alanine and L-phenylalanine) with di-p-nitrophenyl succinate, and subsequent deprotection of the intermediated $C$-protected AABBP, as depicted in Figure 28.

Figure 28. co-AABBP-polyacids composed of bis-(L-aspartic acid)-1,4-butylene diester.

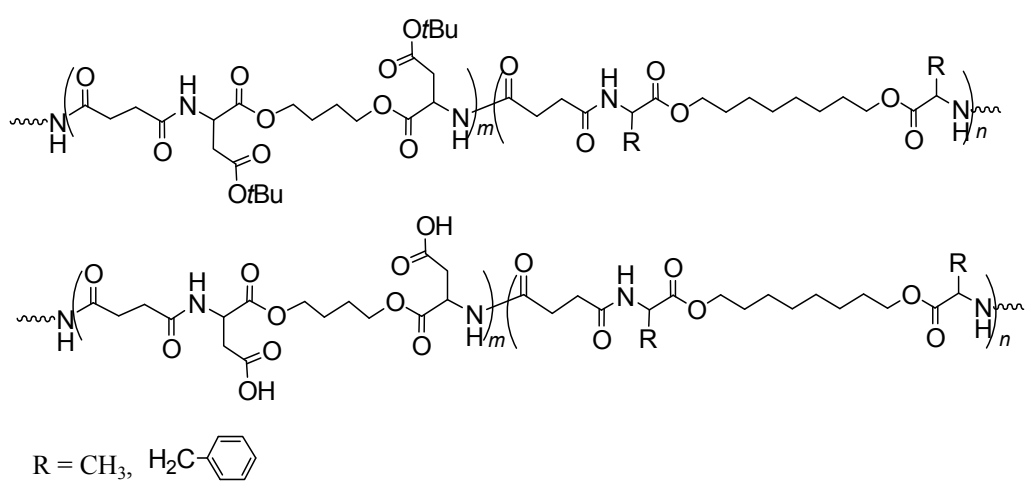

The polyacids were further functionalized by transforming the lateral $\mathrm{COOH}$ groups into activated $N$-oxysuccinimidyl esters [229] that are promising biodegradable carriers for the conjugation of active molecules such as drugs, targeting groups, cell signaling molecules, etc.

Polycationic AABBP with lateral guanidine groups, represented in Figure 29, were obtained by solution active polycondensation of arginine-based AAAD-S according to Figure 20 with activated diesters of succinic, adipic, sebacic [225-227,256] or diglycolic acids [227]. The polymers showed outstanding cell compatibility and are promising non-viral gene delivery agents.

Figure 29. Cationic AABBP composed of L-arginine.

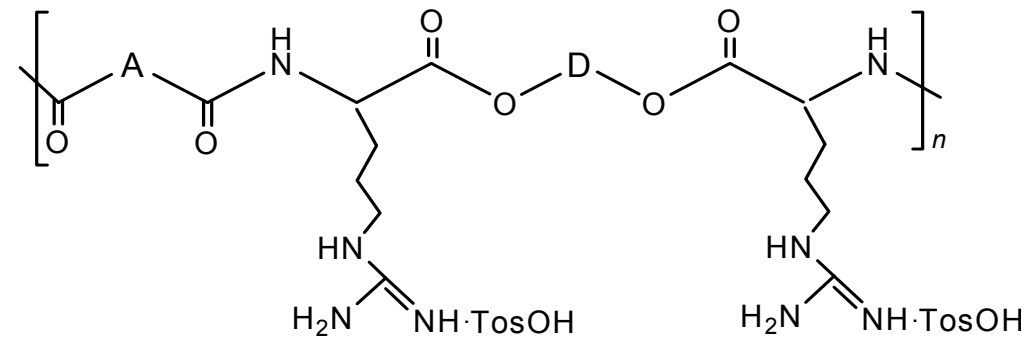

$$
\begin{aligned}
& \mathrm{A}=\left(\mathrm{CH}_{2}\right)_{2},\left(\mathrm{CH}_{2}\right)_{4},\left(\mathrm{CH}_{2}\right)_{8}, \mathrm{CH}_{2}-\mathrm{O}-\mathrm{CH}_{2} ; \\
& \mathrm{D}=\left(\mathrm{CH}_{2}\right)_{3},\left(\mathrm{CH}_{2}\right)_{4},\left(\mathrm{CH}_{2}\right)_{6},\left(\mathrm{CH}_{2}\right)_{12},\left(\mathrm{CH}_{2}\right)_{2}-\mathrm{O}-\left(\mathrm{CH}_{2}\right)_{2},\left(\mathrm{CH}_{2}\right)_{2}-\left[\mathrm{O}-\left(\mathrm{CH}_{2}\right)_{2}\right]_{2},\left(\mathrm{CH}_{2}\right)_{2}-\left[\mathrm{O}-\left(\mathrm{CH}_{2}\right)_{2}\right]_{3}
\end{aligned}
$$

Another types of cationic AABBP (copolymers) containing primary amino groups in the lateral chains were prepared by solution active polycondensation of comonomer pairs bis-( $N^{\varepsilon}-t$-BOC-L-lysine)-1,4-butylene diester (Figure 22) and AAAD-S (composed of L-alanine and L-phenylalanine) with di-p-nitrophenyl succinate, and subsequent deprotection of the intermediated $N$-protected AABBP [229,257], as depicted in Figure 30. 
A series of unsaturated AABBP, depicted in Figure 31, were synthesized by solution polycondensation of activated di-p-nitropheyl fumarate with AAAD-S [258-260]. The polymers can be used as biodegradable carriers for covalent attachment biochemicals through sulfhydryl or amino groups, or to transform into various functional polymers: polyols, polyacids or polyamines by interaction with corresponding thiol or amino reagents; the former gave a much higher degree of transformation (90\%-95\% vs. 23\%-24\%) [260].

Figure 30. Cationic AABBP composed of bis-(L-lysine)-1,4-butylene diester.

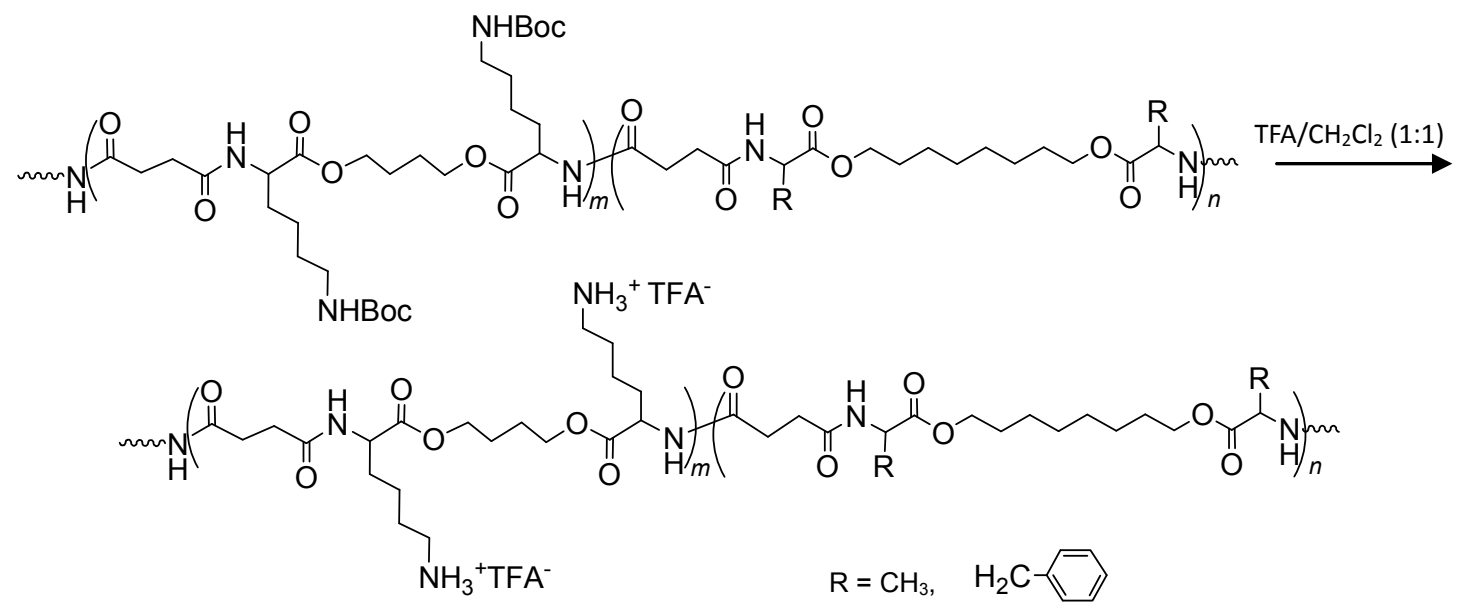

Figure 31. Unsaturated AABBP composed of fumaric acid.

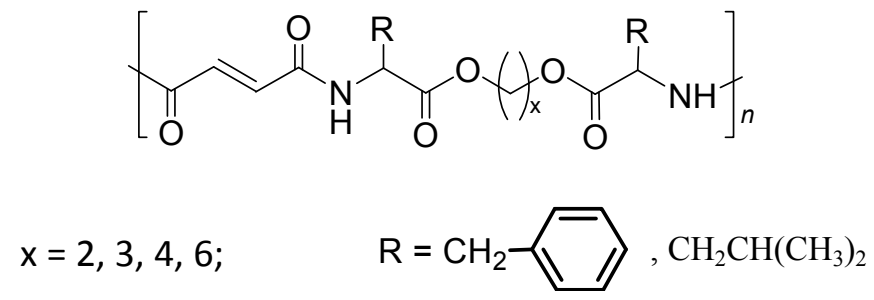

Another functional, "ready-for-use" type epoxy-AABBP, depicted in Figure 32, were synthesized by Zavradashvili et al. [261] via solution polycondensation of activated di-p-nitrophenyl-trans-epoxy succinate with AAAD-S.

Figure 32. AABBP composed of epoxy-succinic acid.<smiles>[R]C(NC(=O)C(C)C)C(=O)OCCOC(=O)C([R])NC(C)(C)C</smiles><smiles>[R]Cc1ccc(CCC(C)C)cc1</smiles>

High-molecular-weight polymers $\left(M_{\mathrm{W}}\right.$ up to 76,000$)$ with desirable material properties have been obtained. Epoxy-AABBP could chemically be modified further under mild conditions: oxirane groups along the backbone were reacted with both nucleophilic and electrophilic reagents, as well as subjected to thermal curing. The macromolecular transformations of the epoxy-polymers substantially broaden material properties and, hence, the potential to apply AABBP as absorbable drug carriers and surgical devices. 
Copolymeric AABBP with a brush-like architecture (Figure 33) containing long-chain alkyl substituents were obtained by Katsarava and coworkers [262,263] using L-lysine $n$-alkyl esters as comonomer in a mixture with AAAD in solution active polycondensation.

Figure 33. Brush-like copolymeric AABBP composed of L-lysine $n$-alkyl esters.

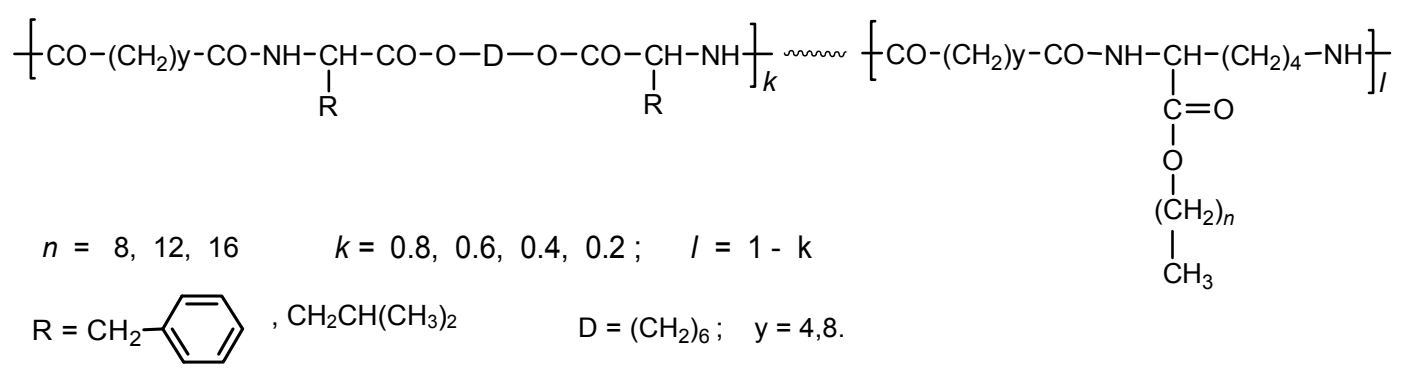

The polymers are promising biodegradable drug carriers that can be drug-loaded via hydrophobic forces. The polymers form nanocomplexes with PEG [263] that are also of interest as drug-carriers.

Various AABBP containing free $\mathrm{OH}$ groups were obtained by Gomurashvili et al. [264] by solution polycondensation of AAAD-S composed of unsubstituted AA glycine and glycerol with di-p- nitrophenyl esters of succinic, glutaric, adipic, and diglycolic acids. Depending on the synthetic strategy used, three types of hydroxyl-containing polymers were synthesized: (i) with pending primary hydroxyls; (ii) with pending secondary hydroxyls; or (iii) a copolymer containing both primary and secondary glycerol hydroxyls (not shown here). Polymers composed of short aliphatic diacids such as succinic, glutaric, and diglycolic acids were water soluble.

Water-soluble AABBP, having the structure given in Figure 34, were also obtained by polycondensation of AAAD-S composed of 1,4-anhydroerythritol and glycine with di-p-nitrophenyl succinate [264].

Figure 34. Water-soluble poly(ester amide)s (PEAs) on the basis of 1,4-anhydroerythritol, glycine, and succinic acid.

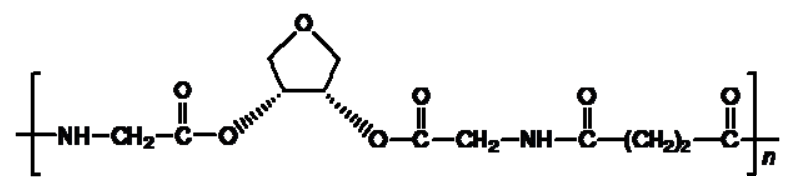

The strategy of the synthesis of AABBP via solution active polycondensation allows constructing biodegradable polymeric drugs. Therapeutic copolymer (Figure 35) was obtained by Gomurashvili et al. [255] by polycondensation of di- $p$-nitrophenyl sebacate with three comonomers: two AAAD-S composed of L-leucine/1,6-hexanediol and L-leucine/17- $\beta$-estradiol, and di- $p$-toluensulfonic acid salt of L-lysine benzyl ester.

\subsubsection{AABBP via Interfacial Polycondensation}

The interfacial polycondensation in a two phase system water/hydrophobic organic solvent is well known and widely used method of polymer synthesis [238]. The main advantage of this method consists of simplicity and a high rate of the reaction. The general scheme of the synthesis of AABBP via interfacial polycondensation is outlined in Figure 36. 
Figure 35. Drug-containing AABBP composed of 17- $\beta$-estradiol, 1,6-hexanediol, L-leucine, L-lysine benzyl ester, and sebacic acid.

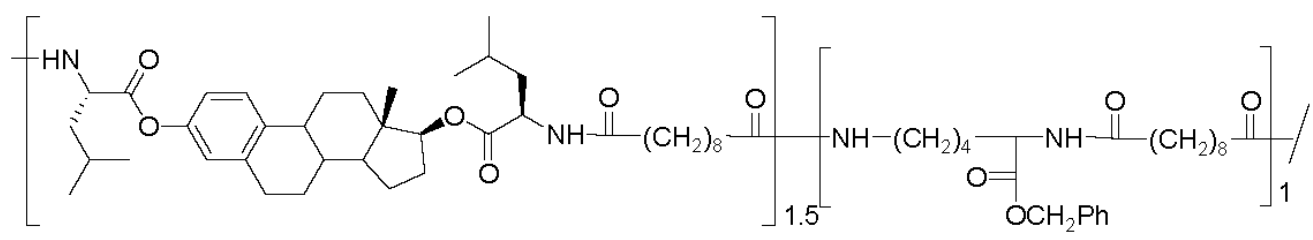

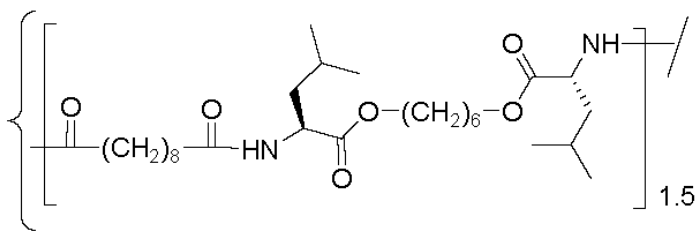

Figure 36. Synthesis of AABBP via interfacial polycondensation.

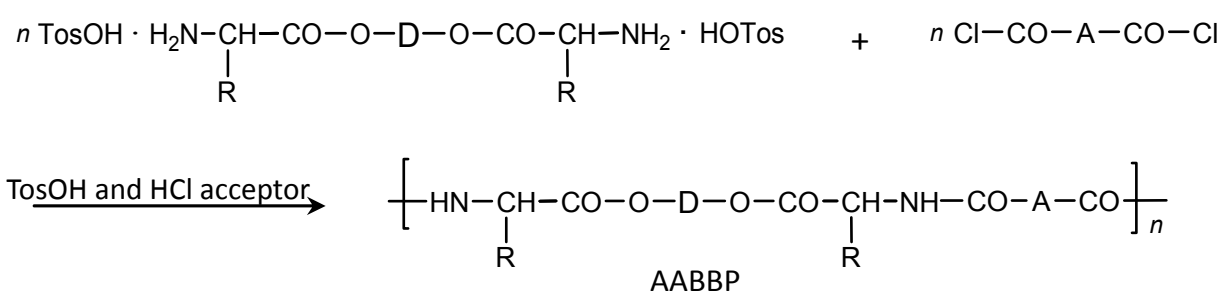

$A=(C H 2) y$ with $y=8$ or higher ; For $D$ and $R$ see Figure 19

Puiggalí et al. [234,265-271] successfully applied this method to the synthesis of various AABBP composed of hydrophobic AA. They obtained high-molecular-weight polymers showing good film-forming properties by interaction of AAAD with sebacoyl chloride. Mequanint et al. [257,272] used the same method for synthesizing AABBP including functional ones (copolymeric AABBP) depicted in Figures 28 and 30. This team carried out a comparative study of solution active and interfacial polycondensations [257] and showed that the latter led to the AABBP with higher yields and molecular weights (Table 1). The interfacial polycondensation, however, results in high-molecular-weight polymers when hydrophobic diacid chlorides such as sebacoyl chloride or higher diacid chlorides are used due to the hydrolytic instability of lower diacid chlorides. This is an important limitation of this method. Solution active polycondensation is applicable virtually to all dicarboxylic acids and represent more universal synthetic method.

Table 1. Comparison of solution and interfacial polycondensation of AABBP (according to [257]).

\begin{tabular}{ccccc}
\hline PEA & Yield (\%) & $\boldsymbol{M}_{\mathbf{W}}(\mathbf{D a})$ & $\boldsymbol{M}_{\mathbf{n}}(\mathbf{D a})$ & PDI \\
\hline 8-Ala-8-Sol & 67 & 51,400 & 36,600 & 1.40 \\
8-Ala-8-Int & 68 & 62,500 & 45,100 & 1.39 \\
8-Phe-4-Sol & 85 & 103,000 & 53,500 & 1.93 \\
8-Phe-4-Int & 78 & 168,000 & 63,600 & 2.64 \\
8-Phe-8-Sol & 61 & 63,300 & 44,400 & 1.43 \\
8-Phe-8-Int & 60 & 111,000 & 71,800 & 1.55 \\
\hline
\end{tabular}




\subsection{AABBP Made of DABA-Based Monomers}

\subsubsection{AABBP via Thermal and Biocatalytic Polycondensation}

High-molecular-weight AABBP were synthesized by Puiggalí and co-workers [234,271] via thermal polycondensation (polyesterification) of DABA-M with diols, as indicated in Figure 37.

Figure 37. Synthesis of AABBP via thermal polycondensation.
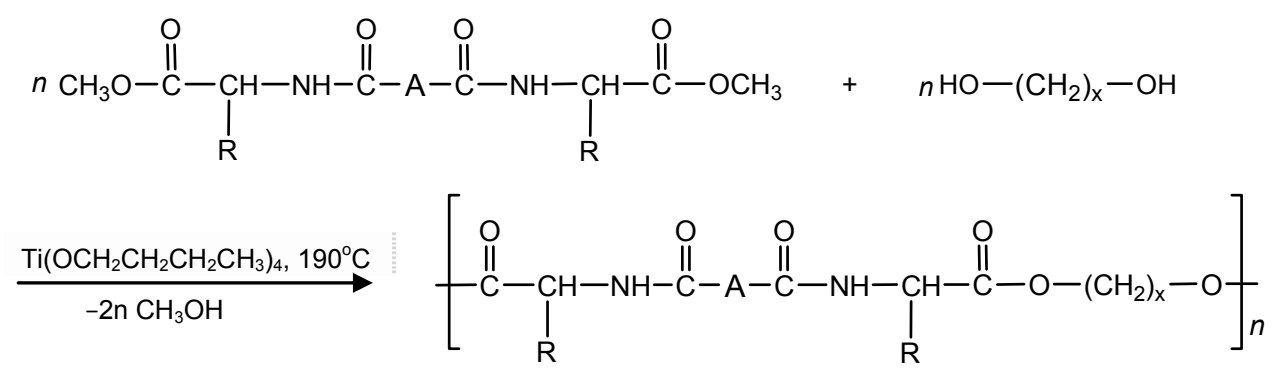

$A=$ none (oxalic acid), $\left(\mathrm{CH}_{2}\right)_{2}$ (succinic acid), $\left(\mathrm{CH}_{2}\right)_{8}$ (sebacic acid), $p-\mathrm{C}_{6} \mathrm{H}_{4}$ (terephthalic acid); $\mathrm{x}=2,4,6,12$.

This method was applied for synthesizing AABBP composed of unsubstituted amino acid glycine. This alternative synthesis route was undertaken because of the difficulty in esterifying 1,4-butanediol with glycine, i.e., unavailability of AABBP composed of the said building blocks through solution active or interfacial polycondensations. The polyesterification was carried out in melt at $190{ }^{\circ} \mathrm{C}$ using titanium butoxide as a catalyst. Later on the method was applied to other diols such as 1,2-ethanediol, 1,6-hexanediol, and 1,12-dodecanediol though their esterification with glycine was not problematic.

Turnell et al. [273] used thermal polycondensation for synthesizing proline-based AABBP via interaction of corresponding DABA-M with diols. Polymers having molecular weights in the range from about 14,000 Da to about 77,000 Da were obtained. These proline-based AABBP assemble as nano-particles in aqueous solutions and form complexes with various cations and biologics, including hydrophobic small molecule drugs and biologics.

Besides the successful synthesis of AABBP unavailable via solution or interfacial polycondensation discussed above (e.g., AABBP composed of 1,4-butanediol and glycine), the advantages of the thermal polycondensation vs. interfacial polycondensation are as follows: (1) oxalic acid derivatives can be obtained with high viscosity, a fact that is not possible by interfacial polymerization because of the high hydrolysis rate of the oxaloyl dichloride; and (2) the intrinsic viscosities of polymers synthesized by thermal condensation are usually higher, especially when interfacial polymerization implies unstable diacid chlorides such as succinyl chloride or the said oxalyl chloride (Table 2). The synthesis of AABBP via thermal polycondensation, however, has some limitations: (1) the synthesis with ethylene glycol was unsuccessful because a high degree of decomposition at high temperature; (2) polymers on the basis of succinic acid are of lower viscosity compared to sebacic acid derivatives, presumably due to the cyclization (imidization) at high temperature. In addition, some polymers such as those containing oxaloyl or terephthaloyl residues showed some coloration.

In general, film- (from the melt state or from the solution) and fiber-forming properties were found for polymers with an intrinsic viscosity higher than $0.5 \mathrm{dL} / \mathrm{g}$ [234]. Potentially, the method of thermal 
polycondensation could be applied to the DABA-M on the basis of other hydrophobic amino acids since $T_{\mathrm{g}}$ and $T_{\mathrm{m}}$ of corresponding AABBP [246] are far below of polyesterification temperature $\left(190^{\circ} \mathrm{C}\right)$. When applicable, the technological advantage of thermal polycondensation consists in the possibility to process polymers from melt directly after the polycondensation, that is without the separation and purification of the resulting polymers. This makes the method rather promising from the industrial point of view.

Table 2. Comparison between the intrinsic viscosities $[\eta]$ of AABBP according to the polycondensation method (according to Ref. [234]).

\begin{tabular}{ccc}
\hline \multirow{2}{*}{ Polymer $^{\text {a }}$} & \multicolumn{2}{c}{$[\boldsymbol{\eta}]^{\mathbf{b}}(\mathbf{d L} / \mathbf{g})$} \\
\cline { 2 - 3 } & Interfacial Polycondensation & Thermal Polycondensation \\
\hline PGHGT & 0.68 & 0.74 \\
PGDGT & 0.60 & 0.68 \\
PGHG0 & $\mathrm{c}$ & 0.60 \\
PGDG0 & $\mathrm{c}$ & 0.73 \\
PGHG2 & 0.23 & 0.38 \\
PGDG2 & 0.20 & 0.40 \\
PGHG8 & 0.37 & 0.51 \\
PGDG8 & 0.41 & 0.48 \\
\hline
\end{tabular}

a Abbreviations: P, polymer; G, glycine; H, 1,6-hexanediol; D, 1,12-dodecanediol; T, terephthalic acid; 0 , oxalic acid; 2, succinic acid; 8 , sebacic acid; ${ }^{\mathrm{b}}$ In dichlorocetic acid at $25{ }^{\circ} \mathrm{C} ;{ }^{\mathrm{c}}$ No polymer obtained.

Monomer pairs DABA-M/alkylene diols are also promising for enzyme catalyzed synthesis of AABBP. In a preliminary study of Omay and Katsarava [274] polymer with $M_{\mathrm{W}}$ up to $13 \mathrm{KDa}$ was obtained after polycondensation of dimethyl ester of $N, N$ '-bis-sebacoyl-L-leucine with 1,12-dodecanediol in the presence of Novozym-435.

\subsubsection{AABBP via Azlactone Method}

AABBP composed of aromatic terephthalic acid were obtained by interaction of corresponding bis-azlactones with diols according to Figure 38. Cleaver and Pratt [275] first described the poly(ester amide) polymer obtained by interaction of leucine-based bis-azlactone $\left(\mathrm{R}=\mathrm{CH}_{2} \mathrm{CH}\left(\mathrm{CH}_{3}\right)_{2}\right.$ in Figure 38) with 1,6-hexanediol $(x=6)$ in chloroform. Only low-molecular weight polymer (inherent viscosity $\eta_{\text {inh }}=0.20$ in $\mathrm{m}$-cresol at $25{ }^{\circ} \mathrm{C}$ and $c=0.1 \%$ ) was obtained. Neither acid nor base type catalyst led to the polymer of higher molecular weight.

Figure 38. Synthesis of AABBP on the basis of bis-azlactone.<smiles>[R]C1N=C(c2ccc(C3=NC([R])C(=O)O3)cc2)OC1=O</smiles><smiles>[Y]C1CCC2(O)COC12</smiles><smiles>[R]C(NCC)C(=O)OC1CCC1(C)OC(=O)C([R])NC(=O)c1ccc(C(C)=O)cc1</smiles>

Kharadze et al. [232] carried out the polymerization reaction of phenylalanine-based bis-azlactone $\left(\mathrm{R}=\mathrm{CH}_{2}-\mathrm{C}_{6} \mathrm{H}_{5}\right.$ in Figure 38) with 1,4-butanediol $(x=4)$ in various organic solvents in the presence of 
acid catalysts. The best result (yield $96 \%$, reduced viscosity $\eta_{\text {red. }}=0.40 \mathrm{dL} / \mathrm{g}$ in $m$-cresol at $25{ }^{\circ} \mathrm{C}$ and $c=0.5 \mathrm{~g} / \mathrm{dL}$ ) was achieved in $O$-dichlorobenzene at $160^{\circ} \mathrm{C}$ in the presence of trifluoroacetic acid.

\subsubsection{AABBP via Nucleophilic Substitution (NS)}

As noted above DABA can be used also as bis-nucleophilic monomers by transforming into corresponding salts. Potassium salts of DABA (composed phenylalanine and adipic or terephthalic acid) were used in solution polycondensation with 1,2-dibromoethane as it is outlined in Figure 39.

AABBP with reduced viscosity up to $0.28 \mathrm{dL} / \mathrm{g}\left(m\right.$-cresol, $\left.25{ }^{\circ} \mathrm{C}, c=0.5 \mathrm{~g} / \mathrm{dL}\right)$ were obtained after this NS polycondensation reaction [232].

Figure 39. Synthesis of AABBP via nucleophilic substitution (NS) polycondensation.

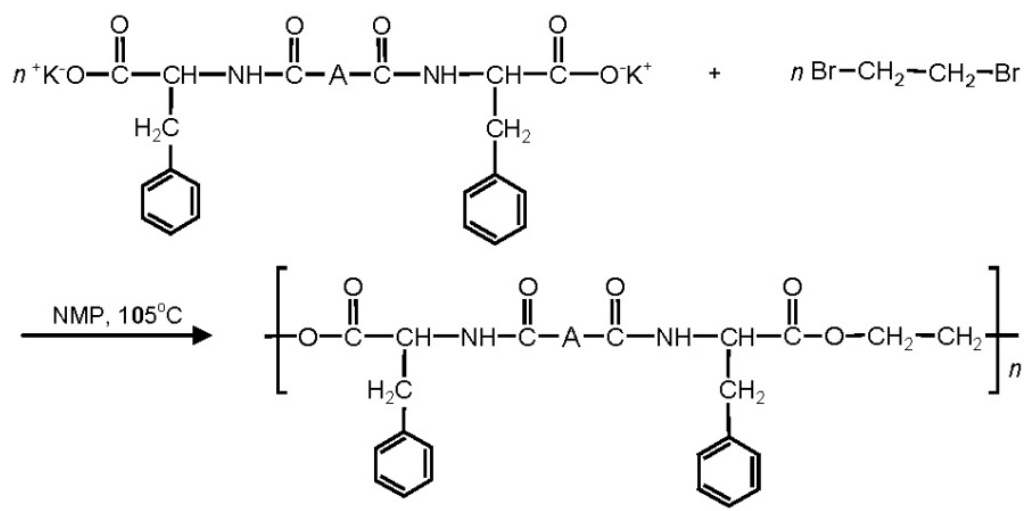

\subsection{AABBP Made by Combining AAAD-S and DABA Monomers}

There are only a few samples of the synthesis of AABBP by the combination of both types of AA-based monomers: AAAD-S and DABA. Activated di-p-nitrophenyl esters of two DABA composed of phenylalanine and adipic or terephthalic acids [233] were polycondensed with AAAD-S composed of phenylalanine and 1,4-butanediol in hexamethylphosphoramide, as represented in Figure 40.

Figure 40. Synthesis of dipeptide-containing AABBP.

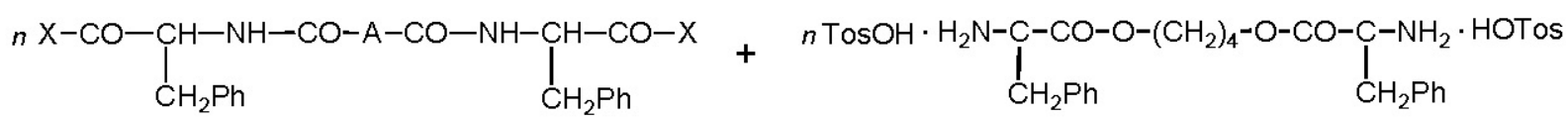
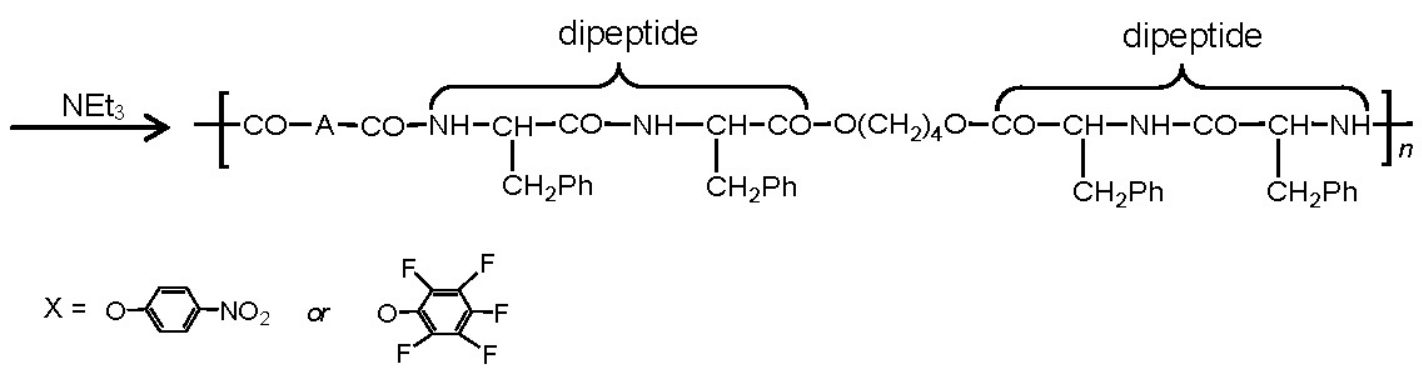

Relatively low-molecular-weight AABBP with $\eta_{\text {red. }}=0.19-0.32 \mathrm{dL} / \mathrm{g}\left(m\right.$-cresol, $\left.25{ }^{\circ} \mathrm{C}, c=0.5 \mathrm{~g} / \mathrm{dL}\right)$ and $86 \%-92 \%$ yield, containing dipeptide Phe-Phe fragments inserted amongst carbonyl group and ether oxygen instead of AA in Figure 17, were obtained. 
Very recently this kind of AABBP was synthesized by solution polycondensation of valine and phenylalanine based bis-azlactone $\left(\mathrm{R}^{1}=\mathrm{CH}\left(\mathrm{CH}_{3}\right)_{2}\right.$ and $\mathrm{CH}_{2}-\mathrm{C}_{6} \mathrm{H}_{5}$, accordingly) with AAAD-S using triethylamine as $p$-toluenesulfonic acid acceptor [276], according to Figure 41. Low-molecular-weight powdery polymers with $\eta_{\text {red. }}=0.1-0.2 \mathrm{dL} / \mathrm{g}$ (in 1,1,2,2-tetrachloroetane/phenol (3:1) mixture at $25{ }^{\circ} \mathrm{C}$ and $c=0.5 \mathrm{~g} / \mathrm{dL}$ ) were obtained that can be explained by the presence of triethylamine that catalyzes side reactions of azlactones [275]) resulting in chain termination. To diminish these side reactions bis-azlactones in part were substituted by activated diester (di- $p$-nitrophenyl sebacate) that increased molecular weight of the obtained co-AABBP $\left(\eta_{\text {red. }}=0.91 \mathrm{dL} / \mathrm{g}\right.$ at $\left.k / l=30 / 70\right)$ [277], depicted in Figure 42.

Figure 41. Synthesis of dipeptide-containing AABBP via bis-azlactones.

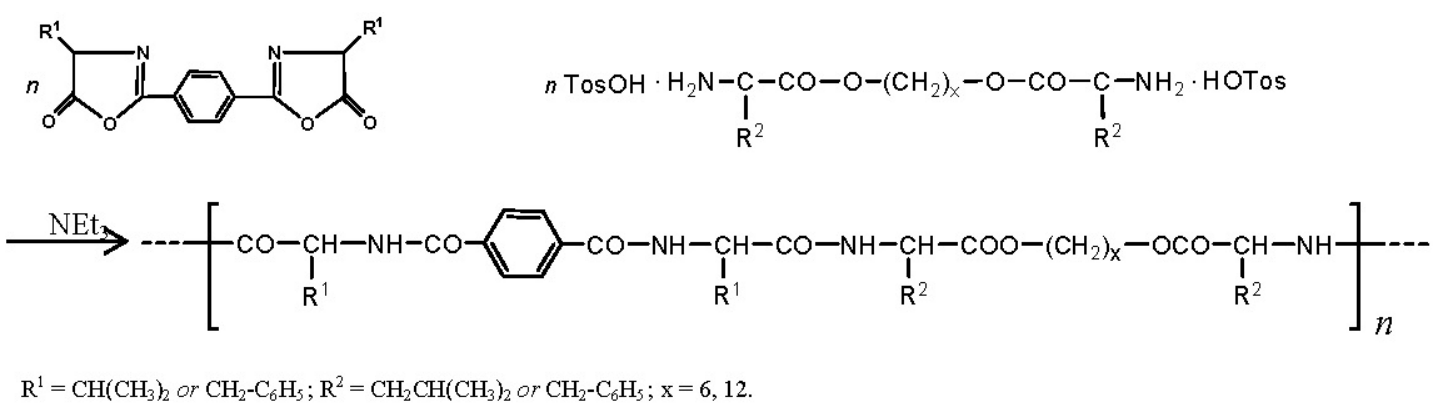

The azlactone method is a convenient way for incorporating rigid and hydrophobic terephthalic acid residue into the AABBP backbones. The incorporation of terephthalic acid fragments substantially decreases the stickiness of AABBP and renders them suitable for preparing resuspendable micro and nanoparticles - promising vehicles for drug delivery.

Figure 42. Copolymeric AABBP on the basis of azlactone and activated sebacate and AAAD-S.

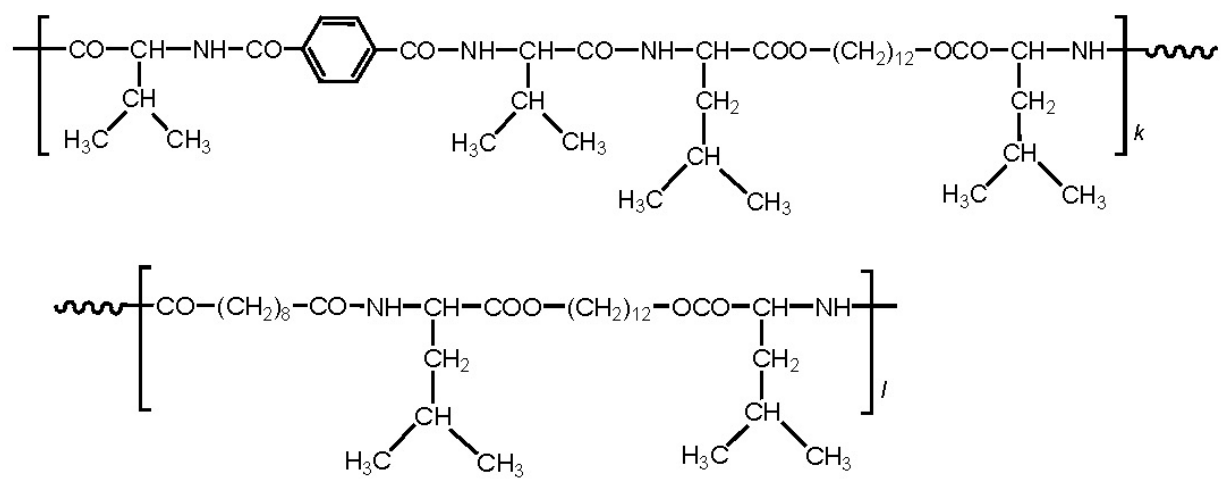

\subsection{Biocompatibility and Some Applications of $\boldsymbol{A A B B P}$}

AABBP composed of adipic acid, L-phenylalanine, and 1,4-butanediol supported the growth of human osteosarcoma and fibroblasts cells and showed the material to be biocompatible [220]. Elastomeric functional co-AABBP composed of sebacic acid $(1.00 \mathrm{~mol})$, L-leucine $(1.50 \mathrm{~mol})$ and 1,6-hexanediol $(0.75 \mathrm{~mol})$, and L-lysine $(0.25 \mathrm{~mol})$ [252] showed excellent blood and tissue compatibility in both in vitro [253] and in vivo (pigs) [254] tests. The same polymer selectively supported the in vitro growth of epithelial cells [253]. The in vivo biocompatibility was tested in porcine coronary arteries, comparing the polymer-coated stents with bare metal stents in 10 pigs [254]. 
All animals survived till sacrificed 28 days later. Prior to sacrifice, angiography revealed identical diameter stenosis in both groups. Histology confirmed similar injury scores, inflammatory reaction, and area stenosis. These results showed the polymer has a high potential for cardiovascular applications.

Recently Yamanouchi et al. [256] reported that the arginine-based AABBP showed good cell compatibility over a wide range of dosages and had minimal adverse effects on the cell morphology, viability, and apoptosis. Memanishvili et al. [225,227] showed that arginine-based AABBP having PEG-like polymeric backbones, possess higher cell compatibility than the said arginine-based polymers [256] not containing ether bonds.

The above-mentioned biological studies of several AABBP indicate that this family of biodegradable polymers is biocompatible.

Selected representatives of AABBP were used for constructing biodegradable hydrogels, nanoformulations, drug-eluting devises and coatings, and so forth. Guo et al. used the unsaturated AABBP for obtaining hybrid hydrogels through photochemical conjugation with PEG-diacrylate [278]. The biodegradable hybrid hydrogels are promising for many biomedical and pharmaceutical applications, such as drug delivery systems, tissue engineering, etc. Legashvili et al. [263] used brush-like co-AABBP (Figure 33) to obtain molecular complexes with PEG that are promising as nanocarriers of drugs. Yamanouchi et al. [256] evaluated complexation of a novel family of synthetic biodegradable L-arginine-based AABBP with DNA, for their capability to transfect rat vascular smooth muscle cells, a major cell type participating in vascular diseases. In whole, Arg-based AABBP [225-227,256] can be attractive candidates for non-viral gene carriers owning to their high cellular uptake nature and reliable cellular biocompatibility. Katsarava et al. [279] used AABBP and their blends for constructing various medical biocomposites. One of them, registered as "PhagoBioDerm" in Republic of Georgia, is produced as elastic films (Figure 43a) and represents innovative wound-dressing device (artificial skin) consisting of lytic bacteriophages, antibiotics, pain killer, and proteolytic enzymes. PhagoBioDerm showed an excellent therapeutic effect in the management of infected wounds and ulcers (of both trophic and diabetic origin) and in the complex treatment of infected local radiation injuries caused by the exposure to ${ }^{90} \mathrm{Sr}$. This team developed also bactericidal wound dressing that represents an alcohol solution of biodegradable co-AABBP containing antimicrobials. The preparation sprayed onto the wound forms a thin, elastic, and transparent film that accelerates healing of superficial wounds, ulcers, and burns (See [220] and references cited therein).

Elastomeric functional co-AABBP [252] of a high biocompatibility [253,254] revealed high elastic properties and excellent adhesion to stainless steel, and was used by MediVas, LLC (San Diego, CA, USA) for developing drug-eluting vascular stent coating (Figure 43b). Currently the polymer-coated stents are under clinical trials. In general, the co-AABBP and related polymers are considered as promising for innovative drug delivery technology (MediVas polymer technology was licensed to DSM Biomedical, http://www.dsm.com/en_US/html/dbm/homepage.htm) [280].

Trollsas et al. of Abbott Vascular [281] studied series of AABBP with various chemical structures, specifically synthesized to optimize the everolimus release rate and the mechanical integrity of drug eluting stent coatings. This team showed that AABBP can be designed to have outstanding coating and controlled release properties that can potentially be used for complex medical application such as a drug eluting stent coatings, etc. 
Some of AABBP show good mechanical characteristics and are promising as resorbable bone substitutes (Figure 43c). The polymers form also microspheres (Figure 43d) suitable as resorbable containers for drug delivery purposes, porous materials (Figure 43e) promising as scaffolds for cell cloning, and nanofibers (Figure 43f), including medicated ones, electrospun from non-toxic solvents like ethanol and apt as dressing for accelerated wound healing. The AABBP can also be made as viscos-flow mass (not shown) that could be impregnated with drugs and bioactive fillers and used, e.g., to seal bone cavities and regenerate/reconstruct bone tissues.

Figure 43. Some biomedical applications of AABBP as resorbable biomaterials: (a) an artificial skin PhagoBioDerm; (b) drug eluting vascular stent; (c) bone substitute; (d) microspheres for drug delivery; (e) porous scaffolds for cell cloning; (f) electrospun microfibers.
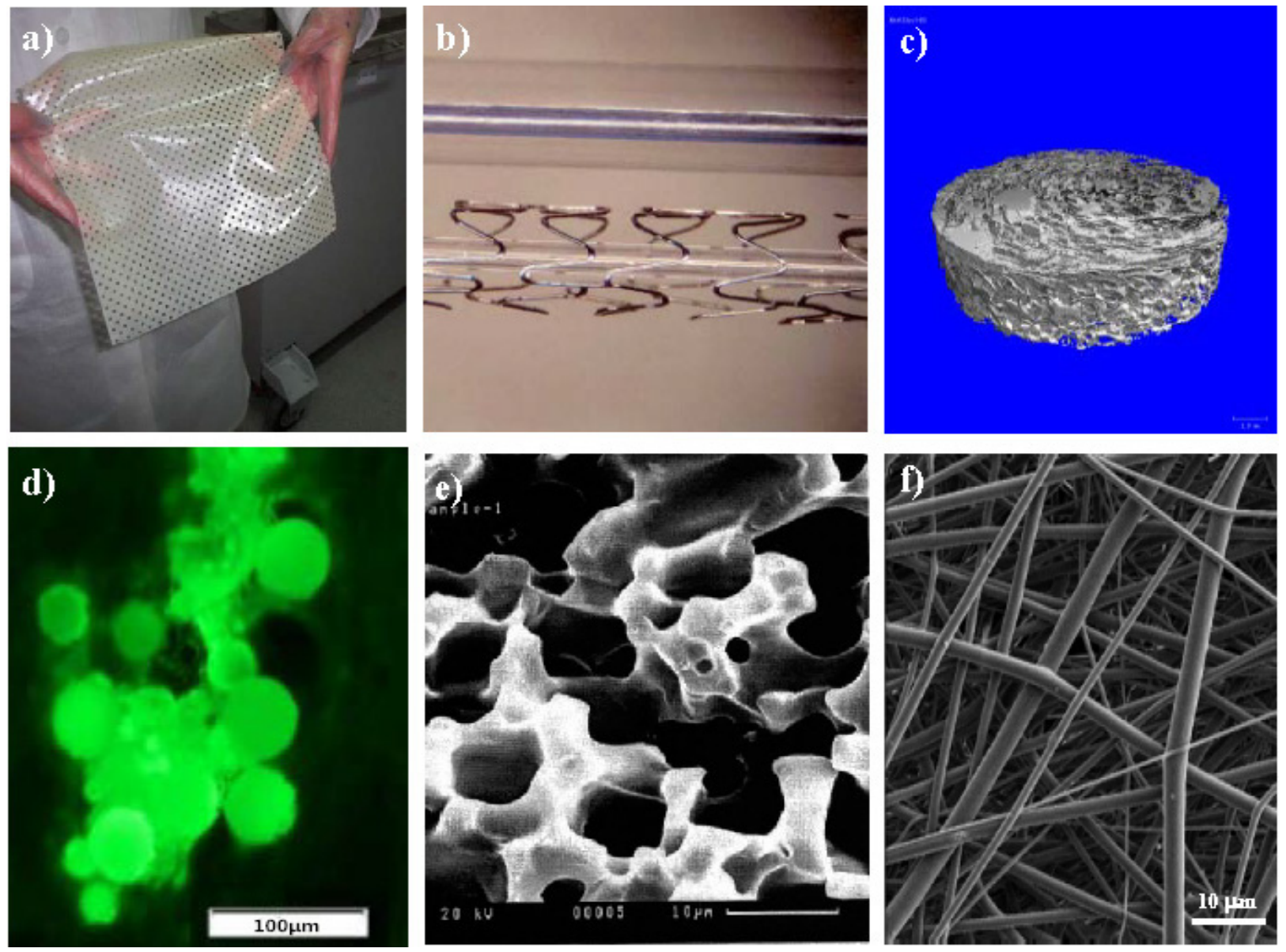

\section{Conclusions}

Poly(alkylene dicarboxylate)s constitute a family of biodegradable polymers with increasing interest since typical limitations associated to limited molecular weights have been overcomed by different improvements on synthesis procedures. Thus, polycondensation reactions have been performed by employing nonspecific enzymes, efficient catalysts such as triflates and chain extenders. Even cyclic ester oligomers have been used to get poly(alkylene dicarboxylate)s via ring opening polymerization. In general, these polymers have an additional interest since can be prepared from biobased monomers such as diols like BDO, fatty acids and other dicarboxylic acids like SA and carbohydrates. The disponibility of different monomers allows getting materials with a wide range of 
properties and applications. Thus, biodegradability can be tuned through the degree of crystallinity and even the melting point of samples, being fundamental the preparation of copolymers. Applications can involve rigid materials that are being developed through the incorporation of cyclic units and elastomeric materials that can mainly be pepared from multifunctional alcohols.

Incorporation of $\alpha$-amino acids into a polyalkylene dicarboxylate chain gives rise to a series of biodegradable poly(ester amide)s with promising expectations since amide groups are able to establish strong intermolecular hydrogen bonding interactions and improve the limited thermal and mechanical properties of polyesters. In addition, polymer properties can also be varied according to the characteristics of the side group of the selected amino acid. The high versatility and biocompatibility provided by natural $\alpha$-amino acids merit attention together with the fact that some polymers can be considered fully derived from renewable resources. Nowadays, a wide diversity of polymerization procedures have been successfully developed to get amino acid based biodegradable poly(ester amide)s (AABBP) with high yield and appropriate molecular weights (i.e., from solution active, interfacial, thermal and biocatalytic polycondensations).

Current developments on poly(alkylene dicarboxylate)s and AABBP cover a broad spectrum that mainly concerns to biodegradable and biocompatible elastomers, hyperbranched polymers, functional polymers for conjugating drugs or cell signaling molecules, hydrogels, nonviral delivery vectors, scaffolds with multiple functionalities, stent coatings, and bactericidal wound dressings. Despite these advances, efforts appear still necessary to validate the promising properties and even to improve peformance characteristics of new AABBP.

\section{Acknowledgments}

J.P. thanks MINECO (Grant MAT2012-36205) and AGAUR (Grant 2009SGR-1208) for supporting research on poly(alkylene dicarboxylate)s and poly(ester amide)s. R.K. thanks CRDF (Grants \#\# G2-116 and GR2-997) and ISTC (Grants \#\# G-446 and G-802) for supporting AABBP synthesis and study.

\section{Conflicts of Interest}

The authors declare no conflict of interest.

\section{References}

1. Lu, T.S.; Sun, Y.M.; Wang, C.S. Novel copolyesters containing naphthalene structure. II. Copolyesters prepared from 2,6-dimethyl naphthalate, 1,4-dimethyl terephthalate, and ethylene glycol. J. Polym. Sci. A 1995, 33, 2841-2850.

2. Byrom, D. Polymer synthesis by microorganisms: Technology and economics. Trends Biotechnol. 1987, 5, 246-250.

3. Raquez, J.M.; Nabar, Y.; Narayan, R.; Dubois, P. Novel high-performance talc/poly[(butylene adipate)-co-terephthalate)] hybrid materials. Macromol. Mater. Eng. 2008, 293, 310-320.

4. Ulery, B.D.; Nair, L.S.; Laurencin, C.T. Biomedical applications of biodegradable polymers. J. Polym. Sci. Part B 2011, 49, 832-864. 
5. Seyednejad, H.; Ghassemi, A.H.; van Nostrum, C.F.; Vermonden, T.; Hennink, W.E. Functional aliphatic polyesters for biomedical and pharmaceutical applications. J. Control. Release 2011, $152,168-176$.

6. Vert, M. Aliphatic polyesters: Great degradable polymers that cannot do everything. Biomacromolecules 2005, 6, 538-546.

7. Okada, M. Chemical syntheses of biodegradable polymers. Prog. Polym. Sci. 2002, 27, 87-133.

8. Sharma, V.; Kundu, P.P. Condensation polymers from natural oils. Prog. Polym. Sci. 2008, 33, 1199.

9. Di Lorenzo, M.L.; Raimo, M.; Cascone, E.; Martuscelli, E. Poly(3-hydroxybutyrate)-based copolymers and blends: Influence of a second component on crystallization and thermal behavior. J. Macromol. Sci. B 2001, 40, 639-667.

10. Andrade, A.P.; Witholt, B.; Chang, D.L.; Li, Z. Synthesis and characterization of novel thermoplastic polyester containing blocks of poly[(R)-3-hydroxyoctanoate $]$ and poly $[(R)-3$-hydroxybutyrate. Macromolecules 2003, 36, 9830-9835.

11. Han, Y.K.; Um, J.W.; Im, S.S.; Kim, B.C. Synthesis and characterization of high molecular weight branched PBA. J. Polym. Sci. A 2001, 39, 2143-2150.

12. Zhu, C.Y.; Zhang, Z.Q.; Liu, Q.P.; Wang, Z.P.; Jin, J. Synthesis and biodegradation of aliphatic polyesters from dicarboxylic acids and diols. J. Appl. Polym. Sci. 2003, 90, 982-990.

13. Saulnier, B.; Coudane, J.; Garreau, H.; Vert, M. Hydroxyl-bearing poly( $\alpha$-hydroxy acid)-type aliphatic degradable polyesters prepared by ring opening (co)polymerization of dilactones based on glycolic, gluconic and L-lactic acids. Polymer 2006, 47, 1921-1929.

14. Kricheldorf, H.R.; Rabenstein, M.; Maskos, M.; Schmidt, M.; Macrocycles. 15. The role of cyclization in kinetically controlled polycondensations. 1. Polyester syntheses. Macromolecules 2001, 34, 713-722.

15. Ahn, B.D.; Kim, S.H.; Kim, Y.H.; Yang, J.S. Synthesis and characterization of the biodegradable copolymers from succinic acid and adipic acid with 1,4-butanediol. J. Appl. Polym. Sci. 2001, 82, 2808-2826.

16. Kricheldorf, H.R.; Behnken, G.; Schwarz, G. Telechelic polyesters of ethane diol and adipic or sebacic acid by meansof bismuth carboxylates as non-toxic catalysts. Polymer 2005, 46, 11219-11224.

17. Kobayashi, S.; Uyama, H.; Kimura, S. Enzymatic polymerization. Chem. Rev. 2001, 101, 3793-3818.

18. Olson, D.A.; Sheares, V.V. Preparation of unsaturated linear aliphatic polyesters using condensation polymerization. Macromolecules 2006, 39, 2808-2814.

19. Liu, W.; Chen, B.; Wang, F.; Tan, T.; Deng, L. Lipase-catalyzed synthesis of aliphatic polyesters and properties characterization. Proc. Biochem. 2011, 46, 1993-2000.

20. Binns, F.; M Roberts, S.; Taylor, A.; Williams, C.F. Enzymatic polymerization of an unactivated diol diacid system. J. Chem. Soc. Perkin Trans. 1993, 1, 899-904.

21. Linko, Y.Y.; Wang, Z.L.; Seppala, J. Lipase-catalyzed synthesis of poly(1,4-butyl sebacate) from sebacic acid or its derivatives with BDO. J. Biotechnol. 1995, 40, 133-138.

22. Binns, F.; Harffey, P.; Roberts, S.M.; Taylor, A. Studies of lipase-catalyzed polyesterification of an unactivated diacid/diol system. J. Polym. Sci. A 1998, 36, 2069-2079. 
23. Uyama, H.; Inada, K.; Kobayashi, S. Lipase-catalyzed synthesis of aliphatic polyesters by polycondensation of dicarboxylic acids and glycols in solvent-free system. Polym. J. 2000, 32, $440-443$.

24. Kobayashi, S.; Uyama, H.; Namekawa, S. In vitro biosynthesis of polyesters with isolated enzymes in aqueous systems and organic solvents. Polym. Degrad. Stab. 1998, 59, 195-201.

25. Yang, J.; Zhang, S.; Liu, X.; Cao, A. A study on biodegradable aliphatic poly(tetramethylene succinate): The catalyst dependences of polyester syntheses and their thermal stabilities. Polym. Degrad. Stab. 2003, 81, 1-7.

26. Lim, J.S.; Hong, S.M.; Kim, D.K.; Im, S.S. Effect of isocyanate-modified fumed silica on the properties of poly(butylene succinate) nanocomposites. J. Appl. Polym. Sci. 2008, 107, 3598-3608.

27. Bikiaris, D.N.; Achilias, D.S. Synthesis of poly(alkylene succinate) biodegradable polyesters I. Mathematical modelling of the esterification reaction. Polymer 2006, 47, 4851-4860.

28. Takasu, A.; Iio, Y.; Oishi, Y.; Narukawa, Y.; Hirabayashi, T. Environmentally benign polyester synthesis by room temperature direct polycondensation of dicarboxylic acid and diol. Macromolecules 2005, 38, 1048-1050.

29. Ishii, M.; Okazaki, M.; Shibasaki, Y.; Ueda, M.; Teranishi, T. Convenient synthesis of aliphatic polyesters by distannoxane-catalyzed polycondensation. Biomacromolecules 2001, 2, 1267-1270.

30. Yashiro, T.; Kricheldorf, H.R.; Huijser, S. Syntheses of polyesters from succinic anhydride and various diols catalyzed by metal triflates. Macromol. Chem. Phys. 2009, 210, 1607-1616.

31. Buzin, P.; Lahcini, M.; Schwarz, G.; Kricheldorf, H.R. Aliphatic polyesters by bismuth triflate-catalyzed polycondensation of dicarboxylic acids and aliphatic diols. Macromolecules 2008, 41, 8491-8495.

32. Jacquel, N.; Freyermouth, F.; Fenouillot, F.; Rousseau, A.; P. Pascault, J.; Fuertes, P.; Saint-Loup, R. Synthesis and properties of poly(butylene succinate): Efficiency of different transesterification catalysts. J. Polym. Sci. A 2011, 49, 5301-5312.

33. Takasu, A.; Ishii, M.; Inai, Y.; Hirabayashi, T.; Inomata, K. Threo-disyndiotactic polymerization of $(e, e)$-alkyl sorbates assisted by bulky organoaluminum lewis acid via "alternating turning over polymerization (atop)" mechanism. Macromolecules 2003, 36, 7055-7064.

34. Takasu, A.; Oishi, Y.; Iio, Y.; Inai, Y.; Hirabayashi, T. Synthesis of aliphatic polyesters by direct polyesterification of dicarboxylic acids with diols under mild conditions catalyzed by reusable rare-earth triflate. Macromolecules 2003, 36, 1772-1774.

35. Garaleh, M.; Lahcini, M.; Kricheldorf, H.R.; Weidner, S.M. Syntheses of aliphatic polyesters catalyzed by lanthanide triflates. J. Polym. Sci. A 2009, 47, 170-177.

36. Sokolsky-Papkova, M.; Langerb, R.; Domb, A.J. Synthesis of aliphatic polyesters by polycondensation using inorganic acid as catalyst. Polym. Adv. Technol. 2011, 22, 502-511.

37. Zhi-Wei, G.; Charles, J.S. Enzymatic synthesis of macrocyclic lactones. J. Am. Chem. Soc. 1998, 110, 1999-2001.

38. Sugihara, S.; Toshima, K.; Matsumura, S. New strategy for enzymatic synthesis of high-molecular-weight poly(butylenesuccinate) via cyclic oligomers. Macromol. Rapid Commun. 2006, 27, 203-207. 
39. Habeych, D.I.; Eggink, G.; Boeriu, C.G. Linear and cyclic ester Oligomers of succinic acid and 1,4-butanediol: Biocatalytic synthesis and characterization. Biocatal. Biotransform. 2011, 29, 299-310.

40. Hofvendahl, K.; Hahn-Hagerda, B. Factors affecting the fermentative lactic acid production from renewable resources. Enzym. Microb. Technol. 2000, 26, 87-107.

41. Zeikus, J.G.; Jain, M.K.; Elankovan, P. Biotechnology of succinic acid production and markets for derived industrial products. Appl. Microbiol. Biotechnol. 1999, 51, 545-552.

42. Polen, T.; Spelberg, M.; Bott, M. Toward biotechnological production of adipic acid and precursors from biorenewables. J. Biotechnol. 2013, 167, 75-84.

43. Chandel, A.K.; Singh, O.V. Weedy lignocellulosic feedstock and microbial metabolic engineering: Advancing the generation of "Biofuel". Appl. Microbiol. Biotechnol. 2011, 89, 1289-1303.

44. Yang, Y.; Lu, W.; Zhang, X.; Xie, W.; Cai, M.; Gross, R.A. Two-step biocatalytic route to biobased functional polyesters from $\omega$-carboxy fatty acids and diols. Biomacromolecules 2010, 11, 259-268.

45. Kaur, G.; Srivastava, A.K.; Chand, S. Advances in biotechnological production of 1,3-propanediol. Biochem. Eng. J. 2012, 64, 106-118.

46. Umare, S.S.; Chandure, A.S.; Pandey, R.A. Synthesis, characterization and biodegradable studies of 1,3-propanediol based polyesters. Polym. Degrad. Stab. 2007, 92, 464-479.

47. Quinzler, D.; Mecking, S. Linear semicrystalline polyesters from fatty acids by complete feedstock molecule utilization. Angew. Chem. Int. Ed. 2010, 49, 4306-4308.

48. Stempfle, F.; Quinzler, D.; Heckler, I.; Mecking, S. Long-chain linear $\mathrm{C}_{19}$ and $\mathrm{C}_{23}$ monomers and polycondensates from unsaturated fatty acid esters. Macromolecules 2011, 44, 4159-4166.

49. Genas, M. Rilsan (Polyamid 11), synthese und eigenschaften. Angew. Chem. Int. Ed. 1962, 74, 535-540.

50. Trzaskowski, J.; Quinzler, D.; Bahrle, C.; Mecking, S. Aliphatic long-chain $\mathrm{C}_{20}$ polyesters from olefin metathesis. Macromol. Rapid Commun. 2011, 32, 1352-1356.

51. Huf, S.; Krügener, S.; Hirth, T.; Rupp, S.; Zibek, S. Biotechnological synthesis of long-chain dicarboxylic acids as building blocks for polymers. Eur. J. Lipid Sci. Technol. 2011, 113, 548-561.

52. Celli, A.; Marchese, P.; Sisti, L.; Dumand, D.; Sullalti, S.; Totaro, G. Effect of 1,4-cyclohexylene units on thermal properties of poly(1,4-cyclohexylenedimethylene adipate) and similar aliphatic polyesters. Polym. Int. 2013, 62, 1210-1217.

53. Berti, C.; Binassi, E.; Colonna, M.; Fiorini, M.; Kannan, G.; Karanam, S. Preparation of Bio-Based 1,4-Cyclohexane Dimethanol Used to Produce Terephthalate Polyesters. U.S. Patent 20100168373, 1 July 2010.

54. Fenouillot, F.; Rousseau, A.; Colomines, G.; Saint-Loup, R.; Pascault, J.P. Polymers from renewable 1,4:3,6-dianhydrohexitols (isosorbide, isomannide and isoidide): A review. Prog. Polym. Sci. 2010, 35, 578-622.

55. Kricheldorf, H.R.; Wulff, D.F. Layer structures 11. Cholesteric polyesters derived from isosorbide, 2,5-bis(dodecyloxy)terephthalic acid and 4,49-dihydroxybiphenyl. Polymer 1998, 39, $6145-6151$. 
56. Okada, M.; Tachikawa, K.; Aoi, K. Biodegradable polymers based on renewable resources. III. Copolyesters composed of 1,4:3,6-dianhydro-D-glucitol,1,1-bis(5-carboxy-2-furyl)ethane and aliphatic dicarboxylic acid units. J. Appl. Polym. Sci. 1999, 74, 3342-3350.

57. Okada, M.; Tsunoda, K.; Tachikawa, K.; Aoi, K. Biodegradable polymers based on renewable resources. IV. Enzymatic degradation of polyesters composed of 1,4:3.6-dianhydro-D-glucitol and aliphatic dicarboxylic acid moieties. J. Appl. Polym. Sci. 2000, 77, 338-346.

58. Kricheldorf, H.R.; Chatti, S.; Schwarz, G.; Kruger, R.P. Macrocycles 27: Cyclic aliphatic polyesters of isosorbide. J. Polym. Sci. A 2003, 41, 3414-3424.

59. Ivan, S.; Vukic, R.N.; Cakic, S.; Simendic, O.; Ristic, V.; Budinski-Simendic, J. Synthesis and characterisation of polyester based on isosorbide and butanedioic acid. J. Polym. Environ. 2012, 20, 519-527.

60. Park, H.S.; Gong, M.S.; Knowles, J.C. Synthesis and biocompatibility properties of polyester containing various diacid based on isosorbide. J. Biomater. Appl. 2012, 27, 99-109.

61. Percec, V.; Chu, P.; Kawasumi, M. Toward "Willowlike" thermotropic dendrimers. Macromolecules 1994, 27, 4441-4453.

62. Voit, B.I.; Lederer, A. Hyperbranched and highly branched polymer architecturess synthetic strategies and major characterization aspects. Chem. Rev. 2009, 109, 5924-5973.

63. Wurm, F.; Frey, H. Linear-dendritic block copolymers: The state of the art and exciting perspectives. Prog. Polym. Sci. 2011, 36, 1-52.

64. Samperi, F.; Battiato, S.; Puglisi, C.; Scamporrino, A.; Ambrogi, V.; Ascione, L.; Carfagna, C. Combined techniques for the characterization of linear-hyperbranched hybrid poly(butylene adipate) copolymers. J. Polym. Sci. Part A 2011, 49, 3615-3630.

65. Fujimaki, T. Processability and properties of aliphatic polyesters, "BIONOLLE", synthesized by polycondensation reaction. Polym. Degrad. Stab. 1998, 59, 209-214.

66. Ichikawa, Y.; Mizukoshi, T. Bionolle (polybutylenesuccinate). Adv. Polym. Sci. 2012, 245, 285-314.

67. Zhao, J.B.; Wu, X.F.; Yang, W.T. Synthesis of aliphatic polyesters by a chain-extending reaction with octamethylcyclotetrasilazane and hexaphenylcyclotrisilazane as chain extenders. J. Appl. Polym. Sci. 2004, 92, 3333-3337.

68. Huang, C.Q.; Luo, S.Y.; Xu, S.Y.; Zhao, J.B.; Liang, S.L.; Yang, W.T. Catalyzed chain extension of poly(butylene adipate)and poly(butylene succinate) with 2,2'-(1,4-phenylene)-bis(2-oxazoline). J. Appl. Polym. Sci. 2010, 115, 1555-1565.

69. Mckee, M.G.; Unal, S.; Wilkes, G.L.; Long, T.E. Branched polyesters: Recent advances in synthesis and performance. Prog. Polym. Sci. 2005, 30, 507-539.

70. Chae, H.G.; Kim, B.C.; Im, S.S.; Han, Y.K. Effect of molecular weight and branch structure on the crystallization and rheological properties of poly(butylene adipate). Polym. Eng. Sci. 2001, 41, 1133-1139.

71. Kim, E.K.; Bae, J.S.; Im, S.S.; Kim, B.C.; Han, Y.K. Preparation and properties of branched polybutylenesuccinate. J. Appl. Polym. Sci. 2001, 80, 1388-1394.

72. Wang, G.; Guo, B.; Li, R. Synthesis, characterization, and properties of long-chain branched poly(butylene succinate). J. Appl. Polym. Sci. 2012, 124, 1271-1280. 
73. Jin, H.J.; Park, J.K.; Park, K.H.; Kim, M.N.; Yoon, J.S. Properties of aliphatic polyesters with n-paraffinic side branches. J. Appl. Polym. Sci. 2000, 77, 547-555.

74. Kim, M.N.; Kim, K.H.; Jin, H.J.; Park, J.K.; Yoon, J.S. Biodegradability of ethyl and n-octyl branched poly(ethylene adipate) and poly(butylene succinate). Eur. Polym. J. 2001, 37, $1843-1847$.

75. Li, F.X.; Xu, X.J.; Li, Q.B.; Li, Y.; Zhang, H.Y.; Yu, J.Y. Thermal degradation and their kinetics of biodegradable poly(butylene succinate-co-butylene terephthalate)s under nitrogen and air atmospheres. Polym. Degrad. Stab. 2006, 91, 1685-1693.

76. Li, F.; Xu, X.J.; Hao, Q.G.; Li, Q.B.; Yu, J.Y.; Cao, A.M. Effects of comonomer sequential structure on thermal and crystallization behaviors of biodegradable poly(butylene succinate-co-butylene terephthalate)s. J. Polym. Sci. B 2006, 44, 1635-1644.

77. Ueda, A.S.; Chatani, Y.; Tadokoro, H. Structural studies of polyesters. IV. Molecular and crystal structures of poly(ethylene succinate) and poly(ethylene oxalate). Polym. J. 1971, 2, 387-397.

78. Turner-Jones, A.; Bunn, C.W. The crystal structures of polyethylene adipate and polyethylene suberate. Acta Crystallogr. 1962, 15, 105-113.

79. Chatani, Y.; Hasegawa, R.; Tadokoro, H. Structure of polyesters. Polym. Prepr. Jpn. 1971, 20, 420.

80. Minke, R.; Blacwell, J. Polymorphic structures of poly(tetramethylene adipate). J. Macromol. Sci. Phys. 1979, B16, 407-417.

81. Minke, R.; Blacwell, J. Single crystals of poly(tetramethylene adipate). J. Macromol. Sci. Phys. 1980, B18, 233-255.

82. Aylwin, P.A.; Boyd, R.H. Aliphatic polyesters as models for relaxation processes in crystalline polymers: 1. Characterization. Polymer 1984, 25, 323-329.

83. Alemán, C.; Puiggalí, J. Effect of the folding of methylene units in the conformational preferences of small diesters. J. Org. Chem. 1997, 62, 3076-3080.

84. Kanamoto, T.; Tanaka, K. Growth and morphology of single crystals of linear aliphatic polyesters. J. Polym. Sci. A 1971, 9, 2043-2060.

85. Brandrup, J.; Immergut, E.H. Polymer Handbook; Wiley-Interscience: New York, NY, USA, 1989.

86. Liau, W.B.; Boyd, R.H. Structure and packing in crystalline aliphatic polyesters. Macromolecules 1990, 23, 1531-1539.

87. Ichikawa, Y.; Kondo, H.; Igarashi, Y.; Noguchi, K.; Okuyama, K.; Washiyama, J. Crystal structures of $\mathrm{a}$ and $\mathrm{b}$ forms of poly(tetramethylene succinate). Polymer 2000, 41, 4719-4727.

88. Armelin, E.; Casas, M.T.; Puiggalí, J. Structure of poly(hexamethylene sebacate). Polymer 2001, 42, 5695-5699.

89. Armelin, E.; Almontassir, A.; Franco, L.; Puiggalí, J. Crystalline structure of poly(dodecamethylene sebacate). Repercussions on lamellar folding surfaces. Macromolecules 2002, 35, 3630-3635.

90. Pan, P.; Inoue, Y. Polymorphism and isomorphism in biodegradable polyesters. Prog. Polym. Sci. 2009, 34, 605-640.

91. Almontassir, A.; Gestí, S.; Franco, L.; Puiggalí, J. Molecular packing of polyesters derived from 1,4-butanediol and even aliphatic dicarboxylic acids. Macromolecules 2004, 37, 5300-5309. 
92. Gestí, S.; Almontassir, A.; Casas, M.T.; Puiggalí, J. Molecular packing and crystalline morphologies of biodegradable poly(alkylene dicarboxylate)s derived from 1,6-hexanediol. Polymer 2004, 45, 8845-8861

93. Gestí, S.; Almontassir, A.; Casas, M.T.; Puiggalí, J. Crystalline structure of poly(hexamethylene adipate). Study on the morphology and the enzymatic degradation of single crystals. Biomacromolecules 2006, 7, 799-808.

94. Gestí, S.; Casas, M.T.; Puiggalí, J. Crystalline structure of poly(hexamethylene succinate) and single crystal degradation studies. Polymer 2007, 48, 5088-5097.

95. Gan, Z.; Abe, H.; Doi, Y. Biodegradable poly(ethylene succinate) (PES). 1. Crystal growth kinetics and morphology. Biomacromolecules 2000, 1, 704-712.

96. Gan, Z.; Abe, H.; Doi, Y. Biodegradable poly(ethylene succinate) (PES). 2. Crystal morphology of melt-crystallized ultrathin film and its change after enzymatic degradation. Biomacromolecules 2000, 1, 713-720.

97. Gan, Z.; Abe, H.; Doi, Y. Crystallization, melting, and enzymatic degradation of biodegradable poly(butylene succinate-co-14 mol \% ethylene succinate) copolyester. Biomacromolecules 2001, 2, 313-321.

98. Iwata, T.; Doi, Y. Crystal structure and biodegradation of aliphatic polyester crystals. Macromol. Chem. Phys. 1999, 200, 2429-2442.

99. Mochizuki, M.; Mukai, K.; Yamada, K.; Ichise, N.; Murase, S.; Iwaya, Y. Structural effects upon enzymatic hydrolysis of poly(butylene succinate-co-ethylene succinate)s. Macromolecules 1997, 30, 7403-7407.

100. Li, X.; Hong, Z.; Sun, J.; Geng, Y.; Huang, Y.; An, H. Identifying the phase behavior of biodegradable poly(hexamethylene succinate-co-hexamethylene adipate) copolymers with FTIR. J. Phys. Chem. 2009, 113, 2695-2704.

101. Li, X.; Sun, J.; Huang, Y.; Geng, Y.; Wang, X.; Ma, Z.; Shao, C.G.; An, H.N.; Yan, T.Z.; Li, L.B. Inducing new crystal structures through random copolymerization of biodegradable aliphatic polyester. Macromolecules 2008, 41, 3162-3168.

102. Liang, Z.; Pan, P.; Zhu, B.; Dong, T.; Hua, L.; Inoue, Y. Crystalline phase of isomorphic poly(hexamethylene sebacate-co-hexamethylene adipate) copolyester: Effects of comonomer composition and crystallization temperature. Macromolecules 2010, 43, 2925-2932.

103. Liang, Z.; Pan, P.; Zhu, B.; Inoue, Y. Isomorphic crystallization of aliphatic copolyesters derived from 1,6-hexanediol: Effect of the chemical structure of comonomer units on the extent of cocrystallization. Polymer 2011, 52, 2667-2676.

104. Díaz, A.; Franco, L.; Puiggalí, J. Study on the crystallization of poly(butylene azelate-co-butylene succinate) copolymers. Thermochim. Acta 2014, 575, 45-54.

105. Díaz, A.; Franco, L.; Estrany, F.; del Valle, L.J.; Puiggalí, J. Poly(butylene azelate-co-butylene succinate) copolymers: Crystalline morphologies and degradation. Polym. Degrad. Stab. 2014, 99, 80-91.

106. Witt, U.; Müller, R.J.; Deckwer, W.D. Studies on sequence distribution on aliphatic/aromatic copolyesters by high-resolution ${ }^{13} \mathrm{C}$ nuclear magnetic resonance spectroscopy for evaluation of biodegradability. Macromol. Chem. Phys. 1996, 197, 1525-1535. 
107. Kleeberg, I.; Hetz, C.; Kroppenstedt, R.M.; Müller, R.J.; Deckwer, W.D. Biodegradation of aliphatic/aromatic copolyesters by thermophilic actinomycetes. Appl. Environ. Microbiol. 1998, 64, 1731-1735.

108. Witt, U.; Einig, T.; Yamamoto, M.; Kleeberg, I.; Deckwer, W.-D.; Müller, R.J. Biodegradation of aliphatic-aromatic copolyesters: Evaluation of the final biodegradability and ecotoxicological impact of degradation intermediates. Chemosphere 2001, 44, 289-299.

109. Kleeberg, I.; Welzel, K.; van den Heuvel, J.; Müller, R.J.; Deckwer, W.D. Characterization of a new extracellular hydrolase from thermobifida fusca degrading aliphatic-aromatic copolyesters. Biomacromolecules 2005, 6, 262-270.

110. Herrera, R.; Franco, L.; Rodríguez-Galán, A.; Puiggalí, J. characterization and degradation behavior of poly(butylene adipate-co-terephthalate)s. J. Polym. Sci. A 2002, 40, 4141-4157.

111. Marten, E.; Müller, R.J.; Deckwer, W.D. Studies on the enzymatic hydrolysis of polyesters. II. aliphatic-aromatic copolyesters. Polym. Degrad. Stab. 2005, 88, 371-381.

112. Jaisankar, V.; Nanthini, R.; Ravi, A.; Karunanidhi, M. A study on biodegradation of aliphatic-aromatic random copolyesters. J. Polym. Mater. 2009, 26, 157-166.

113. Kijchavengkul, T.; Auras, R.; Rubino, M.; Selke, S.; Ngouajio, M.; Fernandez, R.T. Biodegradation and hydrolysis rate of aliphatic aromatic polyester. Polym. Degrad. Stab. 2010, 95, 2641-2647.

114. Javadi, A.; Kramschuster, A.J.; Pilla, S.; Lee, J.; Gong, S.; Turng, L.-S. Processing and characterization of microcellular PHBV/PBAT blends. Polym. Eng. Sci. 2010, 50, 1440-1448.

115. Zarrinbakhsh, N.; Mohanty, A.K.; Misra, M. Improving the interfacial adhesion in a new renewable resourcebased biocomposites from biofuel coproduct and biodegradable plastic. J. Mater. Sci. 2013, 48, 6025-6038.

116. Nobrega, M.M.; Olivato, J.B.; Müller, C.M.O.; Yamashita, F. addition of saturated fatty acids to biodegradable films: Effect on the crystallinity and viscoelastic characteristics. J. Polym. Environ. 2013, 21, 166-171.

117. Madera-Santana, T.J.; Misra, M.; Drzal L.T.; Robledo, D.; Freile-Pelegrin, Y. Preparation and characterization of biodegradable agar/poly(butylene adipate-co-terephatalate) composites. Polym. Eng. Sci. 2009, 49, 1117-1126.

118. Someya, Y.; Sugahara, Y.; Shibata, M. Nanocomposites based on poly(butylene adipate-coterephthalate) and montmorillonite. J. Appl. Polym. Sci. 2005, 95, 386-392.

119. Chivrac, F.; Kadlecová, Z.; Pollet, E.; Avérous, L. Aromatic copolyester-based nano-biocomposites: Elaboration, structural characterization and properties. J. Polym. Environ. 2006, 14, 393-401.

120. Celli, A.; Barbiroli, G.; Berti, C.; di Credico, F.; Lorenzetti, C.; Marchese, P.; Marianucci, E. Thermal properties of poly(alkylene dicarboxylate)s derived from 1,12-dodecanedioic acid and even aliphatic diols. J. Polym. Sci. B 2007, 45, 1053-1067.

121. Berti, C.; Celli, A.; Marchese, P.; Marianucci, E.; Barbiroli, G.; di Credico, F. The effect of aliphatic chain length on thermal properties of poly(alkylene dicarboxylate)s. Polymers 2013, 7, 658-675.

122. Berti, C.; Celli, A.; Marchese, P.; Barbiroli, G.; di Credico, F.; Verney, V.; Commereuc, S. Novel copolyesters based on poly(alkylene dicarboxylate)s: 1. Thermalbehavior and biodegradation of aliphatic-aromatic random copolymers. Eur. Polym. J. 2008, 44, 3650-3661. 
123. Zheng, L.; Li, C.; Zhang, D.; Guan, G.; Xiao, Y.; Wang, D. Novel biodegradable multiblock copolymers comprising poly(butylene succinate) and poly(1,2-propylene terephthalate) with hexamethylene diisocyanate as a chain extender. Polym. Int. 2011, 60, 666-675.

124. Kint, D.P.R.; Wigström, E.; de Ilarduya, A.; Alla, A.; Muñoz-Guerra, S. Poly(ethylene terephthalate) copolyesters derived from (2S,3S)-2,3-dimethoxy-1,4-butanediol. J. Polym. Sci. 2001, 39, $3250-3262$.

125. Zamora, F.; Hakkou, K.; Alla, A.; Rivas, M.; Roffé, I.; Mancera, M.; Muñoz-Guerra, S. Aromatic polyesters fromnaturally occurring monosaccharides: Poly(ethylene terephthalate) and poly(ethylene isophthalate) analogs derived from D-mannitol and galactitol. J. Polym. Sci. 2005, 43, 4570-4574.

126. Zamora, F.; Hakkou, K.; Alla, A.; Espartero, J.L.; Muñoz-Guerra, S.; Galbis, J.A. Aromatic homo- and co-polyesters from naturally occurring monosaccharides: PET and PEI analogs derived from L-arabinitol and xylitol. J. Polym. Sci. 2005, 43, 6394-6410.

127. Zamora, F.; Hakkou, K.; Alla, A.; Marín-Bernabé, A.; de Paz, M.V.; Mtz de Ilarduya, A.; Muñoz-Guerra, S. Polyesters analogous to PET and PBT based on $O$-benzyl ethers of xylitol and L-arabinitol. J. Polym. Sci. 2008, 46, 5167-5179.

128. Zamora, F.; Hakkou, K.; Alla, A.; Rivas, M.; Mtz de Ilarduya, A.; Muñoz-Guerra, S.; Galbis, J.A. Butylene copolyesters based on aldaric and terephthalic acids. Synthesis and characterization. J. Polym. Sci. 2009, 47, 1168-1177.

129. Jansen, M.A.G.; Wu, L.H.; Goossens, J.G.P.; de Wit, G.; Bailly, C.; Koning, C.E.; Portale, G. The incorporation of rigid diol monomers into poly(butylene terephthalate) via solid-state copolymerization and melt copolymerization. J. Polym. Sci. A 2008, 46, 1203-1217.

130. Sablong, R.; Duchateau, R.; Koning, C.E.; de Wit, G.; van Es, D.; Koelewijn, R.; van Haveren, J. Incorporation of isosorbide into poly(butylene terephthalate) via solid-state polymerization. Biomacromolecules 2008, 9, 3090-3097.

131. Lavilla, C.; Gubbels, E.; Martínez de Ilarduya, A.; Noordover, B.A.J.; Koning, C.E.; Muñoz-Guerra, S. Solid-state modification of pbt with cyclic acetalized galactitol and D-mannitol: Influence of composition and chemical microstructure on thermal properties. Macromolecules 2013, 46, 4335-4345.

132. Gubbels, E.; Lavilla, C; Martínez de Ilarduya, A.; Noordover, B.A.J.; Koning, C.E.; Muñoz-Guerra, S. Partially renewable copolyesters prepared from acetalized D-glucitol by solid-state modification of poly(butylene terephthalate). J. Polym. Sci. A 2014, 52, 164-177.

133. Noordover, B.A.J.; van Staalduinen, V.G.; Duchateau, R.; Koning, C.E.; van Benthem, R.A.T.M.; Mak, M.; Heise, A.; Frissen, A.E.; van Haveren, J. Co- and terpolyesters based on isosorbide and succinic acid for coating applications: Synthesis and characterization. Biomacromolecules 2006, 7, 3406-3416.

134. Wu, J.; Eduard, P.; Thiyagarajan, S.; van Haveren, J.; van Es, D.S.; Koning, C.E.; Lutz, M.; Fonseca Guerra, C. Isohexide derivatives from renewable resources as chiral building blocks. ChemSusChem 2011, 4, 599-603.

135. Wu, J.; Eduard, P.; Thiyagarajan, S.; Jasinska-Walc, L.; Rozanski, A.; Fonseca Guerra, C.; Noordover, B.A.J.; van Haveren, J.; van Es, D.S.; Koning, C.E. Semicrystalline polyesters based on a novel renewable building block. Macromolecules 2012, 45, 5069-5080. 
136. Lavilla, C.; Alla, A.; Martínez de Ilarduya, A.; Muñoz-Guerra, S. High Tg. bio-based aliphatic polyesters from bicyclic D-mannitol. Biomacromolecules 2013, 14, 781-793.

137. Shih, Y.F.; Chieh, Y.C. Thermal degradation behavior and kinetic analysis of biodegradable polymers using various comparative models, 1. Macromol. Theory Simul. 2007, 16, 101-110.

138. Rizzarelli, P.; Carroccio, S. Thermo-oxidative processes in biodegradable poly(butylene succinate). Polym. Degrad. Stab. 2009, 94, 1825-1838.

139. Chrissafis, K.; Paraskevopoulos, K.M.; Bikiaris, D.N. Thermal degradation mechanism of poly(ethylene succinate) and poly(butylene succinate): Comparative study. Thermochim. Acta 2005, 435, 142-150.

140. Chrissafis, K.; Paraskevopoulos, K.M.; Bikiaris, D.N. Effect of molecular weight on thermal degradation mechanism of the biodegradable polyester poly(ethylene succinate). Thermochim. Acta 2006, 440, 166-175.

141. Chrissafis, K.; Paraskevopoulos, K.M.; Bikiaris, D.N. Thermal degradation kinetics of the biodegradable aliphatic polyester, poly(propylene succinate). Polym. Degrad. Stab. 2006, 91, 60-68.

142. Soccio, M.; Lotti, N.; Finelli, L.; Gazzano, M.; Munari, A. Aliphatic poly(propylene dicarboxylate)s: Effect of chain length on thermal properties and crystallization kinetics. Polymer 2007, 48, 3125-3136.

143. Chrissafis, K.; Paraskevopoulos, K.M.; Bikiaris, D.N. Thermal degradation kinetics and decomposition mechanism of new aliphatic biodegradable polyesters poly(propylene glutarate) and poly(propylene suberate). Thermochim. Acta 2010, 505, 59-68.

144. Chrissafis, K.; Paraskevopoulos, K.M.; Papageorgiou, G.Z.; Bikiaris. D.N. Thermal decomposition of poly(propylene sebacate) and poly(propylene azelate) biodegradable polyesters: Evaluation of mechanisms using TGA, FTIR and GC/MS. J. Anal. Appl. Pyrol. 2011, 92, 123-130.

145. Bikiaris, D.N.; Papageorgiou, G.Z.; Giliopoulos, D.J.; Stergiou, C.A. Correlation between chemical and solid-state structures and enzymatic hydrolysis in novel biodegradable polyesters. The Case of Poly(propylene alkanedicarboxylate)s. Macromol. Biosci. 2008, 8, 728-740.

146. Tokiwa, Y.; Suzuki, T. Hydrolysis of copolyesters containing aromatic and aliphatic ester blocks by lipase. J. Appl. Polym. Sci. 1981, 26, 441-448.

147. Nagata, M.; Kiyotsukuri, T.; Ibuki, H.; Tsutsumi, N.; Sakai, W. Synthesis and enzymatic degradation of regular network aliphatic polyesters. React. Funct. Polym. 1996, 30, 165-171.

148. Nagata, M.; Ibuki, H.; Sakai, W.; Tsutsumi, N. Synthesis, characterization, and enzymatic degradation of novel regular network aliphatic polyesters based on pentaerythritol. Macromolecules 1997, 30, 6525-6530.

149. Nagata, M.; Machida, T.; Sakai, W.; Tsutsumi, N. Synthesis, characterization, and enzymatic degradation studies on novel network aliphatic polyesters. Macromolecules 1998, 31, 6450-6454.

150. Murase, T.; Iwata, T.; Doi, Y. Direct observation of enzymatic degradation behavior of poly[(R)-3-hydroxybutyrate] lamellar single crystals by atomic force microscopy. Macromolecules 2001, 34, 5848-5853.

151. Kikkawa, Y.; Hirota, T.; Numata, K.; Tsuge, T.; Abe, H.; Iwata, T.; Doi, Y. In-situ atomic force microscopy observation of enzymatic degradation in poly(hydroxyalkanoic acid) thin films: Normal and constrained conditions. Macromol. Biosci. 2004, 4, 276-285. 
152. Iwata, T.; Doi, Y. Morphology and enzymatic degradation of poly(e-caprolactone) single crystals: does a polymer single crystal consist of micro-crystals? Polym. Int. 2002, 51, 852-858.

153. Iwata, T.; Doi, Y. Morphology and enzymatic degradation of poly(L-lactic acid) single crystals. Macromolecules 1998, 31, 2461-2467.

154. Iwata, T.; Doi, Y. morphology and enzymatic degradation of solution-grown single crystals of poly(ethylene succinate). Macromolecules 2001, 34, 7343-7348.

155. Iwata, T.; Kobatashi, S.; Tabata, K.; Yonezawa, N.; Doi, D. Crystal structure, thermal behavior and enzymatic degradation of poly(tetramethylene adipate) solution-grown chain-folded Lamellar crystals. Macromol. Biosci. 2004, 4, 296-307.

156. Casas, M.T.; Puiggalí, J. Enzymatic degradation of poly(octamethylene suberate) lamellar crystals. Polym. Degrad. Stab. 2009, 94, 1941-1947.

157. Ding, M.; Zhang, M.; Yang, J.; Qiu, J.H. Study on the enzymatic degradation of aliphatic polyester-pbs and its copolymers. J. Appl. Polym. Sci. 2012, 124, 2902-2907.

158. Chen, C.H.; Lu, H.Y.; Chen, M.; Peng, J.S.; Tsai, C.J.; Yang, C.S. Synthesis and characterization of poly(ethylene succinate) and its copolyesters containing minor amounts of butylene succinate. J. Appl. Polym. Sci. 2009, 111, 1433-1439.

159. Cao, A.M.; Okamura, T.; Nakayamab, K.; Inoued, Y.; Masuda, T. Studies on synthesis and physical properties of biodegradable aliphatic poly(butylene succinate-co-ethylene succinate)s and poly(butylene succinate-co-diethylene glycol succinate)s. Polym. Degrad. Stab. 2002, 78, $107-177$.

160. Xu, Y.X.; Xu, J.; Guo, B.H.; Xie, X.M. Crystallization kinetics and morphology of biodegradable poly(butylene succinate-co-propylene succinate)s. J. Polym. Sci. B 2007, 45, 420-428.

161. Papageorgiou, G.Z.; Bikiaris, D.N. Synthesis, Cocrystallization, and enzymatic degradation of novel poly(butylene-co-propylene succinate) copolymers. Biomacromolecules 2007, 8, 2437-2449.

162. Lu, S.F.; Chen, M.; Shih, Y.C.; Chen, C.H. Nonisothermal crystallization kinetics of biodegradable poly(butylene succinate-co-propylene succinate)s. J. Polym. Sci. B 2010, 48, 1299-1308.

163. Nikolic, M.S.; Djonlagic, J. Synthesis and characterization of biodegradable poly(butylene succinate-co-butylene adipate)s. Polym. Degrad. Stab. 2001, 74, 263-270.

164. Tserki, V.; Matzinos, P.; Pavlidou, E.; Vachliotis, D.; Panayiotou, C. Biodegradable aliphatic polyesters. Part I. Properties and biodegradation of poly(butylene succinate-co-butylene adipate). Polym. Degrad. Stab. 2006, 91, 367-376.

165. Zhu, Q.-Y.; He, Y.-S.; Zeng, J.-B.; Huang, Q.; Wang, Y.-Z. Synthesis and characterization of a novel multiblock copolyester containing poly(ethylene succinate) and poly(butylene succinate). Mater. Chem. Phys. 2011, 130, 943-949.

166. Ray, S.S.; Yamada, K.; Okamoto, M.; Ueda, K. Control of biodegradability of polylactide via nanocomposite technology. Macromol. Mater. Eng. 2003, 288, 203-208.

167. Singh, N.K.; Purkayastha, B.D.; Roy, J.K.; Banik, R.M.; Yashpal, M.; Singh, G. Nanoparticle-induced controlled biodegradation and its mechanism in poly( $\varepsilon$-caprolactone). ACS Appl. Mater. Interfaces 2010, 2, 69-81.

168. Han, S.I.; Lim, J.S.; Kim, D.K.; Kim, M.N.; Im, S.S. In situ polymerized poly(butylene succinate)/silica nanocomposites: Physical properties and biodegradation. Polym. Degrad. Stab. 2008, 93, 889-895. 
169. Chouzouri, G.; Xanthos, M. In vitro bioactivity and degradation of polycaprolactone composites containing silicate fillers. Acta Biomater. 2007, 3, 745-756.

170. Lee, S.R.; Park, H.M.; Lim, H.; Kang, T.; Li, X.; Cho, W.J.; Ha, C.-S. Microstructure, tensile properties, and biodegradability of aliphatic polyester/clay nanocomposites. Polymer 2002, 43, 2495-2500.

171. Maiti, P.; Batt, C.A.; Giannelis, E.P. New biodegradable polyhydroxybutyrate/layered silicate nanocomposites. Biomacromolecules 2007, 8, 3393-3400.

172. Bikiaris, D.N.; Nianias, N.P.; Karagiannidou, E.G.; Docoslis, A. Effect of different nanoparticles on the properties and enzymatic hydrolysis mechanism of aliphatic polyesters. Polym. Degrad. Stab. 2012, 97, 2077-2089.

173. Chrissafis, K.; Roumeli, E.; Paraskevopoulos, K.M.; Nianias, N.; Bikiaris, D.N. Effect of different nanoparticles on thermal decomposition of poly(propylene sebacate)/nanocomposites: Evaluation of mechanisms using TGA and TG-FTIR-GC/MS. J. Anal. Appl. Pyrol. 2012, 96, 92-99.

174. Vassiliou, A.A.; Bikiaris, D.; El Mabrouk, K.; Kontopoulou, M. Effect of evolved interactions in poly(butylene succinate)/fumed silica biodegradable in situ prepared nanocomposites on molecular weight, material properties, and biodegradability. J. Appl. Polym. Sci. 2011, 119, 2010-2024.

175. Billiet, L.; Fournier, D.; du Prez, F. Combining "click" chemistry and step-growth polymerization for the generation of highly functionalized polyesters. J. Polym. Sci. A 2008, 46, 6552-6564.

176. Anthierens, T.; Billiet, L.; Devlieghere, F.; du Prez, F. Poly(butylene adipate) functionalized with quaternary phosphonium groups as potential antimicrobial packaging material. Innov. Food Sci. Emerg. 2012, 15, 81-85.

177. Aloy, P.; Russell, R.B. Structure-based systems biology: A zoom lens for the cell. FEBS Lett. 2005, 579, 1854-1858.

178. LeDuc, P.R.; Bellin, R.M. Nanoscale intracellular organization and functional architecture mediating cellular behavior. Ann. Biomed. Eng. 2006, 34, 102-113.

179. Fukuda, J.; Khademhosseini, A.; Yeh, J.; Eng, G.; Cheng, J.J.; Farokhzad, O.C.; Langer, R. Micropatterned cell co-cultures using layer-by-layer deposition of extracellular matrix components. Biomaterials 2006, 27, 1479-1486.

180. Coutinho, D.F.; Gomes, M.E.; Neves, N.M.; Reis, R.L. Development of micropatterned surfaces of poly(butylene succinate) by micromolding for guided tissue engineering. Acta Biomater. 2012, 8, 1490-1497.

181. Yin, D.; Wang, X.H.; Yan, Y.; Zhang, R. Preliminary studies on peripheral nerve regeneration using a new polyurethane conduit. J. Bioact. Compat. Polym. 2007, 22, 143-159.

182. Pego, A.P.; Siebum, B.; van Luyn, M.J.; Gallego y van Seijen, X.J.; Poot, A.A.; Grijpma, D.W.; Feijen, J. Preparation of degradable porous structures based on 1,3-trimethylene carbonate and D,L-lactide (co) polymers for heart tissue engineering. Tissue Eng. 2003, 9, 981-994.

183. Guarino, V.; Alvarez-Perez, M.; Cirillo, V.; Ambrosio, L. HMSC interaction with PCL and PCL/gelatin platforms: A comparative study on films and electrospun membranes. J. Bioact. Compat. Polym. 2011, 26, 144-160. 
184. Bruggeman, J.P.; de Bruin, B.-J., Bettinger, C.J.; Langer, R. Biodegradable poly(polyol sebacate) polymers. Biomaterials 2008, 29, 4726-4735.

185. Soccio, M.; Lotti, N.; Finelli, L.; Munari, A. Influence of transesterification reactions on the miscibility andthermal properties of poly(butylene/diethylene succinate) copolymers. Eur. Polym. J. 2008, 44, 1722-1732.

186. Soccio, M.; Lotti, N.; Finelli, L.; Munari, A. Miscibility of biodegradable poly(propylene succinate)/poly(propylene adipate) blends: Effect of the transesterification reactions. Eur. Polym. J. 2009, 45, 3236-3248.

187. Gualandi, C.; Soccio, M.; Govoni, M. Valente, S.; Lotti, N.; Munari, A.; Giordano, E.; Pasquinelli, G.; Focarete, M.L. Poly(butylene/diethyleneglycol succinate) multiblock copolyester as a candidate biomaterial for soft tissue engineering: Solid-state properties, degradability, and biocompatibility. J. Bioact. Compat. Polym. 2012, 27, 244-264.

188. Wang, Y.; Kim, Y.M.; Langer, R. In vivo degradation characteristics of poly(glycerol sebacate). J. Biomed. Mater. Res. A 2003, 66, 192-197.

189. Bettinger, C.J.; Weinberg, E.J.; Kulig, K.M.; Vacanti, J.P.; Wang, Y.; Borenstein, J.T.; Langer, R. Three-dimensional microfluidic tissue-engineering scaffolds using a flexible biodegradable polymer. Adv. Mater. 2006, 18, 165-169.

190. Qiu, H.; Yang, J.; Kodali, P.; Koh, J.; Ameer, G.A. A citric acid-based hydroxyapatite composite for orthopedic implants. Biomaterials 2006, 27, 5845-5854.

191. Webb, A.R.; Kumar, V.A.; Ameer, G.A. Biodegradable poly(diol citrate) nanocomposite elastomers for soft tissue engineering. J. Mater. Chem. 2007, 17, 900-906.

192. Bat, E.; Plantinga, J.A.; Harmsen, M.C.; van Luyn, M.J.A.; Zhang, Z.; Grijpma, D.W. In vivo behavior of trimethylene carbonate and epsilon-caprolactone-based copolymer networks: Degradation and tissue response. J. Biomed. Mater. Res. A 2010, 95A, 940-949.

193. Yang, J.; Webb, A.R.; Ameer, G.A. Novel citric acid-based biodegradable elastomers for tissue engineering. Adv. Mater. 2004, 16, 511-516.

194. Nijst, C.L.E.; Bruggeman, J.P.; Karp, J.M.; Ferreira, L.; Zumbuehl, A.; Bettinger, C.J. Synthesis and characterization of photocurable elastomers from poly(glycerol-co-sebacate). Biomacromolecules 2007, 8, 3067-3073.

195. Stammen, J.A.; Williams, S.; Ku, D.N.; Guldberg, R.E. Mechanical properties of a novel PVA hydrogel in shear and unconfined compression. Biomaterials 2001, 22, 799-806.

196. Djordjevic, I.; Choudhury, N.R.; Dutta, N.K.; Kumar, S. Poly[octanediol-co-(citric acid)-co(sebacic acid)] elastomers: Novel bio-elastomersfor tissue engineering. Polym. Int. 2011, 60, 333-343.

197. Rai, R.; Tallawi, M.; Grigore, A.; Boccaccini, A.R. Synthesis, properties and biomedical applications of poly(glycerol sebacate) (PGS): A review. Prog. Polym. Sci. 2012, 37, 1051-1078.

198. Reneker, D.H.; Chun, I. Nanometre diameter fibres of polymer produced by electrospinning. Nanotechnology 1996, 7, 216-223.

199. Frenot, A.; Chronakis, I.S. Polymer nanofibres assembled by electrospinning. Curr. Opin. Colloid Interface Sci. 2003, 8, 64-75.

200. Jeong, E.H.; Im, S.S.; Youk, J.H. Electrospinning and structural characterization of ultrafine poly(butylene succinate) fibers. Polymer 2005, 46, 9538-9543. 
201. Sutthiphong, S.; Pavasant, P.; Supaphol, P. Electrospun 1,6-diisocyanatohexane-extended poly(1,4-butylene succinate) fiber mats and their potential for use as bone scaffolds. Polymer 2009, 50, 1548-1558.

202. Zhang, D.; Chang, J.; Zeng, Y. Fabrication of fibrous poly(butylene succinate)/wollastonite/ apatite composite scaffolds by electrospinning and biomimetic process. J. Mater. Sci. 2008, 19, 443-449.

203. Tian, L.; Wang, P.; Zhao, Z.; Ji, J. Antimicrobial activity of electrospun poly(butylenes succinate) fiber mats containing pvp-capped silver nanoparticles. Appl. Biochem. Biotech. 2013, 171, 1890-1899.

204. Xu, L.; Ren, Z. Drug-loaded pbs micro spheres with chinese drug by electrospinning. J. Polym. Eng. 2008, 28, 27-31.

205. Yi, F.; LaVan, D.A. Poly(glycerol sebacate) Nanofiber scaffolds by core/shell electrospinning. Macromol. Biosci. 2008, 8, 803-806.

206. Xu, B.; Li, Y.; Fang, X.; Thouas, G.A.; Cook, W.D.; Newgreen, D.F.; Chen, Q. Mechanically tissue-like elastomeric polymers and their potential as a vehicle to deliver functional cardiomyocytes. J. Mech. Behav. Biomed. 2013, 28, 354-365.

207. Ravichandran, R.; Venugopal, J.R.; Sundarrajan, S.; Mukherjee, S.; Ramakrishna, S. Poly(glycerol sebacate)/gelatin core/shell fibrous structure for regeneration of myocardial infarction. Tissue Eng. A 2011, 17, 1363-1373.

208. Kharaziha, M.; Nikkhah, M.; Shin, S.-R.; Annabi, N.; Masoumi, N.; Gaharwar, A.K.; Camci-Unal, G.; Khademhosseini, A. PGS: Gelatin nanofibrous scaffolds with tunable mechanical and structural properties for engineering cardiac tissues. Biomaterials 2013, 34, 6355-6366.

209. Almeida, L.R.; Martins, A.R.; Fernandes, E.M.; Oliveira, M.B.; Correlo, V.M.; Pashkuleva, I.; Marques, A.P.; Ribeiro, A.S.; Durães, N.F.; Silva, C.J.; et al. New biotextiles for tissue engineering: Development, characterization and in vitro cellular viability. Acta Biomater. 2013, 9, 8167-8181.

210. Tang, J.; Zhang, Z.; Song, Z.; Chen, L.; Hou, X.; Yao, K. Synthesis and characterization of elastic aliphatic polyesters from sebacic acid, glycol and glycerol. Eur. Polym. J. 2006, 42, 3360-3366.

211. Simitzis, J.; Soulis, S.; Triantou, D.; Zoumpoulakis, L.; Zotali, P. Synthesis and characterization of hydrolytically degradable copolyester biomaterials based on glycolic acid, sebacic acid and ethylene glicol. J. Mater. Sci. 2011, 22, 2673-2684.

212. Leuchtenberger, W.; Huthmacher, K.; Drauz, K. Biotechnological production of amino acids and derivatives: Current status and prospects. Appl. Microbiol. Biotechnol. 2005, 69, 1-8.

213. Vocus/PRWEB. Available online: http://www.prweb.com/releases/2011/2/prweb8151116.htm (accessed on 21 February 2011).

214. Jacoby, M. Custom-made biomaterials. Chem. Eng. News 2001, 79, 30-35.

215. Nathan, A.; Kohn, J. Chapter 3: Amino acid derived polymers. In Biomedical Polymers: Design-to-Degrade Systems; Shalaby, S.W., Ed.; Hanser Publishers: New York, NY, USA, 1994; p. 117. 
216. Sun, H.; Meng, F.; Dias, A.A.; Hendriks, M.; Feijen, J.; Zhong, Z. $\alpha$-Amino acid containing degradable polymers as functional biomaterials: Rational design, synthetic pathway, and biomedical applications. Biomacromolecules 2011, 12, 1937-1955.

217. Rodríguez-Galán, A.; Franco, L.; Puiggalí, J. Degradable poly(ester amide)s for biomedical applications. Polymers 2011, 3, 65-99.

218. Rodríguez-Galán, A.; Franco, L.; Puiggalí, J. Chapter 4: Biodegradable poly(ester amide)s: Synthesis and applications. In Biodegradable Polymers: Processing, Degradation; Felton, G.P., Ed.; Nova Science Publisher: New York, NY, USA, 2011; p. 207.

219. Bourke, S.L.; Kohn, J. Polymers derived from the amino acid L-tyrosine: Polycarbonates, polyarylates and copolymers with poly(ethylene glycol). Adv. Drug Deliv. Rev. 2003, 55, 447-466.

220. Katsarava, R.; Gomurashvili, Z. Chapter 5: Biodegradable polymers composed of naturally occurring $\alpha$-amino acids. In Handbook of Biodegradable Polymers-Isolation, Synthesis, Characterization and Applications; Lendlein, A., Sisson, A., Eds.; John Wiley \& Sons, Inc.: Hoboken, NJ, USA, 2011; p. 107.

221. Katsarava, R.; Kharadze, D.; Japaridze, N.; Omiadze, T.; Avalishvili, L. Heterochain polymers based on natural amino acids. Synthesis of polyamides from $N^{\alpha}, N^{\varepsilon}$-bis-(trimethylsilyl)-lysine alkyl esters. Makromol. Chem. 1985, 186, 939-954.

222. Gomurashvili, Z.; Kricheldorf, H.R.; Katsarava, R. Amino acid based bioanalogous polymers. Synthesis and study of new regular poly(ester amides)s composed of hydrophobic $\alpha$-amino acids and dianhydrohexitoles. J. Macromol. Sci. 2000, 37, 215-227.

223. Okada, M.; Yamada, M.; Yokoe, M.; Aoi, K. Biodegradable polymers based on renewable resources. V. Synthesis and biodegradation behavior of poly(ester amide)s composed of 1,4:3,6-dianhydro-D-glucitol, $\alpha$-amino acid, and aliphatic dicarboxylic acid units. J. Appl. Polym. Sci. 2001, 81, 2721-2734.

224. Guo, K.; Chu, C.C. Synthesis, characterization and biodegradation of novel poly(ether ester amide)s based on L-phenylalanine and oligoethylene glycol. Biomacromolecules 2007, 8, 2851-2861.

225. Memanishvili, T.; Kupatadze, N.; Tugushi, D.; Torchilin, V.P.; Katsarava, R. Biodegradable arginine-based polymers with PEG-like backbones as potential non-viral gene delivery system. In Proceedings of 1st Russian-Hellenic Symposium with International Participation Biomaterials and Bionanomaterials: Recent Advances and Safety-Toxicology Issues, Iraklion, Greece, 3-9 May 2010.

226. Wu, J.; Yamanouchi, D.; Liu, B.; Chu, C.C. Biodegradable arginine-based poly(ether ester amide)s as a non-viral DNA delivery vector and their structure-function study. J. Mater. Chem. 2012, 22, 18983-18991.

227. Memanishvili, T.; Zavradashvili, N.; Kupatadze, N.; Tugushi, D.; Gverdtsiteli, M.; Torchilin, V.P.; Wandrey, C.; Baldi, L.; Manoli, S.S.; Katsarava, R. Arginine-based biodegradable ether-ester polymers of low cytotoxicity as potential gene carriers. Biomacromolecules 2014, submitted for publication.

228. De Wit, M.A.; Wang, Z.; Atkins, K.M.; Mequanint, K.; Gillies, E.R. Syntheses, characterization, and functionalization of poly(ester amide)s with pendant amine functional groups. J. Polym. Sci. A 2008, 46, 6376-6392. 
229. Atkins, K.M.; Lopez, D.; Knight, D.K.; Mequanint, K.; Gillies, E.R. A versatile approach for the syntheses of poly(ester amide)s with pendant functional groups. J. Polym. Sci. A 2009, 47, 3757-3772.

230. Cleaver, C.S.; Pratt, B.C. Synthesis of 2,2'-bis-[5(4H)-oxazolones]. J. Am. Chem. Soc. 1955, 77, 1544-1546.

231. Katsarava, R.; Kharadze, D.; Kirmelashvili, L. Heterochain polymers based on natural $\alpha$-amino acids. Bis-oxazolinone method of the synthesis of polyamides containing enzymatically cleavable bonds in the main chains. Acta Polym. 1985, 36, 29-38.

232. Kharadze, D.; Kirmelashvili, L.; Medzmariashvili, N.; Beridze, V.; Tsitlanadze, G.; Tughushi, D.; Chu, C.C.; Katsarava, R. Synthesis and $\alpha$-chymotrypsinolysis of regular poly(ester amides)s based on phenylalanine, diols and terephthalic acid. Polym. Sci. A 1999, 41, 883-890.

233. Kharadze, D.; Omiadze, T.; Tsitlanadze, G.; Goguadze, T.S.; Arabuli, N.; Gomurashvili Z.; Katsarava, R. New biodegradable polymers derived from $N, N$-diacyl-bis-phenylalanine. Polym. Sci. A 1994, 36, 1214-1218.

234. Asín, L.; Armelin, E.; Montane, J.; Rodríguez-Galán, A.; Puiggalí, J. Sequential poly(ester amide)s based on glycine, diols, and dicarboxylic acids: Thermal polyesterification $v s$. interfacial polyamidation. J. Polym. Sci. A 2001, 39, 4283-4293.

235. Katsarava, R.; Kharadze, D.; Avalishvili, L. Synthesis of high-molecular-weight polysuccinamides by polycondesation of active succinates with diamines. Makromol. Chem. 1986, 187, 2053-2062.

236. Katsarava, R. Progress and problems in activated polycondensation. Russ. Chem. Rev. 1991, 60, $722-737$.

237. Katsarava, R. Active polycondensation: from peptide chemistry to amino acid based biodegradable polymers. Macromol. Symp. 2003, 199, 419-429.

238. Morgan, P.W. Condensation Polymers: By Interfacial and Solution Methods; Interscience Publishers: New York, NY, USA, 1965; p. 561.

239. Katsarava, R.; Kharadze, D. The study of stability of active phenyl esters of carboxylic acids in aprotic polar solvents. Zhurn. Obshch. Khim. 1991, 61, 2413-2418.

240. Katsarava, R.; Kharadze, D.; Avalishvili, L. Synthesis of polyamides using activated bis- $N$-oxysuccinimide esters of dicarboxylic acids. Vysokomolek. Soed. 1984, A26, 1489-1497.

241. Kricheldorf, H.R.; Shwarz, G. Cyclic polymers by kinetically controlled step-Growth polymerization. Macromol. Rapid Commun. 2003, 24, 359-381.

242. Kricheldorf, H.R. The role of self-dilution in step-Growth polymerizations. Macromol. Rapid Commun. 2008, 29, 1695-1704.

243. Saotome, Y.; Miyazawa, T.; Endo, T. Novel enzymatically degradable polymers comprising $\alpha$-amino acid, 1,2-ethanediol and adipic acid. Chem. Lett. 1991, 1, 21-24.

244. Saotome, Y.; Tashiro, M.; Miyazawa, T.; Endo, T. Enzymatic degrading solubilization of a polymer comprising glycine, phenylalanine, 1,2-ethanediol, and adipic acid. Chem. Lett. 1991, 1, 153-154.

245. Arabuli, N.; Tsitlanadze, G.; Edilashvili, L.; Kharadze, D.; Goguadze, T.; Beridze, V.; Gomurashvili, Z.; Katsarava, R. Heterochain polymers based on natural amino acids. Synthesis and enzymatic hydrolysis of regular poly(ester amide)s based on bis(L-phenylalanine)- $\alpha, \omega$-alkylene diesters and adipic acid. Macromol. Chem. Phys. 1994, 195, 2279-2289. 
246. Katsarava, R.; Arabuli, N.; Beridze, V.; Kharadze, D.; Chu, C.C.; Won, C.Y. Amino acid-based bioanalogous polymers. Synthesis, and study of regular poly(ester amides) based on bis( $\alpha$-amino acid)- $\alpha, \omega$-alkylene diesters, and aliphatic dicarboxylic acids. J. Polym. Sci. A 1999, 37, 391-407.

247. Katsarava, R.D.; Kharadze, D.P.; Bendiashvili, T.M.; Urman, Ya.G.; Slonim, I.Ya.; Alekseeva, S.G.; Cefelin, P.; Janout, V. Synthesis of polyamides by active polycondensation. The structure and kenetical aspects of active esters aminolysis reactions. Acta Polym.1988, 39, $523-533$.

248. Katsarava, R.; Tugushi, D. Agricultural University of Georgia, Tbilisi, GA, USA. Unpublished work, 2014.

249. Katsarava, R.; Mazanashvili, N.; Mchedlishvili, N.; Gomurashvili, Z. Alkylene-DicarboxylateContaining Biodegradable Poly(ester-amides) and Methods of Use. U.S. Patent 20070287987, 13 December 2007.

250. Katsarava, R.; Ochkhikidze, N.; Tugushi, D.; Gomurashvili, Z. Aabb-Poly(depsipeptide) Biodegradable Polymers and Methods of Use. U.S. Patent 20100040664 A1, 18 February 2010.

251. Ochkhikidze, N.; Razmadze, E.; Tugushi, D.; Kupatadze, N.; Gomurashvili, Z.; Katsarava, R. AABB - Poly(depsipeptide)s - A new class of amino acid based biodegradable polymers. In Proceedings of International Symposium "Polycondensation-2008", Tokyo, Japan, 8-11 September 2008.

252. Jokhadze, G.; Machaidze, M.; Panosyan, H.; Chu, C.C.; Katsarava, R. Synthesis and characterrization of functional elastomeric poly(ester amide) copolymers. J. Biomater. Sci. Polym. Ed. 2007, 18, 411-438.

253. DeFife, K.M.; Grako, K.; Cruz-Aranda, G.; Price, S.; Chantung, R.; Macpherson, K.; Khoshabeh, R.; Gopalan, S.; Turnell, W.G. Poly(ester amide) co-polymers promote blood and tissuecompatibility. J. Biomater. Sci. 2009, 20, 1495-1511.

254. Lee, S.H.; Szinai, I.; Carpenter, K.; Katsarava, R.; Jokhadze, G.; Chu, C.C.; Huang, Y.; Verbeken, E.; Bramwell, O.; de Scheerder, I.; et al. In vivo biocompatibility evaluation of stents coated with a new biodegradable elastomeric and functional polymer. Coron. Artery Dis. 2002, 13, 237-241.

255. Gomurashvili, Z.; Zhang, H.; Da, J.; Jenkins, T.D.; Hughes, J.; Wu, M.; Lambert, L.; Grako, K.A.; DeFife, K.M.; Macpherson, K.; et al. Chapter 1: From drug-eluting stents to biopharmaceuticals: Poly(Ester Amide): A versatile new bioabsorbable biopolymer. In ACS Symposium Series 977: Polymers for Biomedical Applications; Mahapatro, A., Kulshrestha, A.S., Eds.; Oxford University Press: Oxford, UK, 2008; pp. 10-26.

256. Yamanouchi, D.; Wu, J.; Lazar, A.N.; Kent, K.C.; Chu, C.C.; Liu, B. Biodegradable arginine-based poly(ester-amide)s as non-viral gene delivery reagents. Biomaterials 2008, 29, 3269-3277.

257. Knight, D.K.; Mequanint, K.; Gillies, E.R. Strategies in functional poly(ester amide) syntheses to study human coronary artery smooth muscle cell interactions. Biomacromolecules 2011, 12, 2475-2487.

258. Chu, C.C.; Katsarava, R.; Guo K. Unsaturated Poly(ester-amide) Biomaterials. U.S. Patent 7863406, 4 January 2011. 
259. Guo, K.; Chu, C.C.; Chkhaidze, E.; Katsarava, R. Synthesis and characterization of novel biodegradable unsaturated poly(ester amide)s. J. Polym. Sci. A 2005, 43, 1463-1477.

260. Chkhaidze, E.; Tugushi, D.; Kharadze, D.; Gomurashvili, Z.; Chu, C.C.; Katsarava R. New unsaturated biodegradable poly(ester amide)s composed of fumaric acid, L-leucine and a, $\omega$-alkylene diols. J. Polym. Sci. A 2011, 48, 544-555.

261. Zavradashvili, N.; Jokhadze, G.; Gverdtsiteli, M.; Otinashvili, G.; Kupatadze, N.; Gomurashvili, Z.; Tugushi, D.; Katsarava, R. Amino acid based epoxy-poly(ester amide)s-A new class of functional biodegradable polymers: Synthesis and chemical transformations. J. Macromol. Sci. A 2013, 50, 449-465.

262. Neparidze, N.; Machaidze, M.; Zavradashvili, N.; Mazanashvili, N.; Tabidze, V.; Tugushi, D.; Katsarava, R. Biodegradable copoly(ester amide)s with hydrophobic lateral substituents. Polim. I Meditsina 2006, 2, 27-33. (In Russian)

263. Legashvili, I.; Nepharidze, N.; Katsarava, R.; Sannigrahi, B.; Khan, I.M. Non-covalent nano-adducts of co-poly(ester amide) and poly(ethylene glycol): Preparation, characterization and model drug-release studies. J. Biomater. Sci. 2007, 18, 673-685.

264. Gomurashshvili, Z.; Turnell, W.G.; Vassilev, V.; Chowdar, N.S. Biodegradable Water Soluble Polymers. U.S. Patent 20070282011 A1, 6 December 2007.

265. Paredes, N.; Rodríguez-Galán, A.; Puiggalí, J. Synthesis and characterization of a family of biodegradable poly(ester amides) derived from glycine. J. Polym. Sci. A 1998, 36, 1271-1282.

266. Paredes, N.; Casas, M.T.; Puiggalí, J.; Lotz, B. Structural data on the packing of poly(ester amide)s derived from glycine, hexanediol, and odd-numbered dicarboxylic acids. J. Polym. Sci. A 1999, 37, 2521-2533.

267. Paredes, N.; Rodríguez-Galán, A.; Puiggalí, J.; Peraire, C. Studies on the biodegradation and biocompatibility of a new poly(ester amide) derived from L-alanine. J. Appl. Polym. Sci. 1998, 69, 1537-1549.

268. Rodríguez-Galán, A.; Pelfort, J.E.; Aceituno, J.; Puiggalí, J. Comparative studies on the degradability of poly(ester amides) derived from L-and L,D-alanine. J. Appl. Polym. Sci. 1999, 74, 2312-2320.

269. Rodríguez-Galán, A.; Fuentes, L.; Puiggalí, J. Studies on the degradability of a poly(ester amide) derived from L-alanine, 1,12-dodecanediol and 1,12-dodecanedioic acid. Polymer 2000, 41, 5967-5970.

270. Paredes, N.; Casas, M.T.; Puiggalí, J. Poly(ester amide)s derived from glycine, even-numbered diols, and dicarboxylic acids: considerations on the packing. J. Polym. Sci. B 2001, 39, 1036-1045.

271. Montane, J.; Armelin, E.; Asín, L.; Rodríguez-Galán, A.; Puiggalí, J. Comparative degradation data of polyesters and related poly(ester amide)s derived from 1,4-butanediol, sebacic acid, and $\alpha$-amino acids. J. Appl. Polym. Sci. 2002, 85, 1815-1824.

272. Karimi, P.; Rizkalla, A.S.; Mequanint, K. Versatile biodegradable poly(ester amide)s derived from $\alpha$-amino acids for vascular tissue engineering. Materials 2010, 3, 2346-2368.

273. Turnell, W.G.; Gomurashvili, Z.D.; Anderl, J.N. Biodegradable Proline-Based Polymers. U.S. Patent 20120027859 A1, 2 February 2012.

274. Omay, D.; Katsarava, R. University of Yalova, Yalova, Turkey. Unpublished work, 2014. 
275. Cleaver, C.; Pratt, B. Polyamides from 2,2'-bis-[5(4H)-oxazolones]. J. Am. Chem. Soc. 1955, 77, 1541-1543.

276. Katsarava, R.; Tugushi, D.; Zavradashvili, N.; Kobauri, S.; Dgebuadze, M. New biodegradable copoly(amide/ester amide)s obtained via bis-azlacton chemistry. In Proceedings of POLYCHAR-19 World Forum on Advanced Materials, Kathmandu, Nepal, 20-24 March 2011.

277. Kobauri, S.; Zavradashvili, N.; Kviria, T.; Machaidze, M.; Katsarava, R. New hydrophobic biodegradable polymers on the basis of bis-azlactones. Ga. Chem. J. 2010, 10, 295-305.

278. Guo, K.; Chu, C.C. Synthesis and characterization of novel biodegradable unsaturated poly(ester amide)/poly(ethylene glycol) diacrylate hydrogels. J. Polym. Sci. A 2005, 43, 3932-3944.

279. Katsarava, R.; Alavidze, Z. Polymer Blends as Biodegradable Matrices for Preparing Biocomposites. U.S. Patent 6703040, 9 March 2004.

280. Market Wired. Available online: http://www.marketwire.com/press-release/Dsm-NV-959896.html (accessed on 11 April 2014).

281. Trollsas, M.; Maslanka, B.; Pham, N.; Lin, Q.; Hossainy, S.; Hsu, L.S.; Ngo, M.H. Polyesteramide coatings for drug eluting stents: Controlling drug release by polymer engineering. In Active Implants and Scaffolds for Tissue Regeneration; Springer: Berlin, Germany, 2011; pp. 127-143.

(C) 2014 by the authors; licensee MDPI, Basel, Switzerland. This article is an open access article distributed under the terms and conditions of the Creative Commons Attribution license (http://creativecommons.org/licenses/by/3.0/). 